\title{
(Interstate) Banking and (Interstate) Trade: Does Real Integration Follow Financial Integration?
}

\author{
Tomasz Michalski ${ }^{\#}$ and Evren Ors ${ }^{\dagger}$ \\ HEC Paris
}

25 October 2011

\begin{abstract}
We conjecture that banks present in two regions charge the appropriate risk premiums for trade-related projects between these markets, whereas higher rates are charged for projects involving shipments to markets where they are absent. These differences affect regional trade flows. US interstate banking deregulation serves as a natural experiment to test our model's implication with the Commodity Flow Survey data. Difference-in-differences estimates suggest that the trade share of state-pairs that allowed pairwise interstate entry increased by $14 \%$ over ten years relative to non-integrated state-pairs. Instrumental variables estimates suggest that an actual increase in bank integration from zero to $2.28 \%$ (the mean) increases trade $17 \%$ to $25 \%$.
\end{abstract}

JEL: F10, F15, G21, G28, R12

Keywords: trade; banking deregulation; finance-growth nexus

* We are thankful for the comments and suggestions made on earlier versions of this paper by Stijn Claessens (the referee), Ahmet Aysan, Thorsten Beck, Lamont Black, Astrid Dick, Charles A. Jeffrey, Ed Kane, Bill Kerr, Yrjö Koskinen, Jacques Olivier, and Federico Sturzenegger, the 2009 HEC Paris Economics Workshop audience, as well as session participants at the 2010 Conference on Bank Structure and Competition of the Federal Reserve Bank of Chicago, 2010 European Financial Association Conference in Frankfurt, 2010 European Economic Association Conference in Glasgow, 2010 Bank of Finland/CEPR Conference in Helsinki, and 2010 Bank Research Conference of the FDIC/JFSR. We also would like to thank Morgan Cullen for providing us with state legislator data and Onur Dalliag for research assistance. All errors remain our own. 


\section{(Interstate) Banking and (Interstate) Trade: Does Real Integration Follow Financial Integration?}

\section{Introduction}

A significant body of empirical evidence, accumulated since the seminal work of King and Levine (1993a, b), indicates that the development of the financial sector furthers economic growth. More recently, research has focused on the channels through which this observed growth may take place. For example, Black and Strahan (2002) show that US intrastate branching and interstate bank entry deregulations between the mid-1970s through mid-1990s had positive and separate impacts on entrepreneurial activity in the form of new business incorporations. Another literature examines the link between financial sector depth and international trade. For example, Manova (2008a) finds that financial liberalization increases country-level exports more in finance-dependent industries as well as in sectors with fewer tangible assets. Finally, a more recent line of research examines whether banking crises caused credit supply shocks in international trade. For example, Paravisini et al. (2011) find that such negative shocks caused a 15\% drop in Peruvian exports during the 2008 financial crisis.

Drawing from these strands of literature, we study a channel of the finance-growth nexus that has received little attention until recently: the effect of banking integration on interregional trade. Specifically, we examine whether the advantage that multi-regional banks possess in resolving information problems has implications for trade across regions. For the main channel, we argue that multi-market banks would make use of the additional information that they gather through their network due to their presence in different economic environments by sharing it among affiliated institutions. This conjecture relies heavily on the assumptions that (i) multi-regional banks operating in a financial conglomerate collect proprietary information on local economic conditions and (ii) that they share this information with other affiliates. There is empirical evidence supporting both legs of this conjecture in the literature, even if in different contexts. Regarding the importance of locally collected information, Coval and Moscowitz $(1999,2001)$ show that US fund managers exhibit a local bias in their portfolio choices, which results in higher returns; whereas Malloy (2005) and Bae et al. (2008) show that local (domestic) analysts make more precise earnings forecasts than non-resident (international) analysts, respectively. Regarding the importance of information flows within a financial conglomerate, Liberti and Mian (2009) show how geographical and hierarchical distance between the loan officers and their supervisors affects loan decisions, providing evidence of various information flow-related frictions within a bank; whereas Mester et al. (2007) and Norden and Weber (2010) show that information generated through corporate deposit accounts can be and is used to improve lending decisions. Finally, Ivashina et al. (2009) and 
Massa and Rehman (2008) show that information is shared between bank and non-bank affiliates of a financial conglomerate even when regulator-imposed firewalls forbid such flows.

In our context, the comparative advantage of multi-regional banks in collecting and sharing information, vis-à-vis single-market banks, would be put to use for projects that involve trade between the markets in which the bank is present when evaluating loan applications (either for higher amounts of borrowing on existing lines of credit for increased working capital needs, or for setting up new lending relationships), monitoring loans, and pricing financial services. If so, the resulting trade patterns would not be random, but would be instead influenced by the multi-market banks' comparative advantage in information gathering over the regions in which they are present. A mere increase in capital availability due to banking integration, on the other hand, would lead to a general increase in trade volumes, without any directional effects on interstate trade patterns. To the best of our knowledge, we are the first to provide tests of directional trade flows following financial integration.

This point can be formally made in a stylized, partial equilibrium model of interregional trade (Michalski and Ors, 2010), in which banks in a given region evaluate loan applications for local manufacturing projects whose target market is another (non-overlapping) region. Banks with a presence in both the manufacturing and the product-destination regions charge appropriate risk premiums on loans for approved projects, given the region-specific information that they already possess. The appropriate (ex ante) pricing and allocation of loans increases trade as the projects with the higher ex ante chance of success are provided capital at lower costs when the bank is present in the target market. The resulting trading activity is not ad hoc but instead shows patterns indicative of multi-region banks' superior ability in capital allocation. If banks have no presence in the target market, they charge an average risk premium that reflects their expectations of the overall probability of success of the average project targeting the unfamiliar product market: projects with a higher chance of success experience a higher cost of capital. As a consequence, trade shares would be lower between regions without integrated banking systems due to a less efficient capital allocation process.

We use the 1977 and 1993 Commodity Flow Survey (CFS) data on interstate shipments among the 48 contiguous US states to test these conjectures. The staggered deregulation of the US interstate banking restrictions serves as a natural experiment that provides variation in financial integration across both state-pairs and time that is useful in identifying the effects of financial integration on trade shares. Between the late 1970s and mid-1990s, various states deregulated their banking markets and opened up to competition from other states' financial institutions at different points in time. Many states formed agreements allowing banks from particular states to enter their markets, typically, but not always, on the basis of reciprocity. This resulted in the expansion of Multi-Bank Holding Companies (MBHC) across state lines through acquisitions of individual banks. During the period that we study, banking integration 
across states evolved solely through MBHCs until the Interstate Bank and Branching Efficiency Act (IBBEA), also known as the Riegle-Neal Act, became effective in 1995 and allowed interstate branching. When we examine trade patterns across state-pairs in the period that followed interstate banking deregulation, our results support the implications of our stylized theory of trade. We find that for a given state, the interstate trade share (i.e., relative trade flow) increases more with states with which bank entry was deregulated at an earlier date than with states with which no such deregulation was undertaken (due to data restrictions, we cannot study absolute trade flows). In other words, state-pairs that allowed their financial institutions entry to each other's banking markets are associated with an increase in trade shares (by approximately 14\% in 1993 with respect to 1977) compared to state-pairs that have no such common bank-entry deregulation. Looking at actual bank-entry data, our preferred estimate suggests that an increase in banking integration from zero to $2.28 \%$ (the mean of the data), as measured by the fraction of common banking assets for a state-pair, leads to an increase in trade of $16.8 \%-20.2 \%$ over the same period. This is consistent with our main hypothesis (channel) that financial institutions entering a new market make use of their informational advantage on the two markets when screening projects that involve trade between the same markets. The magnitudes of the effects that we find, which are robust to different specifications and estimators, are well in line with those predicted by a simple calibration of a standard monopolistic competition trade model and Dixit-Stiglitz love-of-variety preferences, where the marginal costs of production would decrease by $2.5 \%$ as a result of bank integration and the markups in the economy would range between $10 \%$ and $20 \%$. Importantly, we find that our main argument still holds when we account for other explanations of increases in trade flows. Our findings have implications for the integration of the financial sector and international trade: we believe that our study can provide a cautious lower bound estimate of the effects of banking and trade finance barriers on international trade.

The paper is organized as follows. In Section 2, we review the strands of literature that are relevant for our hypothesis. Section 3 presents the theoretical arguments as to why liberalization of banking entry between two states would increase trade flows between them relative to non-deregulating state-pairs as well as our empirical strategy. In Section 4 we present the data that we use in empirical estimations. In Section 5 we discuss the base results, in Section 6 their robustness. Section 7 concludes.

\section{Literature review}

The foundations of the current finance-growth nexus research go back almost a hundred years to Schumpeter (1912) who argued that economies with more effective financial systems grow faster. The culminating evidence since the new empirical tests of King and Levine (1993a and 1993b) shows that deeper financial systems further economic growth (e.g., Demirguc-Kunt and Maksimovic, 1998; Levine and Zervos, 1998; Rajan and Zingales, 1998; and Beck et al., 2000). 
More recently, research on the finance-growth nexus has focused its attention on the channels of the financial system's impact on observed growth. Jayaratne and Strahan (1996) were the first to examine the impact of US intrastate branching deregulation on the real economy: they find that per capita income and output grow faster after deregulation due to increased competition among banks. Black and Strahan (2002) show that the rate of new business formation increases after intrastate branching and interstate banking deregulations, whereas Rice and Strahan (2010) find that small-business loan terms improve following removal of restrictions on interstate branching. Cetorelli and Strahan (2006) show that both the number of establishments in a given industry as well as the fraction of small firms in that sector increase with US banking deregulation. Kerr and Nanda (2009) find that interstate banking deregulation increases entry by new firms but also leads to higher levels of exit among new entrants. In a cross-country analysis, Cetorelli and Gambera (2001) find that the banking market structure can both stifle overall growth in the economy and promote the growth of finance-dependent industries through financing of younger firms.

We examine whether there is a trade-specific component to the finance-growth nexus that would be in line with the informational story of loan provision. In a setting where banks would have more information about the geographic regions in which they are present, we examine whether their expansion into new markets would affect trade growth between the same regions. If the finance-growth nexus is affected by the banks' ability to resolve information problems in trade-related projects, then for a given region we would expect the integration of its banking sector with that of another region to promote trade between these two regions more than trade with other regions with which no such financial integration took place. This forms our testable hypothesis. The alternative hypothesis is that the finance-growth nexus works solely through the provision of higher amounts of credit, leaving trade shares unaffected. In other words, if banks have no geography-based informational advantage, or if our theory is not economically significant, then trade shares for different geographic areas would not be affected as the overall volume of trade increases when credit becomes more available following bank-entry deregulation (as in Jayaratne and Strahan, 1996, for example). Thus, under this alternative hypothesis, all trade flows from a given state would increase by the same proportion on average, leaving the trade shares unaffected.

To the best of our knowledge, the particular mechanism of the finance-growth nexus proposed here has not been studied before, even though the seeds of our conjecture were sown by Morgan et al. (2003, 2004; henceforth MRS). These authors, in their study of the impact of US banking entry deregulation on state-level output volatility, indicate that a possible link may exist between interstate banking deregulation and interstate trade. However, the focus of their paper is clearly on the former rather than the latter: in the published (2004) version of their paper, MRS make only a passing reference to a possible link between banking deregulation and interstate trade, an argument that is made in somewhat more detail in its draft (2003) version. While we explore the same potential link between financial 
integration and trade using the same data set, a tangential topic in MRS (2003, 2004), there are significant differences between our approach and theirs. First, we examine trade shares across all state-pairs; whereas MRS (2003) study aggregate trade flows (exports) that a state has with all of the other states. Second, we examine the potential link between pairwise financial integration and trade after interstate banking deregulation; whereas MRS (2003) focus on the possible effect of the aggregate financial integration of a particular state with the rest of the Union on that state's aggregate exports to the rest of the US and find no apparent link between the two. As a result of these differences, we are able to exploit the variation that exists in the CFS data set using 4,512 state-pair observations; whereas MRS (2003) examine aggregate trade flows using 51 data points. Therefore, our tests have higher statistical power than the unconditional correlations that they examine. Third, we rely on a stylized trade theory that explicitly links multi-state banks' impact on interstate trade and we are able to obtain a gravity equation incorporating the impact of financial intermediation that can be estimated with state-pair data; whereas the theory model in MRS $(2003,2004)$ focuses on state-level banking deregulation and output volatility.

Our work is also related to research on trade and (i) financial sector development, (ii) financial crises, and (iii) financial constraints. Recent papers in the first group examine financial sector development and trade. Using a ten-year panel of 107 countries and 27 industries, Manova (2008b) finds that countries with deeper financial markets export more in capital-dependent industries with less collateralizable assets, with credit availability affecting both fixed- and variable-export costs. In a 30-year panel of 65 countries, Beck (2002) finds that those with more developed financial systems have a higher export share and trade balance in manufactured goods. Svaleryd and Vlachos (2005) observe that among the Organization for Economic Co-operation and Development (OECD) countries, differences in financial development impact industrial specialization patterns with a developed financial system being a source of comparative advantage. Becker and Greenberg (2003) find that financial development helps exports more in industrial sectors with large upfront investments. However, the causality between the availability of finance and trade remains difficult to resolve. Do and Levchenko (2007) show, using geography as an instrument for trade flows in a cross-country study, that the relationship between financial depth and trade may go the other way: comparative advantage of a country in financially dependent industries appears to spur the development of its financial sector.

Our paper differs from these papers in two dimensions. First, we focus on the effects of financial integration between regions, as opposed to financial system depth in a given country, on trade flows. Second, we conduct our tests with (intra-US) interstate trade data. These do not suffer from the complications of country-level international data, such as differences in trade barriers, trade agreements, and legal system origins, to name a few. Second, cross-country comparisons typically require the use of test variables based on broadly aggregated data (like credit to the private sector as a share of the Gross 
Domestic Product (GDP)) and the classification of financial dependence measures that may be influenced by spurious factors (such as foreign direct investment) that also affect trade. In this respect, interstate banking deregulation in the US offers a compelling natural experiment to study the impact of financial integration on the real sector. ${ }^{1}$

Our work is also related to a second strand of literature that studies the impact of banking crises on international trade. Amiti and Weinstein (2011) find that poor health of the main banks of large Japanese exporters would explain one third of the drop in the trade to GDP for Japan in the 1990s. Using a data set that matches exporters with their banks, Paravisini et al. (2011) estimate the negative credit supply shocks account for a 15\% drop in Peruvian exports during the 2008 financial crisis. Minetti and Zhu (2011) study a survey of Italian firms that detailed their export participation and potential credit constraints in year 2000. Using the historical Italian banking regulations that limited the provision of banking services on a regional basis as instruments, they find a statistically significant effect of credit constraints on firm-level exports. Similarly, Ronci (2004) finds that a fall in trade financing that corresponds to a domestic banking crisis leads to significantly lower exports. Chor and Manova (2009) show that the fall in US imports during the crisis was larger for countries and external finance-dependent sectors with adverse credit conditions. However, according to Levchenko et al. (2010) or Eaton et al. (2011), a decline in trade finance played a minor role during the 2008-2009 crisis. These two studies find that the intermediate or durable goods sectors, respectively, would be responsible for the steep decline in trade-to-GDP ratio. Our work complements this literature by examining the effects of a positive shock (through banking integration) on domestic trade of the largest economy in the world.

The third line of research related to our work analyzes the effects of financial or liquidity constraints on exports. Chaney (2005) models how liquidity constraints affect firms' ability to export. Greenaway et al. (2007) show evidence that exporting firms are financially healthier than non-exporting firms. They also find that firms exporting for the first time have lower liquidity and higher leverage, suggesting that such firms are more likely to need bank financing. Using Belgian firm-level data and COFACE creditworthiness scores, Muuls (2008) finds that financially weak firms are less likely to become exporters, and if they export, they reach fewer destinations with fewer products. Manova et al. (2009) study Chinese firms' export performance and show that foreign affiliates and joint ventures perform better than private domestic firms, especially in sectors with higher financial vulnerability: this finding is consistent with credit constraints affecting trade and multinational companies' advantages in international

\footnotetext{
${ }^{1}$ We should note that, as in the case of international studies, differences exist in bank supervision across states. In the US, banks are subject to the oversight of (i) the state banking authorities if they are state-chartered, (ii) the Office of the Comptroller of the Currency and the Fed if they are federally chartered or are Bank Holding Companies (BHCs), and (iii) the Federal Deposit Insurance Corporation if they have federal deposit insurance (which, apart from a few, all banks do).
} 
trade. Zia (2008) finds that the withdrawal of export subsidies to Pakistani firms causes the exports of financially constrained firms to decrease in contrast to those of non-constrained firms. In the model of Suwantaradon (2008), among equally productive firms, the credit-constrained ones never accumulate enough liquidity to be able to export, a prediction that is supported with data from Brazil and Chile.

We suggest one particular channel through which such credit constraints may be eased for exporting firms-the role of multi-market banks' informational advantage in evaluating, screening, and pricing loans for projects that target markets in which the bank is present. Besides anecdotal evidence, ${ }^{2}$ research suggests that information flows, which are crucial for our conjecture, complement the functioning of financial conglomerates' internal capital markets. For example, examining underwriting activities of US banks, Gande et al. (1997) show that MBHCs fulfill a certification role during securities issuance in a way that would suggest a "breach of the firewalls" existing between the commercial and investment banking affiliates of financial conglomerates. Similarly, examining the portfolio choices of mutual funds that are proprietary to the MBHC, Massa and Rehman (2008) find that the former significantly increase their investments in firms borrowing larger amounts from MBHC-affiliated banks, suggesting information flows from the banking subsidiary to the mutual fund subsidiary. These findings give credibility to the existence of information flows between affiliated commercial banks, between which no firewalls are required by regulation. Moreover, as noted in the introduction, evidence indicates that being a local confers informational advantages that outsiders cannot replicate (e.g., Malloy, 2005; Bae et al., 2008; Kang and Kim, 2008). Given this setting, our main hypothesis provides a more specific test on the lending-side effects of information flows across banks operating in local markets. Moreover, our tests are conducted with US state-level data, which alleviate some of the problems associated with firm-level data: firms' decisions to export require additional modeling of the endogenous self-selection process for which there are few good instruments and which involve many unobservables.

In the next section we discuss different channels through which banking integration between regions can increase interregional trade.

\section{Theoretical background}

\subsection{Channels through which banking integration affects trade}

\footnotetext{
${ }^{2}$ Press articles support the argument of information flows across banks of a conglomerate. For some MBHCs, the member institutions of the same organization share information on the credit and economic conditions at other affiliate banks (New York Times, 1990) or seek industry-specific information concerning their commercial customers (Indiana Business, 1993). Information exchange is sometimes eye-to-eye, as some MBHCs pair executives from different states to share information and experiences about their respective markets (Colorado Business, 1993; New York Times, 1990). Early in the 1990s, some organizations were able to combine their credit scoring data sets with a view to share information within the MBHC structure (American Banker, 1993a).
} 
The main channels through which banking integration can affect trade stem from the MBHCs' higher ability to screen, evaluate, and price financial services for manufacturing projects involving interstate "exports." These financial services may be requests for (i) loans (for a new production facility or the expansion of an existing plant), (ii) working capital (for increasing the production volume and covering higher payment delays in out-of-state "exports"), or (iii) payment guarantees (letters of credit). The common underlying mechanism is the region-specific information that affiliates of a financial conglomerate produce and share with other banks in different states belonging to the same organization.

Suppose that a particular bank in region $i$ has a presence in region $j$ (through subsidiaries or branches) but not in region $k$. The presence (absence) in market $j(k)$ gives this bank an informational advantage (disadvantage) in evaluating projects that target market $j(k)$. For example, the bank can have a better ability to evaluate the future economic conditions in region $j$, as opposed to region $k$ where it has no presence, through first-hand information on movements in customer accounts. ${ }^{3}$ This informational advantage would allow the bank to better assess the potential consumer demand in region $j$ for the producer's variety of the manufactured good and its potential success. For example, a North Carolina bank with presence in Ohio may be in a better position to evaluate loan requests for increased working capital for higher production by home-state manufacturers that target the host state (Ohio). Equivalently, the bank's presence in both regions $i$ and $j$ may help it in assessing the potential success of projects linked with industries to which it has already made loans. For example, a car-parts producer in Missouri might be expected to have larger exports to Michigan than to Virginia due to a larger car industry that is located in Michigan. We conjecture that a Missouri bank with presence in Michigan (but no presence in Virginia) is better able to assess the success of such a project than a Missouri bank with a presence in Virginia (but no presence in Michigan). ${ }^{4}$ One can say that it is less costly for a bank to verify the state of the world (as in Townsend, 1979) regarding projects that are destined for region $j$, where it has branches or subsidiaries, than those destined for region $k$ where it does not have a presence. Alternatively, the bank could be ambiguity-averse (as in Klibanoff et al., 2005), granting more loans for projects with shipment destinations for which it can assess probabilities of success better. ${ }^{5}$

\footnotetext{
${ }^{3}$ Relationships with corporate clients generate proprietary information flows within the bank that are not available to outsiders (e.g., Mester et al., 2007; Norden and Weber, 2010; Ivashina et al., 2009; Massa and Rehman, 2008).

${ }^{4}$ Anecdotal evidence supports this conjecture. For example, an executive of a subsidiary bank of NBD, an MBHC in Indiana, claimed: "There are experts in all kinds of banking in the NBD system. [...] If I need some help with a potential commercial customer in the auto industry, call Detroit. There's an NBD bank in the Chicago suburbs that has expertise in the fast-food business. Our affiliation has meant probably $\$ 100$ million in loans to Midwest commerce just because NBD resources are there to tap into." (Indiana Business, 1993).

${ }^{5}$ The bank does not necessarily need to have established a working relationship with the importer when providing trade-related loans to the exporter (such as loans for increases in working capital). In the case when both the exporter and the importer would be clients of the same MBHC, information that is internally available to the financial institution would help improve the process of credit assessment. But this latter channel is not necessarily
} 
Such an informational advantage can manifest itself as a loan-pricing channel. Suppose that a project is undertaken by a firm that is located in state $i$ and targets market $m$ (with $m=\{j, k\}$ as before). The project will be successful (i.e., sales will take place) with probability $q_{m}$ or it will fail to deliver any sales with probability $\left(1-q_{m}\right)$. The said project can be one of two types. Type-1 projects involve some risk $q_{m, 1}>0$ for generating sales in state $m$ while type- 2 projects are completely unsuccessful $\left(q_{m, 2}=0\right)$. A fraction $\chi$ of projects targeting market $m$ is of type- 1 and a fraction $(1-\chi)$ is of type-2. Neither the entrepreneurs located in $i$, nor banks that are not operating in the region $m$ can know the type of the project at hand ex ante, even though they know a priori the fraction of type-1 and type-2 projects (i.e., they know $\chi$ ). Suppose that a bank located in region $i$, evaluating the loan application for a project targeting region $j$, knows the distribution of $q_{j}$ if it already has a presence (either through subsidiaries or branches) in state $j$. On the other hand, a bank that does not have a presence in state $k$ can only form expectations about the probability of success $q_{k}$. Then, for accepted projects in state $i$ aiming to sell to consumers in state $j$, the bank learns, thanks to its presence in region $j$, whether the project is of type- 1 or type-2, as well as the related probability of success $q_{j}$ prior to lending. Suppose that banks require a rate of return $r$ on its projects, on average. As a result, the bank with presence in region $j$ charges $R_{j}=r / q_{1}$ (commensurate with the risk of the type-1 project) but will not lend if the project is of type-2. For projects that target state $k$ on which the bank does not have such information, it will charge the interest rate $R_{k}=r /[E(q)]$ where $E(q)=\chi q_{1}$. If for the two destinations the number of firms with successful projects (i.e., generating positive sales) obtaining loans is the same, projects targeting sales to state $j$ would enjoy lower marginal costs relative to those targeting state $k$ since $R_{j}<R_{k}$. Therefore, the value of flows from $i$ to $j$ will be weakly greater than flows from $i$ to $k$, irrespective of the demand structure, since the (financial) barriers to trade will be lower between $i$ and $j$ than those between $i$ and $k$.

Banking integration can also increase trade through the information asymmetries channel. Banks with presence in both states $i$ and $j$ could solve asymmetric information problems (i.e., when the firm knows the quality of its project and/or the effort provided in its execution but the bank does not) better for projects targeting state $j$. This could be due to better project monitoring or ex ante screening. For example, the knowledge of demand conditions at $j$ could help banks to weed out projects with lower success probabilities and increase accepted projects' quality. Therefore, there could be lower credit constraints (or lower loan costs) for firms serving state $j$ compared to those serving state $k$. Note that the loan-pricing channel may exist even without informational asymmetries between the bank and its borrowers.

A separate loan processing costs channel may also exist for projects targeting destinations where the bank has branches or subsidiaries. Fixed and variable costs of loan processing may be reduced if an 
MBHC-member bank has access to information that is proprietary to the financial conglomerate (for example, other affiliated banks' loan default and loss rates in the destination state). While obtaining credit information for a given firm from external sources (such as credit bureaus or registries) is unlikely to be prohibitively costly, requesting such information for a representative sample of firms in the destination state on a regular interval (say, every week or month) could be. Moreover, there could be implicit costs if the purchased information is not current enough to give the bank an advantage over its competition.

A letter of credit channel may also be at play. Banks with a presence in multiple markets may be able to increase the speed of payments collection. This specific role of banks, which is especially important in international trade (i.e., Grath, 2010), was presumably also important in the pre-banking deregulation environment. MBHCs would be more efficient in providing letters of credit to potential importers if both exporters and importers were members of the same banking network. ${ }^{6}$ Alternatively, MBHCs process and settle payments (i.e., clear checks of affiliated banks) faster, presumably because both sides to a trade transaction are clients of the same financial conglomerate (Berger and Humphrey, 1988; American Banker, 1993b). These effects could translate into lower working capital requirements for firms shipping to states with bank links.

Another possible channel at play is the project selection channel. A bank will accept a project whenever the firm is expected to repay the loan. This means that banks are going to accept projects of firms that have high productivity, i.e., firms that enjoy higher expected profits (relative to firms with lower productivity). In the view of our discussion above, a fall in loan processing costs or the increase of project success rates for firms from state $i$ targeting state $j$ 's market will make them more profitable and increase the number of financed projects from state $i$ to state $j$ relative to the projects targeting market $k$.

We can easily embed these banking channels into a standard, stylized monopolistic competition model of trade with heterogeneous firms as in Melitz (2003), albeit without discriminating among them because our data do not allow such a differentiation (see Michalski and Ors, 2010). In this exercise all of the channels cited above would come into play through the introduction of financial intermediaries as the sole providers of capital for trade-related projects. Importantly, such an exercise allows us to obtain a theoretical gravity equation, which can be used to formally justify the empirical models of Section 3.3.

There are other channels that are more difficult to capture in a simple trade model, but may be important nevertheless. For example, better asset diversification by banks that entered into different states

\footnotetext{
${ }^{6}$ A senior bank examiner at the Federal Reserve Bank of Chicago confirmed this conjecture: “... it would make a difference if both the exporter and importer were a customer of the same MBHC with multiple banks in different states. This would allow for more streamlined or efficient credit approval process between affiliated banking organizations within the same holding company organization." However, the same source also stated that it was difficult to judge whether the associated effect would be economically large: "Due to efficiencies, the transaction might be slightly lower cost and could be put together more quickly, but unaffiliated banks in different states could work together to get this type of financing done to remain competitive as the industry consolidated."
} 
may have increased the stability of these banking organizations. This would increase the loanable funds in these states, which in turn would increase trade between the state-pairs connected by banks more so than between the unconnected ones. We examine the presence of such a risk-sharing channel in Section 6.6.

The increase in loanable funds by banks may in turn increase trade credit by sellers of manufactured goods according to the distributional view of this form of financing (e.g., Fisman and Love, 2003; Love et al., 2007; Klapper et al., 2010; Coulibaly et al., 2011). However, such an increase in trade credit need not result in directional trade shares even if trade flows increase: as producers choose to increase trade credit they are likely to extend it to firms irrespective of the state of location of the buyers.

Finally, acquiring MBHCs could bias the lending of its affiliates towards sectors that are important in the headquarters' state and in which the acquiring parent holding company has expertise. ${ }^{7}$ This could increase intra-industry trade (in the same sectors) between the states that experienced banking integration. Results shown in Section 6.7 appear to be in line with such a story.

Additional remarks are in order for the sake of completeness. Banks could rely on external information purchased from other organizations rather than use or share internally available information. Both theoretical (e.g., Pagano and Japelli, 1993; Padilla and Pagano, 1997, 2000) and empirical (e.g., Kallberg and Udell, 2003; Djankov et al., 2007; Brown et al., 2009; and Houston et al., 2010) research shows that information sharing across independent banks, through outside sources, such as credit registries or credit bureaus, can be used to resolve asymmetric information problems in lending. If this alternative channel was the norm during the years we study, then banking integration between two states should have no directional effect on trade shares: trade would increase toward all other states leaving trade shares unaffected. If, on the other hand, MBHC-affiliated banks typically chose to share the proprietary information available within the MBHC to evaluate loan or letter of credit requests, then we would observe higher trade flows between state-pairs whose banking systems have become integrated. Our results are consistent with the second argument. While these two hypotheses are not mutually exclusive, and should have both a positive effect on overall trade flows, an examination of directional trade shares allows us unequivocally to determine the presence of the second channel.

\subsection{A conservative calibration exercise}

The loan price channel offers a conservative lower bound of the strength of the effects of bank entry on trade flows that we should expect. To obtain a quantitative benchmark, we employ a standard monopolistic competition trade model with homogeneous firms and Dixit-Stiglitz love-of-variety utility

\footnotetext{
${ }^{7}$ There is anecdotal evidence that MBHC headquarters altered lending practices of acquired banks gearing them closer to those of the parent organization and replaced managers of the overtaken organizations with those from the parent company (see Crain's Detroit Business, 1995; The Business Journal-Milwaukee, 1990).
} 
(Michalski and Ors, 2010). To do this, we only need to make assumptions on the markups charged by firms and the decreases in production (financing) costs associated with bank deregulation and entry. We leave out calibrating the other effects (existence of which will further increase the flows between states with more bank integration), as they are difficult to quantify. The results of our calibration of the loanprice channel are in Table 1. The cells of Table 1 show the percentage increases in expected trade flowsand hence trade shares-under different scenarios for markups (rows) and production costs (columns).

For the calibration, we refer to studies that tried to uncover the markups in various industries for the US by estimating the standard monopolistic competition model. For example, Hanson (2005) finds for most industries markups in the range 15.1\%-25.4\%, Head and Ries (2001) find 9.6\%-14.5\%, Lai and Trefler (2002) claim on average $23.2 \%$. Based on these and other estimates, we assume in Table 1 that the markups for the manufacturing sector lie between $10 \%-25 \%$.

There are few estimates of the effects of US banking deregulations on business loan rates. Jayaratne and Strahan (1998) find that intrastate branching deregulation leads to a 15 to 33 basis points decrease in business loan rates, but find no impact from interstate bank-entry deregulation. Rice and Strahan (2010) point to a 21 to 88 basis-point decrease in small-business loan rates following the relaxing of interstate branching restrictions, some of which were put in place following the passing of the IBBEA of 1994 as this legislation allowed states to control the incursion of out-of-state branching. These rate decreases amount to a $2.5 \%$ to $17.3 \%$ drop in small-business loan rates depending on the year and the extent of branching deregulation. As capital is not the only factor of production and assuming, as in factor accounting exercises, that it constitutes only one third of the costs, this implies a fall in the marginal costs anywhere from $0.8 \%$ to $5.7 \%$. For these reasons, in Table 1 we present calibration results for different scenarios regarding the fall in the total marginal costs in the range of $1 \%$ to $5 \%$.

The potential effects of improved financial conditions even with small changes in loan pricing can be easily on the order of $50 \%$, depending on the level of competition in the industry (as measured by the markups) and the fall in the cost of credit and the ensuing fall in total marginal costs (which are equal to the average variable costs in this model). Hence, the posited informational advantage that the presence in region $j$ confers to the representative loan-granting bank could generate large differences in trade flows (and trade shares) from region $i$ to region $j$ compared to those from region $i$ to $k$.

\subsection{Empirical models}

To test our conjecture, we estimate gravity equations, which relate trade flows between regions with a set of predictors. Given Dixit-Stiglitz preferences, modern trade theory (that we adapt to our setting) predicts that exports $X_{i m}$ from region $i$ to $m$ would be given by (see Arkolakis et al., 2011): 


$$
X_{i m}=N_{i}\left(\frac{I_{m}}{P_{m}}\right) \Gamma_{i m},
$$

where $N_{i}$ is the number of firms in state $i, I_{m}$ is the income in the destination region, $P_{m}$ is the price index at the destination, and $\Gamma_{i m}$ is a collection of trade "resistance" parameters and production costs (which may be origin-destination specific due to targeted bank lending). We assume that $\Gamma_{i m}=T_{i m} \times \Phi_{i m}$, where $T_{i m}$ represents trade barriers like transport costs and $\Phi_{i m}$ captures the effect of banking integration. In the empirical specifications detailed below, we control for the differences that the variables in Eq. (1) exhibit at the state level. ${ }^{8}$

We reformulate the standard gravity model to obtain flows between state-pairs in terms of region $i$ 's trade shares with all the other states but we exclude shipments within the origin-state. ${ }^{9}$ The share of exports to destination $m$ in total exports of state $i$ (including exports to state $m$ ), defined as $S_{i m}=X_{i m} / \Sigma X_{i l}$, can be transformed after taking logarithms and some algebra to:

$$
\ln \left(S_{i m}\right)=-\Theta_{i}+\beta_{1} \ln \left(I_{m}\right)-\beta_{2} \ln \left(P_{m}\right)+\Xi_{i m}+\beta_{3} \ln \left(T_{i m}\right),
$$

where $\Xi_{i m}=\ln \left(\Phi_{i m}\right)$ and $\Theta_{i}=\Sigma_{m} X_{i m}$ is the state $i$ fixed effect. Our variable of interest is a proxy for $\Xi_{i m}$, i.e., the effect of interstate banking integration.

In a first step, we assume that the state-level bank-entry deregulations were exogenous to trade flows and specify difference-in-differences models. Several arguments can support the notion that interstate trade was not the driver of bank-entry deregulation. The first set of arguments concerns the way deregulation occurred. As Fig. 1 documents, there were four modes of bank-entry deregulation at the state level. First, numerous states opened up their banking systems non-reciprocally (unconditionally) towards MBHCs from all other states. In fact, the most frequent way in which state-pairs opened was through at least one state in the pair deregulating in a national non-reciprocal manner (33.8\%). In such a general deregulatory approach, trade with specific states could not have played a role in the decision to liberalize entry to all other states' banks. Second, if deregulation were to follow trade flows, then we would have observed states opening up in a non-reciprocal (unconditional) fashion to selected trade partners. But only Oregon initially opened up its banking system to some states non-reciprocally in 1986 before extending this privilege to banks from all states in 1989. In contrast, many states opened up their banking systems to some or all states on a reciprocal basis at once. In fact, the second largest group of cases is when both states deregulated nationally in a reciprocal fashion (21.6\%), followed by bilateral reciprocal agreements

\footnotetext{
${ }^{8}$ In the data that are available to us, we do not observe the mass of exporting firms, the interest rates charged on loans that they requested, or the costs of processing of their loans. We are thus unable to test for the strength of particular channels through which the bank integration may operate on state-pair trade flows (though we investigate some of them in Section 6).

${ }^{9}$ For studies of home bias in interregional trade in the US, refer to Wolf (2000) and Hillberry and Hummels (2003).
} 
(8.8\%), and those where one state in the same year deregulated in a national non-reciprocal and the other in a national reciprocal manner (7.2\%). Therefore the effective opening dates, which are the deregulatory events used in our difference-in-differences models, would not only depend on the state that deregulated based on reciprocity (possibly an endogenous decision), but also on the counterparty states' willingness to reciprocate (unlikely to be an endogenous decision from the point of view of the first state that initiated the deregulation). Finally, 500 state-pairs (22.2\% of the sample) did not open until the passage of the IBBEA act in 1995 (not shown in Fig. 1): we examine them separately in Section 6.2. In Fig. 2, panels 1 through 4 detail the geographic distribution of interstate banking deregulations over time. In our regressions we control for any geographic patterns of deregulation through fixed effects.

Second, the political economy explanations put forward to explain interstate banking deregulation do not include trade flows. Given the Kane (1996) and Kroszner and Strahan (1999) findings, we would argue that states were likely to deregulate at similar periods under the political pressure of similar constituencies, and not as a result of higher prior trade flows between them. Kroszner and Strahan (1999) suggest various political economy drivers for deregulation, which include: the importance of lobbying groups such as small banks that were against deregulation for fear of loss of local market power; insurance industry that opposed banks' sale of insurance products at their expense; and small businesses that were for deregulation to access cheaper financing. Their results would suggest that similar constituencies, unrelated with trade, might have been lobbying for protection from out-of-region bank competition in a regional compound, resulting in region-level interstate deregulation. Kane (1996) argues that the bank and thrift (i.e., savings and loans) failures, which occurred in separate waves in different regions due to different economic shocks, were important triggers of interregional financial deregulation. The concept of regional bank-opening was prevalent among the states during the earlier period of deregulation; states (and pressure groups) typically feared that an unconditional opening of their banking systems would lead to acquisitions by large money-center banks. Another idea behind regional liberalization, again unrelated to trade, was that it would lead to a creation of regional banks that, in the event of a nationwide deregulation, would be strong enough to compete with these money-center banks.

These arguments support our assumption that interstate banking deregulations were exogenous to trade flows and shares. This, in turn, allows us to specify difference-in-differences models:

$$
\begin{aligned}
\ln \left(\text { TRADE_SHARE }_{i m t}\right)= & \alpha_{i t}+\beta_{1} \ln \left(G D P_{-} D E S T_{m t}\right)+\beta_{2} \ln \left(\text { WAGE_DEST }_{m t}\right) \\
& +\beta_{3} D_{-} 1993_{t}+\beta_{4} D_{-} D E R E G_{i m}+\beta_{5}\left(D_{-} 1993_{t} \times D_{-} D E R E G_{i m}\right) \\
& +\mathrm{X} \text { GEOGRAPHIC_CONTROLS } \\
\text { im } & +\varepsilon_{i m t},
\end{aligned}
$$


where subscript $i$ denotes the origin-state, $m$ the destination-state, and $t$ indexes time in years; $\ln \left(T R A D E \_S H A R E\right), \ln \left(G D P \_D E S T\right), \ln \left(W A G E \_D E S T\right)$, and GEOGRAPHIC_CONTROLS correspond to $\ln (S), \ln (I), \ln (P)$, and $\ln (T)$ of Eq. (2), respectively. All of these variables are described below in Section 4. We include D_DEREG to capture the potential differences between the deregulating (the treatment group) and the non-deregulating state-pairs (the control group), and $D_{-} 1993$ to capture the changes in the level of trade shares through time since 1977 (we only have two years of data due to CFS availability). Given the origin-state-and-year fixed effects $\left(\alpha_{i t}\right)$, the remaining variation due to deregulation (treatment) would be captured by $\beta_{5}$, the coefficient of the interaction of these two indicator variables, which corresponds to $\Xi_{i m}$ in (2) in the difference-in-differences models. We estimate Eq. (3) using the pooled Ordinary Least Squares (OLS) estimator with origin-state-and-year fixed effects and the Within estimator with origin-destination state-pair fixed effects. In the latter estimator, the geography-related timeinvariant control variables become redundant.

We also estimate a Poisson version of the difference-in-differences model following Santos Silva and Tenreyro (2006):

$$
\begin{aligned}
\text { TRADE_FLOW } W_{i m t}= & \exp \left[\alpha_{i t}+\beta_{1} \ln \left(G D P_{-} D E S T_{m t}\right)+\beta_{2} \ln \left(W A G E_{-} D E S T_{m t}\right)\right. \\
& +\beta_{3} D D_{-} 1993_{t}+\beta_{4} D_{-} D E R E G_{i m}+\beta_{5}\left(D_{-} 1993_{t} \times D_{-} D E R E G_{i m}\right) \\
& \left.+\mathrm{X} \text { GEOGRAPHIC_CONTROLS } S_{i m}\right]+v_{i m t},
\end{aligned}
$$

where the dependent variable, TRADE_FLOW allows for zero flows. Alternatively, we use TRADE_SHARE $E_{i m t}$ as a dependent variable when timeinvariant origin-destination state-pairs $\left(\alpha_{i m}\right)$ and a year-effect $\left(D \_1993\right)$ are included in (4).

In a second set of regressions, we take into account actual bank entry and examine the impact of realized banking integration as of 1993, as measured by the fraction of banking assets that are common for an origin-destination state-pair, on trade:

$$
\begin{aligned}
\ln \left(\text { TRADE_SHARE }_{i m t}\right)= & \alpha_{i m}+\gamma_{1} \ln \left(G D P_{-} D E S T_{m t}\right)+\gamma_{2} \ln \left(W A G E_{-} D E S T_{m t}\right) \\
& +\gamma_{3} D_{-} 1993_{t}+\gamma_{4} B A N K_{-} I N T E G_{i m t}+\phi_{i m t} .
\end{aligned}
$$

Here, however, our test variable $\left(B A N K_{-} I N T E G_{i m t}\right)$, which corresponds to $\Xi_{i m}$ in Eq. (2), is potentially endogenous to trade. We estimate Eq. (5) with Instrumental Variables (IV) regressions where we follow MRS (2004) and instrument BANK_INTEG $G_{i m t}$ with the number of years since deregulation for the origin- 
and destination-state and a "dummy" variable indicating whether origin- and destination-state deregulated entry as of 1993. We also estimate the Poisson-IV version of Eq. (5): ${ }^{10}$

$$
\begin{aligned}
T R A D E_{-} S H A R E_{i m t}= & \exp \left[\alpha_{i m}+\gamma_{1} \ln \left(G D P_{-} D E S T_{m t}\right)+\gamma_{2} \ln \left(W A G E_{-} D E S T_{m t}\right)\right. \\
& \left.+\gamma_{3} D_{-} 1993_{t}+\gamma_{4} B A N K_{-} I N T E G_{i m t}\right]+\omega_{i m t} .
\end{aligned}
$$

Next, we detail the data sources used to construct the variables needed to estimate models (3) through (6).

\section{Data}

Our dependent variables, the value (in dollars) of trade flows (TRADE_FLOW $W_{i m t}$ ) from state $i$ to state $m$ and the share of trade (TRADE_SHARE $E_{i m t}$ ) from state $i$ to state $m$ with respect to the sum of all trade originating from state $i$, are based on shipment data available in the CFS. ${ }^{11}$ This survey is stratified across industries, geography, and firm size. During the interstate banking deregulation period, only two surveys were conducted in 1977 and 1993. For our purposes it is fortunate that the 1977 CFS precedes the first interstate banking deregulation by Maine in 1978. The timing of the 1993 survey, a year before the enactment of the IBBEA legislation that deregulated interstate banking and branching at the federal level as of 1995, is also fortunate: there is no confounding of state-level deregulations up to 1993 that are central for our identification strategy (the federal banking deregulation when IBBEA came into effect in 1995). Moreover, the North American Free Trade Agreement (NAFTA), which could impact the surveyed flows, did not come to existence until 1994. The 1977 CFS covered approximately 19,500 manufacturing establishments (plants) in the 50 states plus the District of Columbia with one or more employees. The 1993 survey, on the other hand, covered approximately 100,000 mining, manufacturing, wholesale, and retail establishments. Both surveys exclude establishments involved in crude oil and natural gas extraction, farming and services, as well as direct imports and exports across US borders. Participating establishments reported the value, weight, type, origin, destination, and the mode of transportation (land, water, air) of sample shipments over four one-week periods during the calendar year, with one week per each quarter.

The CFS data that we use have five major drawbacks. First, we are dealing with survey data as opposed to actual trade data on interstate "exports," which cannot be observed since the states do not collect this information. Moreover, survey sampling methods and sizes change over time. As a result we resort to trade shares as opposed to trade flows (or to specifications with trade flows that are equivalent to

\footnotetext{
${ }^{10}$ Quantatively very similar estimates obtain with origin-state-and-year fixed effects and controls for geography.

${ }^{11}$ This survey, originally conducted by the Department of Transportation's Bureau of Transportation Statistics, is now jointly administered with the US Census Bureau: http://www.bts.gov/programs/commodity_flow_survey/ and http://www.census.gov/svsd/www/cfsmain.html.
} 
those with trade shares, thanks to time-varying origin-state fixed effects $\alpha_{i t}$ ). A second problem is that the publicly available versions of the CFS that we have access to aggregate the surveyed shipments data at the state level. As a result, our dependent variable is at the state level (and not establishment, firm, county, or metropolitan area level, any of which would have allowed us to conduct more precise tests). The third difficulty is that, as indicated above, the number of sampled establishments is more than five times larger in the 1993 survey than the 1977 CFS, leading to even larger sampling errors for the latter data set, especially for the smaller states. These larger sampling errors engender higher standard errors in our regressions, which render our estimates less precise. As a result, even though we account for the resulting heteroskedasticity, the survey data that we use make it more difficult for us to find any evidence supporting our hypothesis. The fourth drawback is that starting from 1993, the CFS includes wholesalers' shipments alongside manufacturers' data. Unfortunately, the publicly available version of the CFS does not disaggregate shipments by the nature of establishments even though it breaks them down by industry segments starting with 1993 (which are not available in the 1977 survey). As a result, we cannot exclude wholesalers' shipments from the 1993 survey to make them conform to 1977 data. The inclusion of wholesalers' data in 1993 can inflate sampled trade flows in that year compared to 1977 data, but the trade shares that we focus on are less likely to be affected by this inclusion. The fifth drawback is that, because the CFS was devised to examine manufacturing shipment flows, as opposed to studying their nature, we cannot discern what proportion of the sampled shipments was for their final destination of “consumption." Despite these drawbacks, we use CFS as it is the only source for US interstate trade data.

We exclude Alaska and Hawaii because a majority of the flows from these two states to the rest of the US are missing. These two states are also special because they are geographically detached from the other 48 states and face considerably larger (physical) trade barriers. We also drop the District of Columbia that has very few manufacturing establishments. As we focus on the 48 contiguous states of the Union, our full sample includes 2,256 (=48×47) state-pairs on an annual basis, which gives us 4,512 observations for 1977 and 1993 combined.

We combine the CFS data with two types of banking data. First, we collect interstate banking entry deregulation dates from Amel (2000) to create the effective dates (years) of deregulation. These dates are established to ascertain that the deregulation by a given state $i$ could possibly lead to integration of its banking sector with that of state $m$ : for example, if state $i$ allows entry by all the other states on a reciprocal basis, entry of state $m$ 's banks into state $i$ 's banking sector cannot occur unless state $m$ allows access of state $i$ 's banks into its own banking sector as well. Using effective deregulation years, we create a deregulation indicator variable $\left(D_{-} D E R E G_{i m}\right)$ that equals one if banks from at least one of the states $i$ or $m$ in a state-pair could enter the other state's market as of 1993, and zero otherwise. Second, we use data from bank financial statements (the so-called Call Reports), which all US banks have to report to their 
federal regulators, to calculate a measure of banking systems' integration at the state-pair level. For this, we collect the total assets of banks and data on bank holding company structures. We account for the conglomerate structure since, prior to the IBBEA that was signed into law in 1994, interstate bank entry occurred mostly through the acquisition of banks in a given state by MBHCs from other states rather than de novo entry. We define the integration variable (BANK_INTEG $\left.G_{i m t}\right)$ for a given state-pair $i$ and $m$ to be the ratio of banking assets in state $i$ owned by banks in state $m$ plus the banking assets in state $m$ owned by banks in state $i$ divided by the sum of states $i$ and $m$ 's total banking assets. ${ }^{12}$ Given that the MBHC structure was the primary way of banking market entry prior to the enactment of the IBBEA in 1995, we attribute total assets by the headquarter state of the highest-level institution in the conglomerate, if any.

One could argue that banks could follow trade flows and enter the banking markets of states with which their home state has the strongest economic ties. If so, as mentioned above, our banking market integration variable would be endogenous to trade flows and its use would yield biased and inconsistent estimates. We use the instruments suggested by MRS (2004) for BANK_INTEG $G_{\text {imt }}$ : interstate banking deregulation indicator variables for the origin and destination states (D_DEREG_ORIG it $_{\text {, }}$ D_DEREG_DEST $\left.T_{m t}\right)$ and variables that keep track, of years since deregulation (YEARS_DEREG_ORIG YEARS_DEREG_DEST $T_{m t}$ ). The latter are equal to zero in 1977 since none of the states had deregulated interstate bank entry by that year. Maine is the first state to do so by 1978 .

Our gravity equations require that we account for destination-state's income $\left(I_{m}\right)$ and producerprice index $\left(P_{m}\right)$. GDP figures for the destination state, GDP_DEST $T_{m}$, are taken from the US Bureau of Economic Analysis. We expect the coefficient estimate of $\ln \left(G D P \_D E S T_{m t}\right)$ to be positive and close to 1.0 in line with the theory and the empirical trade literature. As a proxy for price levels, which are unavailable at the state level, we follow the standard practice and use destination-state manufacturing wage index (WAGE_DEST $T_{m t}$ ), based on the payroll hours worked, from the US Commerce Department Annual Survey of Manufactures. Theoretically, the coefficient estimate for $\ln \left(W A G E \_D E S T_{m t}\right)$ should be negative (a higher destination price index implies lower demand).

The gravity equation also requires us to control for trade barriers $\left(T_{i m}\right)$ between origin-destination state-pairs (GEOGRAPHIC_CONTROLS in the formulation of Eqs. (3) and (4)). Even though the US constitution bars states from levying explicit tariffs on interstate trade, differences in state and local taxes or regulations engender implicit barriers to interstate trade. In line with the trade economics literature, we use the great-circle distance between the capital cities for each state-pair $\left(\ln \left(D I S T A N C E_{-} C A P S_{i m}\right)\right)$ to account for trade and/or finance barriers (see Section 6.5 for more detail). We also use a set of variables

${ }^{12}$ Two states' banking systems may also be integrated through tertiary links: ownership of assets by state $n$ 's banks in states $i$ and $j$ would create an additional channel of integration. We leave out such tertiary channels, and as a result, our BANK_INTEG $G_{i m t}$ variable provides a lower estimate of existing bank links, thus making it more difficult for us to detect any existing effects empirically. 
that account for the characteristics of the origin-destination state-pair's geography that could affect trade. The variable $A D J A C E N C Y_{\text {im }}$ is meant to capture the effects of the origin-state having one or more neighboring states on its trade flows toward the destination state. $A D J A C E N C Y_{\text {im }}$ is equal to the inverse of the number of states with which the origin-state has a common border if the origin-destination state-pair has a common border, and zero otherwise. States that have access to a common waterway are likely to enjoy lower transportation costs. With the indicator variable $D_{-} R I V E R_{i m}$, we account for the fact that a pair of states might be on the Mississippi or Columbia river systems as well as the Great Lakes shoreline. We also account for whether the destination state is a US border or coastal state for two reasons. First, due to the presence of "border effects," such states may be more remote than others and hence have a naturally lower trade share. Second, even if the survey participants are asked to exclude shipments specifically destined to other countries, some of the shipments to the border-states captured by the CFS may in fact be destined for international exports, a factor that could potentially inflate trade shares to states on the US borders. Thus, the indicator variable $D_{-} C O A S T A L \_D E S T_{i m}$ is equal to one for states on the Atlantic and Pacific Oceans, and zero otherwise; the indicator variable D_BORDER_DEST im is equal to one for states on the US national frontier, and zero otherwise. These controls are only used in the timevarying origin-state fixed-effects $\left(\alpha_{i t}\right)$ models, since origin-destination state-pair fixed effects $\left(\alpha_{i m}\right)$ account for state-pair geography.

The summary statistics for our sample are presented in Table 2. The average trade flow between the exporting-importing state-pairs is $\$ 930.85$ million, with a standard deviation of $\$ 2.19$ billion. For 120 state-pair observations in 1977 and 167 in 1993, the observed trade flow is zero. Of course, this does not mean that there is actually no trade between these state-pairs, but that the CFS sampling scheme either (i) did not detect any shipments (presumably due to actual low trade flows emanating from smaller states), or (ii) the shipments were small and rounded to zero when reported, or (iii) the estimate was not published by CFS administrators because of high survey sampling errors. These 287 state-pair-year observations will drop out of our sample when the logarithm of trade share is used as a dependent variable, a wellknown problem in the empirical trade literature. The trade share for the average state-pair is $2.13 \%$ (which is an expected statistic $(=100 \% \div 47)$ given that each state has 47 partners, after excluding Alaska, Hawaii, and the District of Columbia from the sample, and a sum of trade shares of 100\%), with a standard deviation of $3.53 \%$, a minimum of zero, and a maximum of $47.70 \%$. The deregulation indicator variable has a mean of 0.7190 , suggesting that $28.10 \%$ of state-pairs had not opened their markets to one another as of 1993 (this despite the fact that up to that point, all of the 48 contiguous states had deregulated bank entry to some extent). $A D J A C E N C Y_{i m}$, which is equal to the inverse of the number of neighboring states the state of origin has if a particular state-pair are adjacent and zero otherwise, has a mean of 0.0213 for the full sample. Of our 4,512 state-pair observations, one-third have a destination- 
state that is on the US borders ( $D \_B O R D E R \_D E S T_{\text {im }}$ has a mean of 0.3333 ), and approximately $44 \%$ have a destination-state that is on the seacoast (D_COASTAL_DEST $T_{\text {im }}$ has a mean of 0.4375). For the 4,512 state-pairs in our sample, the mean distance between state capitals is 1,677.23 kilometers, $22.70 \%$ share a common river system, and $13.83 \%$ are on the same coast.

The summary statistics for BANK_INTEG $G_{i m t}$, the endogenous (instrumented) variable in the IV regressions, indicate that on average, only $0.19 \%$ of state-pairs' banking assets were integrated with the maximum level of integration of $18.45 \%$ in 1993 (between Florida and North Carolina). The low average for BANK_INTEG $G_{i m t}$ is due to the fact that only $14.98 \%$ state-pairs in the US had formed any banking links as of 1993, and fewer still $(2.75 \%)$ had any links in $1977 .{ }^{13}$ The indicator variables D_DEREG_ORIG it $_{\text {it }}$ and D_DEREG_DEST $T_{m}$, which we use as IVs for our endogenous variable BANK_INTEG $G_{i m t}$, point out that almost two-thirds of states had deregulated as of 1993 to other states (their mean is 0.6450 in 1993 and zero in 1977). However, most deregulation took place in the latter years in our sample: the mean for the variables tracking the number of years since deregulation $\left(Y E A R S \_D E R E G \_O R I G_{i t}\right.$ and YEARS_DEREG_DEST $T_{m t}$ ) is 3.4907 years in 1993 (and zero in 1977).

Another problem with the CFS data, besides sampling errors, is the rounding of the reported flows. The smallest unit of measure in the CFS is $\$ 1$ million, which means that for very small sampled shipments, the errors in the calculated trade shares between 1993 and 1977 can easily be more than 10\% for reported flows below $\$ 10$ million. ${ }^{14}$ To check the robustness of our results to sampling and rounding errors in the trade survey data, we also examine a subsample with 3,512 state-pair-year observations for which trade flows are \$10 million or more (in constant 1977 dollars). Admittedly arbitrary, the threshold of $\$ 10$ million was chosen so as to minimize the influence of observations with large measurement errors while minimizing the number of observations that are dropped. ${ }^{15}$

\section{Empirical model estimates}

\footnotetext{
${ }^{13}$ The non-zero bank links in 1977 are due to the fact that some states had allowed bank entry before the passage of the 1956 Douglas Amendment to the Bank Holding Company Act that forbade any further interstate banking expansion. The interstate banking links existing by then were grandfathered by the 1956 Act. BANK_DEREG ${ }_{i m}$ for those pairs would still be zero in 1977, since no interstate banking deregulation took place before 1978.

${ }^{14}$ The standard errors on the estimate of global (i.e., total at the state-level) shipments reported in the 1977 CFS documentation are especially high for smaller states: for example, the reported standard error is $23 \%$ for Vermont, $16 \%$ for Maine, and 11\% for New Hampshire, whereas it is 5\% for New York and 4\% for California. The measurement errors in state-pair trade flows that we use here are likely to be even greater.

${ }^{15}$ Due to the availability of the CFS data and the threshold that we impose, the number of trade pairs for exporting states differs in the $\$ 10$ million flow sample: for example, we have $47 \times 2$ observations for Illinois, New Jersey, Pennsylvania, and Wisconsin, whereas only $9 \times 2$ for Wyoming. This feature of the subsample does not affect our model estimates given that we include state or state-pair fixed effects and account for heteroskedasticity. In unreported estimations, we also used thresholds of \$5 and \$20 million (in constant 1977 dollars). These thresholds would limit CFS rounding (reporting) errors to $20 \%$ and $5 \%$ of the surveyed value, respectively.
} 
The main estimates of the gravity Eqs. (3) through (6) are presented in Tables 3 and 4, respectively. In all of our estimations, we use robust standard errors clustered by the origin-state to account for heteroskedasticity, with the exception of Poisson estimators where we have robust errors.

Before we focus on our test variables, we first check the validity of our gravity equation by comparing its estimates with the findings in the literature. The coefficient estimates for $\ln \left(G D P \_D E S T_{m t}\right)$, $\ln \left(W A G E \_D E S T_{m t}\right)$, and geographical controls in Table 3 are in line with those found in the empirical trade literature. The logarithm of destination-state's GDP has a coefficient estimate that is statistically significant and typically slightly above (below) but close to 1.0 in the OLS (Poisson) regressions presented in Table 3, which is consistent with the Santos Silva and Tenreyro (2006) findings that compare OLS and Poisson estimates of gravity equations. The coefficient estimates for $\ln \left(W A G E \_D E S T_{m t}\right)$, which proxies for the manufacturing price index in the destination-state, typically enters with the expected negative sign in the regressions, although it is not statistically significant with the exception of one regression where it is negative and marginally statistically significant at the $10 \%$ level. The year indicator variable $D \_1993$ has a negative (positive) and statistically significant coefficient estimate when we use TRADE_SHARE $E_{\text {imt }}\left(T R A D E \_F L O W_{i m t}\right)$ as a dependent variable: between 1977 and 1993, the average origin-destination trade shares have slightly decreased, possibly due to faster growth in trade shares of states for which the flow was unobserved or zero in 1977; whereas the average sampled trade flows have increased, which is likely to be due to both CFS' larger sampling scheme in 1993 as well as higher trade flows, though we cannot differentiate which effect dominates.

The coefficient estimates for geographic characteristics presented in Table 3 (with the exception of state-pair fixed-effects models that preclude geography variables) and the proxy for trade barriers are also in line with those found in the literature. Adjacent states have higher and always statistically significant (at the 1\% level) trade shares in all of our estimates. In the same tables, the log of distance between state capitals has a negative and always statistically significant (at the $1 \%$ level) coefficient estimate: the higher the distance between two state capitals, the lower the trade shares, a result that may be due to higher trade and/or finance barriers between more distant states. Being linked through a river system (which includes the Great Lakes) has a positive and statistically significant effect on trade in all estimates except for the OLS estimates with the full sample, where the coefficient estimates are positive but not statistically significant. Trade towards destination states that are on the US international borders is higher, but statistically significant only in the log-linear models (columns 1 and 2) of Table 3. Trade towards destination states that are on the coasts is lower, but statistical significance is typically lacking except in the first two columns of Table 3. Being on the same shoreline (D_SAME_COAST $T_{\text {im }}$ ) does not appear to have any impact on trade. Next, we focus on the coefficient estimates of our test variables. 


\subsection{Difference-in-differences model estimates}

Table 3 columns 1 through 3 present the estimates of Eq. (3) using the "full" sample of 4,225 observations after dropping 287 observations with zero trade shares, with column 4 using the subsample of 3,512 observations with trades of $\$ 10$ million of more. Empirical models of columns 1 and 2 include origin-state-and-year fixed effects $\left(\alpha_{i t}\right)$, and those of columns 3 and 4 origin-destination state-pair fixed effects $\left(\alpha_{i m}\right)$. Models in the first two columns of Table 3 are estimated with pooled-OLS with indicator variables for various fixed effects, while those in columns 3 and 4 are estimated using a Within estimator.

The coefficient estimate of interest is $\beta_{5}$ for the interacted-indicator variables D_1993 $\times$ _D_DEREG $G_{i m}$, which captures the treatment effect of interstate banking deregulation. In Table 3 column 2, the coefficient estimate for the interacted-indicator variables is 0.0752 (statistically significant at the $10 \%$ level). This means that for a state-pair that has deregulated entry to each other's banks before or on 1993, their trade share was greater by $7.52 \%$ on average going from 1977 to 1993 compared to the trade share of a state-pair where no such deregulation occurred. In column 3, when we include origindestination state-pair fixed effects $\left(\alpha_{i m}\right)$, the coefficient estimate for $D \_1993_{t} \times D \_D E R E G_{i m}$ is 0.0598 but not statistically significant at the conventional levels (it has a $p$-value of 0.165 ). One possible explanation for the observed discrepancy between columns 2 and 3 may be due to the survey sampling errors that are, as noted above, larger for small states because fewer establishments have been surveyed among the more limited set of firms populating a smaller state. To check for this possibility, we re-estimate the empirical model of column 3 using the subsample with trade flows of $\$ 10$ million or more and report the results in column 4 of Table 3: $\beta_{5}$ for the interacted-indicator variables $\left(D_{-} 1993_{t} \times D_{-} D E R E G_{i m}\right)$ is estimated to be 0.0924 , which is statistically significant at the $1 \%$ level. In other words, we find that, compared to statepairs that did not deregulate, out-of-state bank-entry deregulation leads to a statistically significant $9.24 \%$ increase in trade shares by 1993. Importantly, the $\beta_{5}$ estimate is statistically significant with origindestination state-pair fixed effects. When compared with the results of columns 2 and 3, estimates in column 4 suggest that survey sampling errors do have an impact on model estimates.

Another possible explanation for the discrepancy in the estimates for $\beta_{5}$ in Table 3 may be the choice of the log-linear gravity equation. Santos Silva and Tenreyro (2006) point out that OLS estimates of log-linear models would lead to biased estimates because of Jensen's inequality: the expected value of a logged variable is not equal to the logarithm of the expected value. This engenders heteroskedasticity that is exacerbated in our case given that CFS sampling design results in higher sampling errors for smaller states. Further, the log-linear gravity model rules out the 287 observations for which the trade 
flows, and hence trade share, is zero. ${ }^{16}$ One argument is that these observations are subject to even larger sampling errors than those with less than a given, albeit arbitrary, threshold such as $\$ 10$ million. However, a valid counter-argument would be that zero trade-share observations carry information without which the estimation results would be biased or worse, inconsistent. To deal with the problem of zero trade shares, we follow Santos Silva and Tenreyro (2006) and estimate Eq. (4) using pooled-Poisson and Within-Poisson regressions and present the results in the last four columns of Table 3.

The coefficient estimate of $\beta_{5}$ for the interacted-indicator variables $\left(D \_1993_{t} \times D \_D E R E G_{i m}\right)$ in column 6 (with origin-state-and-year fixed effects) suggests a statistically significant $19.86 \%$ increase in trade shares by 1993 for state-pairs that deregulate bank entry to each other's institutions as opposed to state-pairs that do not deregulate such entry. This coefficient estimate is more than twice the size of the one obtained using the pooled-OLS estimator in column 2 of the same table. Controlling for origindestination state-pair effects to deal with unobservables appears to be important: the estimate of $\beta_{5}$ in column 7, with origin-destination state-pair fixed effects $\left(\alpha_{i m}\right)$ with a Within-Poisson estimator, is $0.1335 .{ }^{17}$ In the last column of Table 3, we check whether CFS sampling errors affect these Poisson estimates using the subsample of 3,512 observations with trades larger than or equal to $\$ 10$ million. The estimate of $\beta_{5}$ is 0.1425 with the model including $\alpha_{i m}$. This coefficient estimate is very close to that in column 7, whereas this was not the case between columns 3 and 4 with OLS regressions. This is likely to be due to the fact that the Poisson maximum likelihood estimation procedure gives equal weights to all observations given the first-order condition on which it is based (see, for example, Santos Silva and Tenreyro, 2006), whereas the OLS, which minimizes the sum of the squared-errors, gives more weight to outliers, which, in our case, also contain the observations with the higher sampling errors.

In unreported regressions (in Appendix Table A1), ${ }^{18}$ we replace the deregulation dummy $\left(D_{-} D E R E G_{i m}\right)$ in the interaction term $\left(D_{-} 1993_{t} \times D_{-} D E R E G_{i m}\right)$ with the number of years since the bilateral entry-liberalization $\left(Y E A R S \_D E R E G_{i m}\right)$ so as to account for the time it takes banks, and hence indirectly trade, to respond to deregulation. When the subsample with trade flows higher than $\$ 10$ million 1977 dollars is used, the coefficient estimate for D_1993 $\times$ YEARS_DEREG $G_{\text {imt }}$ in the log-linear (Within) regression model with the state-pair fixed effects is 0.0205 , whereas the corresponding coefficient estimate for the Poisson (Within) regression is 0.0211 , with both coefficients being statistically significant at the $1 \%$ level. With the average number of years since bilateral deregulation being 5.83 years, these

\footnotetext{
${ }^{16}$ Alternative solutions for dealing with zeros in a log-linear model include adding \$1 million or a very small positive but non-zero number (say, $\$ 1$ ) to all TRADE_FLOW estimating a Tobit model. We rule out these arbitrary solutions, as they generate biased and potentially inconsistent estimates (Santos Silva and Tenreyro, 2006).

${ }^{17}$ Note that the Within-Poisson estimator drops 62 state-pair observations for which the dependent variable, TRADE_FLOW, is zero both in 1977 and 1993 resulting in 4,450 instead of the full sample of 4,512 observations.

${ }^{18}$ This and other Appendix tables are available at www.hec.fr/ors.
} 
estimates suggest that for the typical state-pair, the impact of banking deregulation amounts to $11.95 \%$ $(=0.0205 \times 5.83)$ and $12.30 \%(=0.0211 \times 5.83)$ increase in trade flows in the log-linear and Poisson models, respectively. These results are in the same order of magnitude as the comparable estimates of $9.24 \%$ and $14.25 \%$ obtained in columns 4 and 8 of Table 3.

Based on the Within-Poisson state-pair fixed-effect version of the difference-in-differences model in column 8 of Table 3, we conclude that there is, on average, a $14.25 \%$ increase in trade over the decade that ends in 1993 for state-pairs that deregulated entry to each other's banks. However, following deregulation, the size of bank entry differs across state-pairs, which suggests that entry's impact on trade may differ based on the level of actual financial integration, a question that we examine next.

\subsection{Instrumental variables estimates using actual bank entry}

To examine the effects of actual bank entry on trade, we estimate Eqs. (5) and (6) where the test variable, BANK_INTEG $G_{i m t}$, is instrumented following MRS (2004). The first four columns of Table 4 present the estimates of the log-linear Eq. (5) whereas the last four columns provide the estimates of the Poisson Eq. (6), all of which incorporate origin-destination state-pair fixed effects $\left(\alpha_{i m}\right)$.

In Table 4 column 1, we present the estimates of the base-case Within state-pair fixed-effects loglinear model without the endogenous test variable. In the Within regression presented in column 2, $B A N K_{-} I N T E G_{i m t}$ has a coefficient estimate of 0.5469 , which is not statistically significant. As explained above, the fixed-effects estimates presented in column 2 are potentially biased and inconsistent if $B A N K_{-} I N T E G_{i m t}$ is endogenous to trade. In the IV-GMM-2S regression presented in column 3, the coefficient estimate for the instrumented BANK_INTEG $G_{i m t}$ is 7.3626 (statistically significant at the 5\% level). This indicates that for the state-pair experiencing a one-standard-deviation increase in the banking integration variable (an increase of 0.0118 , or 1.18\%), the trade share increases by 0.0869 $(=7.3626 \times 0.0118)$, that is by $8.69 \%$. Observing that the average integration in the full sample reported in Table 2 was low (0.0019), we consider this to be a high estimate of the impact of banking integration on real integration through trade. Given the preponderance of zeros in $B A N K_{-} I N T E G_{i m t}$, another way to interpret this result is to use the move from zero to the mean of the explanatory variable. In 1993, the average bank integration for states that had established bank links was 0.0228 , or $2.28 \%$ of their combined banking assets. The coefficient estimate of 7.3626 would suggest that for a state-pair, whose banks were not integrated before, if bank integration would suddenly increase to this mean value (say, due to a merger between two large depository institutions), the trade between these two states would increase by $0.1679(=7.3626 \times 0.0228)$, that is, by $16.79 \%$. This result is well within the range of values obtained from our calibration exercise and presented in Table 1. 
To check the validity of our instruments we conduct a series of identification tests that are presented at the bottom of column 3 of Table 4. First, the under-identification test strongly rejects (at the $1 \%$ level) the null hypothesis that our model is under-identified, which indicates that the rank condition necessary and sufficient for identification of our model is satisfied. However, the rejection of the underidentification test does not rule out the problem of weak instruments, which we test for in a second step. It should be noted that with valid instruments, IV estimates are asymptotically consistent but inevitably biased in finite samples (see, for example, Cameron and Trivedi, 2005, p. 108). The question is whether the IV bias is at a tolerable level, such as $10 \%$ or $20 \%$ of the OLS bias. The weak identification test with the test statistic of 14.20 rejects the null hypothesis of weak instruments with a Stock and Yogo (2005) critical value that corresponds to a $10 \%$ maximal IV relative bias. This critical threshold value suggests that the finite sample bias of IV estimates is less than $10 \%$ of the OLS bias, that is, low. Finally, in the over-identification test, the underlying joint-null hypothesis is that our instruments are valid and that the exclusion restrictions imposed on the instruments are correct. The Hansen- $J$ statistic in column 3 of Table 4 indicates that we cannot reject the null, validating the over-identifying restrictions imposed on the model. These test results suggest that our IV model is properly identified, does not suffer from the weak instruments problem, and has a small finite-sample IV bias compared to the OLS bias.

Next, we check to what extent these results may be affected by the CFS sampling-error problems mentioned above. In Table 4, column 4, we re-estimate the log-linear model of column 3 using the subsample of 3,512 observations with a minimum trade size of $\$ 10$ million. The results indicate that, as in the case of difference-in-differences estimates, the log-linear model estimates are affected by sampling errors. The coefficient estimate for BANK_INTEG $G_{i m t}$ is 11.0970 , indicating that an increase in bank integration from zero to the sample mean in 1993 (2.28\%) between the origin-destination states would increase their trade by $25.28 \%$. One more time, the results of the identification tests indicate that our endogenous variable is properly instrumented: in column 4 we reject the under-identification and weakidentification tests as we should (and at the same significance level as in column 3), and we cannot reject the over-identification test. It seems that CFS sampling errors lead, as in the case of difference-indifferences estimates, to under-estimation of the impact of bank integration on trade.

As in the case of the difference-in-differences case, we also estimate Poisson models with IV, however, with two caveats. The first is that we can estimate Eq. (6) with origin-destination state-pair fixed effects, but using a Poisson-IV estimator rather than a "Within-Poisson-IV" estimator, which, to the best of our knowledge, does not exist. This by itself is not a concern, given that estimating a pooled-IVPoisson regression with many indicator variables representing state-pair fixed effects is equivalent to estimating a Within-Poisson regression with the corresponding fixed effects (see, for example, Cameron 
and Trivedi, 1998, pp. 280-282). The second caveat is that for Poisson-IV estimates, we could not conduct identification tests since we could find no references for such tests for these estimators.

With these caveats in mind, we observe in column 7 of Table 4 that the coefficient estimate for $B A N K_{-} I N T E G_{\text {imt }}$ is equal to 8.8660 (statistically significant at the $1 \%$ level), which is more than three times higher than the uninstrumented estimate of 2.6194 for $B A N K_{-} I N T E G_{i m t}$ in column 6. The estimate

in column 7 suggests that if a state-pair that was not financially integrated and would see banking integration rise from zero to the sample mean in 1993 (0.0228), the origin-destination trade share would increase by $20.20 \%$, an economically significant increase that would take place over 16 years. We also check, as we did in the case of difference-in-differences estimates, to what extent the Poisson-IV regressions are affected by the presence of sampling errors in the CFS data. In column 8 we re-estimate the model of column 7 with the 3,512 observations for which trade size is at least $\$ 10$ million. The coefficient estimate of $B A N K_{-} I N T E G_{i m t}$ is 8.5802 (statistically significant at the $1 \%$ level), a value that is very close to that obtained in column 7 using the full sample. Overall, our IV-GMM-2S and IV-Poisson estimates suggest that, given actual bank entry, an increase in banking integration from zero to the sample mean $(0.0228)$ would increase trade in a state-pair in the range of roughly $16.8 \%$ to $25.2 \%$.

\section{Robustness checks}

In this section we conduct a series of robustness checks. To conserve space, but also to limit the effects of sampling errors, we limit ourselves to the subsample with trade flows above $\$ 10$ million.

\subsection{The subsample with trade shares less than $5 \%$ as of 1977}

First, we re-estimate our main difference-in-differences and IV models after removing 510 statepair observations for which the trade share was more than 5\% as of 1977 and for which the potential concern of endogeneity would be the most acute. If bank deregulation were endogenous to trade, one would expect that the effect would be most pronounced for state-pairs with the highest level of trade shares prior to the start of the deregulatory process in 1978. The results are presented in Table 5 where the first two columns present the state-pair fixed-effect difference-in-differences model using the Within and Within-Poisson estimators, respectively. The coefficient estimate for $D \_1993_{t} \times D \_D E R E G_{i m}$ is equal to 0.1043 in the case of the log-linear model and 0.1868 in the case of the Poisson model, and both of these estimates are statistically significant at the $1 \%$ level. Comparable coefficient estimates in our previous regressions were equal to 0.0924 (Table 3, column 4) and 0.1425 (Table 3, column 8), respectively. It is not surprising that we obtain higher estimates here: state-pairs with trade shares less than 5\% as of 1977 correspond to those that would benefit the most from the bank-entry deregulation. 
Next we compare the IV regression results. IV-GMM-2S results with state-pair fixed effects in column 3 of Table 5 indicate that the coefficient estimate for the instrumented BANK_INTEG $G_{\text {imt }}$ is equal to 22.3229 (statistically significant at the $1 \%$ level). ${ }^{19}$ In column 4 of Table 5 , the Poisson-IV coefficient estimate for BANK_INTEG $G_{i m t}$ is equal to 26.8871 (statistically significant at the $1 \%$ level). For a state-pair whose banking markets were not linked in 1977, if the bank integration were to increase by $2.28 \%$ (the sample mean in 1993), trade between these two states would increase by $50.89 \%$ to $61.3 \%$ over 15 years.

\subsection{Federal interstate banking deregulation: the IBBEA of 1994}

As a second robustness check, we examine another event that further deregulated interstate banking: the IBBEA that was signed into legislation in 1994 and became effective in $1995 .{ }^{20}$ Prior to the enactment of IBBEA, all 48 contiguous states had opened up their banking markets to at least some other states. Nevertheless, 500 (out of 2,256) state-pairs had not deregulated bank entry as of 1994. Importantly for us, a new CFS was conducted in 1997, three (two) years after IBBEA became law (effective). We create a separate database by combining the 1993 CFS data with those of the 1997 survey. The short period between these two surveys works against us finding any effect, as does the introduction of NAFTA in 1994, which may have changed the geography of interstate trade.

In Table 6, we present OLS and Poisson difference-in-differences models with the 1993-1997 data. Even though the sampling issues were better handled in the 1993 and 1997 surveys compared to the 1977 CFS, we nevertheless restrict ourselves to the subsample with trade sizes of $\$ 10$ million or more (in 1977 dollars) to be consistent with the previous estimates. ${ }^{21}$ Importantly, the bases of comparison for difference-in-differences models are now different. In the previous difference-in-differences estimations in Table 3, we measured the effect of the treatment (the opening of the banking market) on trade shares, by comparing the state-pairs that opened their respective markets to each others' banks as of 1993 (i.e., the treated) to those that did not as of the same date (the control group). Here, we are comparing those state-pairs that were forced to open their respective banking markets through federal deregulation (the new treatment group) to those state-pairs that had already opened up bank entry prior to 1994. These new estimates should give us an idea as to how the treated in this federal deregulation fare in terms of trade shares relative to those already treated earlier. Another point regarding Table 6 is that state-of-origin-and-

${ }^{19}$ This IV-GMM-2S regression is properly identified: (i) the null hypothesis of under-identification is rejected at the $1 \%$ level (the under-identification test statistic is equal to 17.29); (ii) the null hypothesis of weak-instruments is rejected, albeit at the $20 \%$ level (the weak-identification test statistic is equal to 7.97 , with the critical threshold for $20 \%$ maximal IV-bias being equal to 6.71); and (iii) the joint-null hypothesis of valid instruments and correct exclusion restrictions cannot be rejected (Hansen- $J$ statistic equal to 1.34 with a $p$-value of 0.7186 ).

${ }^{20}$ While IBBEA is potentially exogenous, its congressional approval may have been influenced by views and voting patterns of the representatives of states that stood to benefit the most from the federal banking deregulation.

${ }^{21}$ We obtain very similar results after estimating the empirical models in Table 6 with (i) the full sample, or (ii) the subsample with trade sizes equal to or higher than $\$ 10$ million in constant 1993 dollars. 
year fixed-effect models are presented because we obtained unreasonable estimates for $\ln \left(G D P \_D E S T_{m t}\right)$ and $\ln \left(W A G E \_D E S T_{m t}\right)$ in our attempts to estimate origin-destination state-pair fixed-effects models, which were discarded as they could not be justified as proper gravity models. ${ }^{22}$

The log-linear difference-in-differences model estimates are presented in column 1 of Table 6 . The coefficient estimate of interest for the interacted-indicator variables, D_1997 $\times$ D_FEDERAL_DEREG $G_{i m}$, is equal to 0.0404 (statistically significant at the $10 \%$ level), suggesting that the trade shares for the state-pairs that were forced to open up their markets to each others' banks has increased by $4.04 \%$ between 1993 and 1997. In the same column the coefficient estimate for $D \_F E D E R A L \_D E R E G_{i m}$ is equal to -0.0849 (statistically significant at the $10 \%$ level): in 1993 the state-pairs for which the federal deregulation would lead to an opening of their market to their respective banks had trade shares that were lower by $8.49 \%$ compared to other state-pairs that had deregulated bank entry earlier. In other words, even though trade shares have increased post-IBBEA on average for the 500 state-pairs affected by the act, the improvement over the short period of time postRiegle-Neal was not enough to catch up with the group of state-pairs that had opened their banking markets earlier. In terms of trade shares, the 500 state-pairs affected by IBBEA for out-of-state bank entry still had lower trade shares than other state-pairs by $4.45 \%(=-8.49 \%+4.04 \%)$ in 1997. In column 2 of Table 6, we present the difference-in-differences model obtained with the Poisson estimator. The coefficient estimate of interest for the interacted-indicator variables, $D \_1997_{t} \times D \_F E D E R A L \_D E R E G_{i m}$, is equal to 0.1079 (statistically significant at the $1 \%$ level), and that for D_FEDERAL_DEREG $G_{i m}$ is equal to -0.1942 (statistically significant at the $1 \%$ level). As in the case of the log-linear model, the estimates from the Poisson model confirm the pattern observed in column 1 of Table 6: even if by 1997 the trade shares increase by $10.79 \%$ for the newly treated group, these state-pairs were still behind the previously treated group by $8.63 \%(=-19.42 \%+10.79 \%)$. The observed patterns point out that bank liberalization has level effects on trade shares (and flows) that need not be persistent: state-pairs that deregulated later started to catch up with the pairs that liberalized earlier, though the convergence may not have yet occurred fully as of 1997 due to the short period after the IBBEA.

The robustness checks in this section suggest that when we examine the effect of the federal deregulation over a different time period, we obtain results that are in essence similar to those we obtained before. $^{23}$

\footnotetext{
${ }^{22}$ One possible explanation as to why state-pair fixed effects or origin- and destination-state fixed-effects models fail may be due to a much lower amount of variation in the dependent and/or explanatory variables in the 19931997 data compared to 1977-1993 data, which could result in most of the variation being soaked up by the state-pair effects.

${ }^{23}$ Ideally, we would like to examine the effect of actual bank entry on trade post-IBBEA. But, we cannot estimate IV regressions in this case because the federal legislation on bank-entry deregulation applies to all of the
} 


\subsection{Changes in implicit trade barriers among US states}

Next, we assess whether changes in implicit barriers to trade among US states might be driving our results, which could be the case if interstate banking deregulation and integration were to proxy for other deregulations that took place over the same period. Although the US Constitution bars explicit barriers to interstate trade, implicit barriers that exist in different forms may be reduced over time via decreases in local taxes, loosening of state regulations on manufactured goods, introduction of or increases in existing subsidies, deregulation in other sectors (such as transportation), construction, or expansion of infrastructure (roads, highways, or airports), etc. Further, during the 1977-1993 period, 33 out of 48 contiguous states deregulated intrastate branching (Amel, 2000). Of these, six occurred concurrently in 1988, five in 1987, four in 1985 and 1990, and two in 1982 and 1991. Intrastate branching deregulations need to be accounted for as they reduced loan prices and loan losses (e.g., Jayaratne and Strahan, 1998).

The many ways through which intrastate branching deregulation and implicit trade barriers may vary across state-pairs and over time make it impossible to control for each and every one of them explicitly. Instead, we add time-varying origin-state and time-varying destination-state fixed effects to our empirical specifications, over and above the already existing origin-destination state-pair fixed effects. The other time-varying variables, $\ln \left(G D P \_D E S T_{m t}\right)$ and $\ln \left(W A G E S \_D E S T_{m t}\right)$, are now dropped since they are subsumed by the time-varying fixed effects of the new model. This approach controls for any originor destination-state-specific trade barriers that may have been reduced between 1977-1993.

In Table 7 the coefficient estimate for $D_{-} 1993_{t} \times D_{-} D E R E G_{i m}$ for the log-linear (Poisson) difference-in-difference model in column 1 (2) of Table 7 is equal to $0.0797(0.1837)$ and statistically significant at the $5 \%$ level (1\% level). These results are similar to the corresponding coefficient estimates of $0.0924(0.1425)$ in Table 3 columns 4 (8), respectively. The coefficient estimate for BANK_INTEG for the log-linear (Poisson) IV model in column 3 (4) of Table 7 is equal to 5.9316 (5.8149) and statistically significant at the $1 \%$ level ( $1 \%$ level). ${ }^{24}$ Although these results are lower than the comparable IV estimates of 11.0970 and 8.5802 in Table 4 columns 4 and 8 , respectively, they also indicate that the findings are still economically relevant even when we account for time-invariant state-pair effects,

500 state-pairs at the same time. There is no good instrument that could possibly provide across-state-pair variation in what is a federal deregulation and serve as a legitimate IV for BANK_INTEG $G_{\text {imt }}$.

${ }^{24}$ The log-linear IV model identification test results are indicative of valid instruments: the null hypothesis of under-identification is rejected at the $1 \%$ level (with a Kleibergen-Paap rk LM test statistic of 17.61); the null hypothesis of weak instruments is rejected for $10 \%$ maximal IV relative bias [Kleibergen-Paap rk Wald $F$-test statistic 10.86 for which the Stock and Yogo (2005) critical value is 10.27]; and the null hypothesis of appropriate exclusion restrictions and valid instruments cannot be rejected (Hansen $J$-statistic of 2.50 not statistically significant). 
separate time-varying origin- and destination-state effects, as well as a time (year) effect. We conclude that changes in intrastate branching deregulations or implicit trade barriers across US states that may be taking place about the same time as the interstate banking deregulations do not drive our results.

\subsection{A Huang (2008) test: Destination state-pairs with common Metropolitan Statistical Areas (MSAs)}

Next, we adapt the approach used by Huang (2008) to our setting to rule out the possibility that our results “... could be a manifestation of heterogeneity in different regions' growth paths ... or difference of expected future growth opportunities across states, independent of and not caused by, changes in state-level banking regulations" (Huang, 2008, p. 679). The data at our disposal are at the state-level, and as a result we cannot compare contiguous counties in adjacent states that deregulated their banking systems at different points in time as in Huang (2008). Nevertheless, for a number of originstates, we can compare trade flows from the same origin-state to two different but adjacent destinationstates that share an MSA and with which interstate banking deregulation took place at different points in time. Such an approach would allow us to control for other omitted variables that are not accounted for in our state-pair fixed-effects specifications.

We note that among the 48 contiguous US states that we study, there are 41 state-pairs that share a common MSA. We construct a separate data set (based on the same 1977-1993 data) in which we generate a dependent variable TRADE_SHARE $E_{\text {imt }} / T R A D E \_S H A R E_{\text {int }}$ : the ratio of trade share from any origin-state $i$ to a destination-state $m$ to the trade share from the same origin-state $i$ to the destination-state $n$ that has a common MSA with the first destination-state $m$ (which is equivalent to TRADE_FLOWS $S_{i m t} / T R A D E \_F L O W S_{\text {int }}$ given that TRADE_SHARE $E_{i m t}$ and TRADE_SHARE $E_{\text {int }}$ have the same denominator). We only consider unique ratios: if trade share (flows) ratio of state-pair $i-m$ to statepair $i$ - $n$ is included, then we leave out the ratio of state-pair $i$ - $n$ to state-pair $i$ - $m$. When an MSA is shared by more than two destination-states (say, $p, q$, r), we consider only unique triplets (i.e., $i-p-q, i-p-r$, and $i$ $q-r)$. Note that now we have state-triplet fixed effects. Even though the potential number of observations that we can obtain in this setting is 3,772 (= $46 \times 41 \times 2)$ unique observations for 1977 and 1993 combined, we limit ourselves to the 2,832 observations with trade flows higher than \$10 million in 1977 dollars. The latter restriction is imposed due to concerns about measurement errors in the CFS data. The

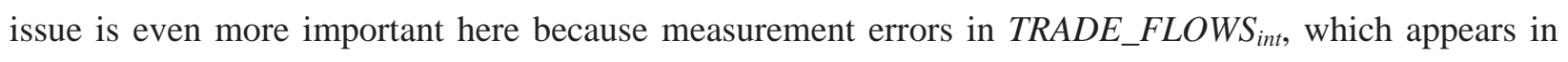
the denominator of the trade flows ratio of flows between $i-m$ and $i-n$, would further magnify the variance of the dependent variable, making our version of the Huang (2008) test less precise. We estimate the following difference-in-differences model: 


$$
\begin{aligned}
& \ln \left(\frac{\text { TRADE_SHARE }}{\text { imt }}\right)=\alpha_{i m}+\beta_{1} \Delta_{m n t} \ln \left(G D P_{-} \_ \text {DEST }\right)+\beta_{2} \Delta_{m n t} \ln \left(W A G E_{\text {int }} \text { THEST }\right)+\beta_{3} D_{-} 1993_{t} \\
& +\beta_{4} \Delta_{i m n} D_{-} D E R E G+\beta_{5}\left(D_{-} 1993_{t} \times \Delta_{i m n} D_{-} D E R E G\right)+\rho_{i m n t},
\end{aligned}
$$

where $\Delta$ stands for the difference in the explanatory variables pertaining to the origin-destination pairs in the numerator and the denominator, respectively: $\Delta_{\mathrm{mnt}} \ln \left(W A G E \_D E S T\right)=\ln \left(W A G E \_D E S T_{m t}\right)-$ $\ln \left(W A G E \_D E S T_{n t}\right)$. We only consider cases where one of the state-pairs deregulates bank entry but the other one does not, so as to obtain a test that would be easier to interpret. We also order the data so that the state-pair $i-m(i-n)$ that deregulates (does not deregulate) is always in the numerator (denominator) of the trade flow ratio. The coefficient estimates for $D_{-} 1993_{t} \times \Delta_{m n t} D \_D E R E G$ in columns 1 and 2 of Table 8 are not statistically significant, although the one obtained with the Within-Poisson estimator is equal to 0.0506. Since accounting for bank-entry size may yield more precise Huang (2008) tests, we turn our attention to IV regressions with state-triplet fixed effects, and estimate the following log-linear IV model:

$$
\begin{aligned}
\ln \left(\frac{T R A D E_{-} S H A R E_{\text {imt }}}{\text { TRADE_SHARE }}\right) & =\alpha_{i m n}+\gamma_{1} \Delta_{m n t} \ln \left(G D P_{-} \text {DEST }\right)+\gamma_{2} \Delta_{m n t} \ln \left(W A G E_{-} D E S T\right)+\gamma_{3} D{ }_{-} 1993_{t} \\
& +\gamma_{4} \Delta_{i m n t} \text { BANK_INTEG }+\zeta_{\text {imnt }} .
\end{aligned}
$$

In Table 8 column 3, the log-linear model coefficient estimate for BANK_INTEG $G_{\text {imt }}$ is 6.2526 (statistically significant at the 5\% level), whereas for the Poisson-IV model in column 4 , the equivalent coefficient estimate is 12.6944 (statistically significant at the 5\% level). These results are of the same order of magnitude as the comparable estimates of 11.0970 and 8.5802 found in Table 4, columns 4 and 8, respectively. These findings suggest that in the Huang (2008) test setting, where the use of a pair of destination states that share an MSA allows us to control for other omitted variables, actual banking integration leads to higher trade flows across states. We conclude that our main findings are not driven by heterogeneity in the growth paths or expected future growth opportunities of different regions.

\subsection{Accounting for information asymmetries}

If the main channel that lies behind our findings is the interstate banks' higher ability to resolve asymmetric information problems in trade-related loans, then our results should be more pronounced with the addition of proxies for information asymmetries and information flows as in Portes and Rey (2005).

One such proxy for information asymmetries across regions is distance (Portes and Rey, 2005). Even though distance between the borrowing firms and their lenders has been increasing over time, thanks to banks' adoption of new technologies such as credit scoring systems (e.g., Petersen and Rajan, 
2002), and even though firms have been borrowing over increasingly higher distances from larger banking organizations (e.g., Berger et al., 2005), distance continued to have an impact in lending (e.g., Brevoort and Hannan, 2006) even during the post-IBBEA era. Note that distance is also likely to serve as a proxy for the within-MBHC information frictions. Berger and DeYoung (2006) find evidence that is consistent with MBHC agency costs increasing with distance but decreasing over time between the headquarters and its affiliates. Liberti and Mian (2009) find that information sharing within the banking conglomerate is subjected to frictions that arise in the organization due to both hierarchical and geographical distances. These findings are important for us, as they point to the dual role of distance as a proxy in our setting. On the one hand, the higher the distance between two states, the more banking integration is likely to have a positive impact on trade flows if our main channel is driving our results. On the other hand, the higher the distance between banking conglomerate's headquarters and its affiliates, the more frictions internal to the banking organization are likely to hinder information flows, which, in return, would have a negative effect on trade flows. Which of these effects will dominate is an empirical issue. Of course, in contrast to asset flows (as in Portes and Rey, 2005; and Portes et al., 2001), when examining trade flows in manufactured goods, one also needs to control for higher trade costs with further-away destinations, such as higher shipping costs, something which we do through origin-destination state-pair fixed effects. To test the impact of asymmetric information, for which distance serves as a proxy, we estimate the following IV model:

$$
\begin{aligned}
\ln \left(\text { TRADE_SHARE }_{i m t}\right)= & \alpha_{i m}+\gamma_{1} \ln \left(G D P_{-} D E S T_{m t}\right)+\gamma_{2} \ln \left(W_{-} A G E_{-} D E S T_{m t}\right) \\
& +\gamma_{3} D_{-} 1993_{t}+\gamma_{4} B A N K_{-} I N T E G_{i m t} \\
& +\gamma_{5} B A N K_{-} I N T E G_{i m t} \times \ln \left(D I S T A N C E_{-} C A P S_{i m}\right)+v_{i m t},
\end{aligned}
$$

where the coefficient estimate of interest is that of the interaction of distance with bank integration. This approach requires that $B A N K_{-} I N T E G_{i m t} \times \ln \left(D I S T A N C E \_C A P S_{i m}\right)$ also be instrumented, for which we add interactions of $\ln \left(D I S T A N C E_{-} C A P S_{i m}\right)$ with the IVs for BANK_INTEG $G_{i m t}$ to the instrument list. The results are presented in columns 1 and 2 of Table 9. In the log-linear model estimated using IV-GMM-2S estimator with origin-destination state-pair fixed effects (which soaks up the distance between statepairs), the coefficient estimate for $B A N K_{-} I N T E G_{i m t}$ is equal to -48.8252 (marginally statistically significant with a $Z$-score of 1.64 and a $p$-value of 0.101 ), whereas the coefficient estimate for $B A N K_{-} I N T E G_{i m t} \times \ln \left(D I S T A N C E \_C A P S_{i m}\right)$ is equal to 10.3627 (statistically significant with a $Z$-score of 1.93 and a $p$-value of 0.054). The latter estimate suggests that the impact of banking integration increases with distance. Note that the overall effect of banking integration is positive in the sample given that $\ln \left(D I S T A N C E_{-} C A P S_{\text {im }}\right.$ ) is equal to 5.0948 (which corresponds to 163 kilometers) for the first percentile 
of that variable's frequency distribution. In fact, for a state-pair 1,293 kilometers apart (the sample mean, the $\log$ of which is equal to 7.2105), that would experience an increase from zero to $2.28 \%$ in banking integration (the sample mean in 1993), the log-linear model estimates in column 1 of Table 9 suggest a $59.04 \%$ increase in trade flows $(0.5904=[-48.8252+10.3627 \times 7.2105] \times 0.0228)$. This estimate, which is more than twice the size of the effect calculated based on the estimate in column 4 of Table 4 , points to a more pronounced effect of banking integration on trade when distance is taken into account. Given our calibration exercise (Table 1), this effect would still be supported by plausible and small decreases in marginal costs that would obtain from the loan-pricing channel only. However, these estimates may suffer from a weak instruments problem: in column 1 of Table 9, the weak-identification test (Kleibergen-Paap rk Wald $F$ ) statistic is equal to 4.63 , which is just below the critical threshold value of 4.73 for $30 \%$ maximal IV relative bias, even though we reject the under-identification test (indicating that our results do not suffer from an under-identification problem) and we cannot reject the over-identification test (validating the over-identifying restrictions). ${ }^{25}$ The fact that the weak instruments problem is larger here is not surprising given that we are asking the very same instruments to explain the newly introduced interaction effects as well. In the Poisson-IV model results (with state-pair fixed effects) in column 2 of Table 9, we obtain a similar coefficient estimate of 9.2020 (statistically significant at the $10 \%$ level) for the interaction of BANK_INTEG $G_{i m t} \times \ln \left(D I S T A N C E \_C A P S_{i m}\right)$.

However, distance remains constant, whereas information asymmetries are likely to change (most likely decrease) over time as communication technologies evolve (Portes and Rey, 2005; Portes et al., 2001). This suggests that time-varying information asymmetries need to be explicitly accounted for, otherwise banking integration that varies over time could potentially proxy for the evolution in information flows, possibly biasing the estimates in columns 1 and 2 of Table 9. To accommodate timevarying information flows between state-pairs, we create a proxy based on the state-of-birth data to capture the prior familiarity between the two states. ${ }^{26}$ Using census data for the years 1980 and 1990 (the

\footnotetext{
${ }^{25}$ A slight modification of two of our IVs, taking the square root of years since deregulation for the origin- and destination-states, improves these results somewhat: weak-identification test results go over the critical value of $30 \%$ maximal IV relative bias, while the estimates and other identification tests remain quantitatively the same.

${ }^{26} \mathrm{We}$ considered but ruled against alternative proxies for information asymmetries. We contemplated, following Portes and Rey (2005) and Portes et al. (2001), to use phone traffic or tourist flows between US states: unfortunately, neither of them is available between 1977 and 1993. As an alternative, we considered first-class letter volume but were informed by the US Postal Service that such data are not available for origin-destination statepairs. We also considered taking the most important newspaper in each state and looking for the number of references in that publication to each of the remaining 47 states as of 1977 and 1993 . We decided against this approach for the following reasons. First, the coverage in Factiva and Lexis-Nexis, online news search databases, only starts in 1980, and even then, the coverage of state-level local newspapers, even the most prominent ones, is scarce (only seven major newspapers are covered in 1985 and 32 in 1993). Second, word-based searches are fraught with difficulties: for example, Washington, besides being the name of a state, is also a common reference to the seat of the federal government, a county name in 30 different states, and a popular name for individuals. Finally, we
} 
closest census years to CFS in 1977 and 1993), we calculate the following time-varying ratio, called BIRTH_INTEG $G_{\text {imt }}$ : the sum of the number of people living in state $i$ who were born in state $m$ plus the number of people living in state $m$ who were born in state $i$, divided by the sum of the number of people living in states $i$ and $m$ who were born outside of these states. ${ }^{27}$

The results in columns 3 and 4 of Table 9 indicate that as information flows (information asymmetries) between a state-pair increase (decrease), the trade share between them increases, as one would expect: the coefficient estimates for $\ln \left(B I R T H_{-} I N T E G_{i m t}\right)$ are equal to 0.3249 , which is statistically significant at the 5\% level, in the IV-GMM-2S model (column 3), and to 0.4902, which is statistically significant at the $1 \%$ level, in the IV-Poisson model. Importantly, the addition of the $\ln \left(B I R T H \_I N T E G_{i m t}\right)$ to specification (9) does not materially affect the coefficient estimates of BANK_INTEG $G_{i m t} \times$ $\ln \left(D I S T A N C E_{-} C A P S_{i m}\right) .{ }^{28} \mathrm{We}$ conclude that our main findings are robust to the addition of proxies for information asymmetries.

\subsection{Ex ante potential for risk-sharing}

Next, we examine whether the ex ante potential of state-pairs for financial risk-sharing (as of 1977) contributes to growth in trade. MBHCs may have expanded at least in part to exploit a potential for risk-sharing to diversify their assets. For example, a New York-based bank with presence in Texas would be safer as it would diversify away the effects of oil price shocks, since the latter state is an exporter of oil to its home state. Such presence could enable the bank to increase lending in both states, which in turn would contribute to trade in manufactured goods between these regions. We examine this possibility in two different ways by adapting to our state-pair setting the state-level approaches used in Acharya et al. (2011) and MRS (2004).

To adapt Acharya et al. (2011), we first conjecture that the overall US industrial portfolio represents the most diversifiable industrial "market" portfolio (denoted by $M$ ) that any individual state could hope to attain as of 1976. Full economic integration with another state would be a step in increasing portfolio diversification with a view to reach $M$ and its benefits would vary among state-pairs. We use ten one-digit Standard Industrial Classification (SIC) industry gross products to calculate industry return and risk as of 1976, based on 1964-1976 data on segment growth and its standard deviation. Using the actual

considered interstate airline traffic, which is available from 1990, but not very appropriate as a proxy for interstate information flows as certain states receive much more air traffic because they host airline hubs.

27 As an alternative, we also used a proxy based on actual state migration flows over the past five years and obtained similar results. We prefer BIRTH_INTEG: the alternative is more likely to be affected from trade flows.

${ }^{28}$ We chose not to interact $\ln \left(B I R T H_{-} I N T E G_{i m t}\right)$ with $B A N K_{-} I N T E G_{i m t}$, because identification tests of the IVmodel suggested that such specifications showed little improvement over the (biased) OLS estimates. Note that the inclusion of $\ln \left(\right.$ BIRTH_INTEG $\left._{i m t}\right)$ in the empirical models does not materially affect the log-linear model identification test results, in which weak-instruments remain a problem. When included separately in our base regressions of Sections 5.1 and 5.2, $\ln \left(B I R T H \_I N T E G_{i m t}\right)$ did not qualitatively and quantitatively affect the results. 
industrial portfolio weights, we calculate the portfolio return $(\mu)$ and risk $(\sigma)$ as of 1976 for: (i) the "market portfolio" $M$ for the US, (ii) each of the 48 contiguous states of the Union (denoted by $i$ ), and (iii) each "pro-forma" state-pair under the scenario of full risk-sharing (full economic integration) between state-pairs (denoted by $i-m$ ). Then, we take the difference of two L1 distances (given two vectors $X_{i}$ and $X_{m}$, a measure $D_{i m}=\Sigma\left|x_{i}-x_{m}\right|$ where $x_{i}$ and $x_{m}$ are the respective vector rows) in the risk-return space: $\Delta D_{i m}=D_{i, M}-D_{i+m, M}$, where $D_{i, M}$ measures the distance between the individual state $i$ 's portfolio to the US "market portfolio" and $D_{i+m, M}$ measures the distance between the "pro-forma" state-pair portfolio and the US "market portfolio." State-pairs with the highest potential for risk-sharing are the ones whose distance to the US market portfolio $M$ would decrease the most following "pro-forma" pair wise (full) economic integration of states $i$ and $m$. We rerun our regressions after splitting the sample into the top and bottom halves based on $\Delta D_{i m}$. Difference-in-differences and IV regression results (unreported to conserve space but available in the first two columns of Appendix Tables A2 and A3) suggest no role for a risk-sharing channel when we rely on industry portfolios to construct our test.

As an alternative, we replicate Section "V.C. Convergence in State Cycles" of MRS (2004) with minor adjustments: (i) we use the Gross State Product (GSP) growth between 1964-1976, (ii) we calculate the average of the absolute value of annual fluctuation differences (L1 distance) for each statepair over 1964-1976, (iii) we split the sample of state-pairs into two in terms of the MRS (2004) measure of real activity similarity, and (iv) we use the most and least similar state-pair half-samples to run our regressions. The difference-in-differences and IV regression results (in columns 3 and 4 of Appendix Tables A2 and A3) provide no support to the ex ante potential for the risk-sharing hypothesis. These results suggest that states that are most dissimilar in terms of economic fluctuations do not appear to enjoy higher trade following banking integration. Since our data are limited to manufacturing, our tests may not capture all the effects of risk-sharing that could arise when trade in other sectors of the economy is also considered.

\subsection{Ex ante potential to trade}

Could state-pairs with the highest potential to trade as of 1976 benefit most from banking deregulation? Theoretically, trade between two regions can be driven by (i) inter-industry trade arising from the differences in endowments (in terms of production factors or technology), or (ii) intra-industry trade in sectors producing the same goods (due to increasing returns or Ricardian productivity differences).

To assess the potential for intra-industry trade, we split the sample into state-pairs that are most (top 50\%) and least similar (lowest 50\%) in terms of the industrial structure as of 1977 and rerun our difference-in-differences and IV regressions. We calculate industrial similarity in the following way. For each state-pair, we calculate the L1 distance between the vectors containing GDP shares of two-digit SIC 
in manufacturing. State-pairs with the lowest distance using these measures are considered to be most similar to one another in terms of industrial structure. In difference-in-differences and IV regressions (columns 5 and 6 of Appendix Tables A2 and A3), we find, however weakly, that financial integration benefitted trade in manufacturing of states with similar industry structures. This is also consistent with the possibility that MBHCs may align their affiliates' lending in the sectors in which the bank dominating the financial conglomerate has more experience and banking integration affects industrial structures across states.

We also assess the potential for US states to trade because of differences in endowments (interindustry trade). We use proxies measuring the availability and cost of factors of production that shape comparative advantage in different industries. We rely on 12 factors that differ on a state-to-state basis for 1976 as in the Ellison and Glaeser (1999) study of agglomeration: electricity, natural gas and coal prices, percentage of farmland in the total area, cattle per capita, percentage of timberland in total area, average manufacturing wage, percentage of adults without a high school degree, percentage of unionized labor, percentage of adults with a BA degree or higher, population density, and the difference between the state income share and share of manufacturing in total US manufacturing. For each factor and state, we calculated the difference between a particular measure and its average for the 48 states and normalized it by the standard deviation: each state is characterized with a vector of 12 such normalized factors. Next, we calculated the L1 distance between these vectors for each state-pair. The most dissimilar states according to this measure have the largest discrepancies in such-measured endowments, and have the largest potential to increase inter-industry trade. In results presented in the last two columns of Appendix Tables A2 and A3, we do not find that trade among states with the highest potential for inter-industry trade increased as a result of banking integration. The evidence suggests that, when one considers the trade flows in the manufacturing sector, banking integration appears to generate more intra-industry rather than inter-industry trade.

\subsection{Alternative channels of financial integration}

Another possibility is that non-bank financial integration already in place across state-pairs as of 1977 could be driving our results and that interstate banking integration serves as proxy for the former. To assess for this possibility, we use a variation of the approach in Kalemli-Ozcan et al. (2010), who find that, as the neoclassical theory would predict, faster-growing US states, where the marginal product of capital should be higher, were attracting capital from the rest of the US over the 1977-2000 period. These authors study the ratio of GSP to state-level personal income: if output is higher than income, this would mean that the state is a net debtor to the rest of the US states; if this ratio increases over time, then the state experiences net capital inflows. 
We assume that two states that have dissimilar output/income ratios at a given time period are more likely to have experienced higher net capital flows from the state with the low output/income ratio to the state with the high output/income ratio (the theory is silent on what the gross capital flows should be). Then we approximate the scope of the theoretical net capital flows between states for the period 1963-1976 using data from Asdrubali et al. (1996). For each state-pair, we calculate the L1 distance between the average output/income ratio, which is computed as in Kalemli-Ozcan et al. (2010).

We first check whether banking integration serves as a proxy for non-bank financial integration. Some state-pairs in our sample were already financially linked as of 1977 through grandfathered banks (i.e., through MBHCs established before the 1956 Douglas Amendment to the Bank Holding Company Act). For the 62 state-pairs linked this way, the correlation of banking integration with our measure of potential net capital flows is -0.23 (statistically significant at the 10\% level) in 1977 and -0.03 in 1993 (statistically insignificant). These correlation coefficients suggest that our proxy for non-bank financial integration does not capture banking integration. ${ }^{29}$ Then, using the output/income ratio, we split the statepairs in our sample into the most and least similar states, and rerun our regressions. The difference-indifferences or IV regression estimates (not reported to conserve space, but available in Appendix Table A4) indicate that it is highly unlikely that prior non-bank financial integration is driving our main results.

\subsection{Political economy drivers prior to 1977}

Finally, it is possible that state-pairs with prior political economy links, such as the same political party in power, may have benefitted more from trade. We create an index of political party in control of the state's governance as in Kroszner and Strahan (1999, p. 1447): the index is the sum of the one-third weights given to each of the three elements of a state government (the lower chamber, the upper chamber, and the governor's office) if it is held by the Democrats, and zero otherwise. We calculate the L1 differences in this index for each state-pair using ten years of data prior to 1977. We split the sample into two halves based on the computed L1 distance and rerun our difference-in-differences and IV regressions (results not reported to conserve space, available in the first four columns of Appendix Table A5). We do not find any evidence indicating that state-pairs that were most similar according to our measure enjoyed higher increases in trade following banking integration relative to those that were most dissimilar.

Given the Kroszner and Strahan (1999) findings that a higher proportion of Democrats in the state government tends to delay deregulation or that Democrats were more likely to vote against the WylieNeal interstate-branching deregulation proposition of 1991, we revisit the regressions for the politically

\footnotetext{
${ }^{29}$ Exclusion of these 62 state-pairs does not alter either qualitatively or quantitatively results of Sections 5.1 or 5.2 .
} 
most similar state-pairs where the Republicans dominated the legislature during the pre-1977 decade. We obtained coefficient estimates for $D_{-} 1993_{t} \times D_{-} D E R E G_{\text {imt }}$ and $B A N K_{-} I N T E G_{\text {imt }}$ that cannot be distinguished from zero at conventional significance levels (shown in the last two columns of Appendix Table A5). We conclude that prior political economy connections, as measured by the same party or the Republican Party dominating the government for the origin and the destination states during 1967-1976, do not drive our main findings.

\section{Conclusion}

We estimate the size of financial barriers to interstate trade stemming from the lack of free interstate banking in the US states prior to 1995. Our approach is unique in the sense that we conduct tests of financial integration on directional trade flows in manufacturing, which is consistent with the role of banks solving problems involving information asymmetries. Our results suggest that the barriers to trade stemming from the banking channel can, in fact, be economically important, even within such a homogeneous economic area as the 48 contiguous states of the Union. Using different estimation methods, we find that the removal of banking barriers to trade increased trade volumes by $14 \%$ between state-pairs undergoing banking liberalization in the period 1977-1993 relative to state-pairs that did not give such access to its banking markets. Basing on actual bank entry, we find that an increase in banking integration from zero to the sample mean in 1993 (2.28\%) would increase trade in a state-pair in the range of $16.8 \%$ to $25.2 \%$. These estimates fall within the range predicted by a simple calibration of a standard model of an economy with monopolistic competition and Dixit-Stiglitz love-of-variety preferences if the marginal costs of production would decrease by $2.5 \%$ as a result of bank integration and the markups in the economy being between $10 \%$ and $20 \%$. The results are robust to problems posed by sampling errors, zero trade flows or shares, or estimation methods, and do not appear to be driven by the potential problem of endogeneity. They also survive tests in which we consider alternative channels.

Note that we estimated the impact of banking deregulation on trade shares between states. Our results say nothing about the potential increase in aggregate trade flows from a particular state as a result of increase in credit (i.e., capital) availability following bank-entry deregulation and the corresponding, firm entry, growth of that state's GDP, etc. What we observe is probably the lower-bound estimate for trade barriers coming from the lack of a unified banking system that occur in international trade. 


\section{References:}

Acharya, V. V., Imbs, J., Sturgess, J., 2011. Finance and efficiency: do bank branching regulations matter? Review of Finance 15, 135-172.

Amel, D., 2000. State laws affecting the geographic expansion of commercial banks. Unpublished working paper. Board of Governors of the Federal Reserve System.

American Banker, 1993a. Common systems fuel First Union’s expansion strategy, April 12.

American Banker, 1993b. NationsBank aims to keep its cash management rank, December 16.

Amiti, M., Weinstein, D., 2011. Exports and financial shocks. Quarterly Journal of Economics (forthcoming).

Arkolakis, C., Costinot, A., Rodríguez-Clare, A., 2011. New trade models, same old gains? American Economic Review (forthcoming).

Asdrubali, P., Sorensen, B. E., Yosha, O., 1996. Channels of interstate risk sharing: United States $1963-$ 90. Quarterly Journal of Economics 111, 1081-1110.

Bae, K.-H., Stulz, R. M., Tan, H., 2008. Do local analysts know more? A cross-country study of the performance of local analysts and foreign analysts. Journal of Financial Economics 88, 581-606.

Beck, T., 2002. Financial development and international trade: is there a link? Journal of International Economics 57, 107-131.

Beck, T., Levine, R., Loayza, N., 2000. Finance and the sources of growth. Journal of Financial Economics 58, 261-300.

Becker, B., Greenberg, D., 2003. The real effects of finance: evidence from exports. Unpublished working paper. University of Chicago Graduate School of Business.

Berger, A. N., DeYoung, R., 2006. Technological progress and the geographic expansion of the banking industry. Journal of Money, Credit and Banking 38, 1483-1513.

Berger, A. N., Humphrey, D., 1988. Interstate banking and the payments system. Journal of Financial Services Research 1, 131-145.

Berger, A. N., Miller, N. H., Petersen, M. A., Rajan, R. G., Stein, J. C., 2005. Does function follow organizational form? Evidence from the lending practices of large and small banks. Journal of Financial Economics 76, 237-269.

Black, S. E., Strahan, P. E., 2002. Entrepreneurship and bank credit availability. Journal of Finance 57, 2807-2833.

Brevoort, K. P., Hannan, T. H., 2006. Commercial lending and distance: evidence from Community Reinvestment Act data. Journal of Money, Credit and Banking 38, 1991-2012. 
Brown, M., Jappelli, T., Pagano, M., 2009. Information sharing and credit: firm-level evidence from transition countries. Journal of Financial Intermediation 18, 151-172.

Business Journal-Milwaukee, 1990. Norwest aims for 20 percent of the local corporate market, October 1.

Cameron, C. A., Trivedi, P. K., 1998. Regression Analysis for Count Data. Cambridge University Press, New York, NY.

Cameron, C. A., Trivedi, P. K., 2005. Microeconometrics: Methods and Applications. Cambridge University Press, New York, NY.

Cetorelli, N., Gambera, M., 2001. Bank structure, financial dependence and growth: international evidence from industrial data. Journal of Finance 56, 617-648.

Cetorelli, N., Strahan, P. E., 2006. Finance as a barrier to entry: competition and industry structure in local US markets. Journal of Finance 61, 437-461.

Chaney, T., 2005. Liquidity constrained exporters. Unpublished working paper. University of Chicago.

Chor, D., Manova, K., 2009. Off the cliff and back? Credit conditions and international trade during the global financial crisis. Unpublished working paper. Singapore Management University and Stanford University.

Colorado Business, 1993. Sad saga: Colorado's late, great banks, June.

Coulibaly, B., Sapriza, H., Zlate, A., 2011. Trade credit and international trade during the 2008-09 global financial crisis. International Finance Discussion Papers No. D2011-4. Board of Governors of the Federal Reserve System.

Coval, J. D., Moskowitz, T. J., 1999. Home bias at home: local equity preference in domestic portfolios. Journal of Finance 54, 2045-2073.

Coval, J. D., Moskowitz, T. J., 2001. The geography of investment: informed trading and asset prices. Journal of Political Economy 109, 841-881.

Crain's Detroit Business, 1995. Winning out West, June 26.

Demirgüç-Kunt, A., Maksimovic, V., 1998. Law, finance, and firm growth. Journal of Finance 53, $2107-$ 2137.

Djankov, S., McLiesh, C., Shleifer, A., 2007. Private credit in 129 countries. Journal of Financial Economics 84, 299-329.

Do, Q.-T., Levchenko, A., 2007. Comparative advantage, demand for external finance, and financial development. Journal of Financial Economics 86, 796-834.

Eaton, J., Kortum, S., Neiman, B., Romalis, J., 2011. Trade and the global recession. NBER Working Paper 16666.

Ellison, G., Glaeser, E. L., 1999. The geographic concentration of industry: Does natural advantage explain agglomeration? American Economic Review AEA Papers and Proceedings 89, 311-316. 
Fisman, R., Love, I., 2003. Trade credit, financial intermediary development, and industry growth. Journal of Finance 58, 353-374.

Gande, A., Puri, M., Saunders, A., Walter, I., 1997. Bank underwriting of debt securities: modern evidence. Review of Financial Studies 10, 1175-1202.

Grath, A., 2010. The Handbook of International Trade and Finance. Kogan Page, London, U.K.

Greenaway, D., Guariglia, A., Kneller, R., 2007. Do financial factors affect exporting decisions? Journal of International Economics 73, 377-395.

Hanson, G. H., 2005. Market potential, increasing returns and geographic concentration. Journal of International Economics 67, 1-24.

Head, K., Ries, J., 2001. Increasing returns versus national product differentiation as an explanation for the pattern of US-Canada trade. American Economic Review 91, 858-876.

Hillberry, R., Hummels, D., 2003. Intranational home bias: some explanations. Review of Economics and Statistics 85, 1089-1092.

Houston, J. F., Lin, C., Lin, P., Ma, Y., 2010. Creditor rights, information sharing, and bank risk taking. Journal of Financial Economics 96, 485-512.

Huang, R. R., 2008. Evaluating the real effect of bank branching deregulation: comparing contiguous counties across US state borders. Journal of Financial Economics 87, 678-705.

Indiana Business, 1993. Big is not so bad: the crop of new bank names sprouting in Indiana includes a bunch of competitive and well-managed banks, May 1.

Ivashina, V., Nair, V.B., Saunders, A., Massoud, N., Stover, R., 2009. Bank debt and corporate governance. Review of Financial Studies 22, 41-77.

Jayaratne, J., Strahan, P. E., 1996. The finance-growth nexus: evidence from bank branch deregulation. Quarterly Journal of Economics 111, 639-670.

Jayaratne, J., Strahan, P. E., 1998. Entry restrictions, industry evolution, and dynamic efficiency: evidence from commercial banking. Journal of Law and Economics 41, 239-273.

Kalemli-Ozcan, S., Reshef, A., Sorensen, B. E., Yosha, O., 2010. Why does capital flow to rich states? Review of Economics and Statistics 92, 769-783.

Kallberg, J. G., Udell, G. F., 2003. The value of private sector business credit information sharing: the US case. Journal of Banking \& Finance 27, 449-469.

Kane, E. J., 1996. De jure interstate banking: why only now? Journal of Money, Credit and Banking 28, 141-161.

Kang, J.-K., Kim, J.-M., 2008. The geography of block acquisitions. Journal of Finance 63, 2817-2858. 
Kerr, W. R., Nanda, R., 2009. Democratizing entry: banking deregulations, financing constraints, and entrepreneurship. Journal of Financial Economics 94, 124-149.

King, R., Levine, R., 1993a. Finance, entrepreneurship and growth. Journal of Monetary Economics 32, 513-542.

King, R., Levine, R., 1993b. Finance and growth: Schumpeter might be right. Quarterly Journal of Economics 108, 717-738.

Klapper, L., Laeven, L., Rajan, R., 2010. Trade credit contracts. Unpublished working paper. World Bank, International Monetary Fund, and University of Chicago.

Klibanoff, P., Marinacci, M., Mukerji, S., 2005. A smooth model of decision making under ambiguity. Econometrica 47, 1849-1892.

Kroszner, R. S., Strahan, P. E., 1999. What drives deregulation? Economics and politics of the relaxation of bank branching restrictions. Quarterly Journal of Economics 114, 1437-1467.

Lai, H., Trefler, D., 2002. The gains from trade with monopolistic competition: specification, estimation, and mis-specification. NBER Working Paper 9169.

Levchenko, A., Lewis, L., Tesar, L., 2010. The collapse in international trade during the 2008-2009 financial crisis: in search of the smoking gun. IMF Economic Review 58, 214-253.

Levine, R., Zervos, S., 1998. Stock markets, banks, and economic growth. American Economic Review $88,537-558$.

Liberti, J. M., Mian, A., 2009. Estimating the effect of hierarchies on information use. Review of Financial Studies 22, 4057-4090.

Love, I., Preve, L.A., Sarria-Allende, V., 2007. Trade credit and bank credit: evidence from recent financial crises. Journal of Financial Economics 83, 453-469.

Malloy, C., 2005. The geography of equity analysis. Journal of Finance 60, 719-755.

Manova, K., 2008a. Credit constraints, equity market liberalizations and international trade. Journal of International Economics 76, 33-47.

Manova, K., 2008b. Credit constraints, heterogeneous firms, and international trade. NBER Working Paper 14531

Manova, K., Wei, S.-J., Zhang, Z., 2009. Firm exports and multinational activity under credit constraints. Unpublished working paper. Stanford University, Columbia University, and International Monetary Fund.

Massa, M., Rehman, Z., 2008. Information flows within financial conglomerates: evidence from the banks-mutual funds relation. Journal of Financial Economics 89, 288-306.

Melitz, M. J., 2003. The impact of trade on intra-industry reallocations and aggregate industry productivity. Econometrica 71, 1695-1725. 
Mester, L. J., Nakamura, L. I., Renault, M., 2007. Transactions accounts and loan monitoring. Review of Financial Studies 20, 529-556.

Michalski, T., Ors, E., 2010. (Interstate) banking and (interstate) trade: does real integration follow financial integration? This is an early and different version of paper herein that circulated as the CEPR Discussion Paper 7963.

Minetti, R., Zhu, S. C., 2011. Credit constraints and firm export: microeconomic evidence from Italy. Journal of International Economics 83, 109-125.

Morgan, D. P., Rime, B., Strahan, P. E., 2003. Bank integration and state business cycles. NBER Working Paper 9704.

Morgan, D. P., Rime, B., Strahan, P. E., 2004. Bank integration and state business cycles. Quarterly Journal of Economics 119, 1555-1584.

Muuls, M., 2008. Exporters and credit constraints. A firm level approach. Unpublished working paper. London School of Economics.

New York Times, 1990. Bank tests its formula in Texas, February 8.

Norden, L., Weber, M., 2010. Credit line usage, checking account activity, and default risk of bank borrowers. Review of Financial Studies 23, 3665-3699.

Padilla, A.J., Pagano, M., 1997. Endogenous communication among lenders and entrepreneurial incentives. Review of Financial Studies 10, 205-236.

Padilla, A.J., Pagano, M., 2000. Sharing default information as a borrower discipline device. European Economic Review 44, 1951-1980.

Pagano, M., Jappelli, T., 1993. Information sharing in credit markets. Journal of Finance 43, 1693-1718.

Paravisini, D., Rappoport, V., Schnabl, P., Wolfenzon, D., 2011. Dissecting the effect of credit supply on trade: evidence from matched credit-export data. Unpublished working paper. Columbia Business School and NYU Stern School of Business.

Petersen, M. A., Rajan, R. G., 2002. Does distance still matter? The information revolution in small business lending. Journal of Finance 57, 2533-2570.

Portes, R., Rey, H., 2005. The determinants of cross-border equity flows. Journal of International Economics 65, 269-296.

Portes, R., Rey, H., Oh, Y., 2001. Information and capital flows: the determinants of transactions in financial assets. European Economic Review 45, 783-796.

Rajan, R. G., Zingales, L., 1998. Financial dependence and growth. American Economic Review 88, 559586.

Rice, T., Strahan, P. E., 2010. Does credit competition affect small-firm finance? Journal of Finance 65, 861-889. 
Ronci, M., 2004. Trade finance and trade flows: panel data evidence from 10 crises. IMF Working Paper 04-225.

Santos Silva, J. M. C., Tenreyro, S., 2006. The log of gravity. Review of Economics and Statistics 88, 641-658.

Schumpeter, J., 1912. A Theory of Economic Development. Harvard University Press, Cambridge, MA.

Stock, J. H., Yogo, M., 2005. Testing for weak instruments in linear IV regression. In: Andrews, D.W., Stock, J. H. (Eds.), Identification and Inference for Econometric Models: Essays in Honor of Thomas Rothenberg, Cambridge University Press, Cambridge, U.K., pp. 80-108.

Suwantaradon, R., 2008. Financial frictions and international trade. Unpublished working paper. Singapore Management University.

Svaleryd, H., Vlachos, J., 2005. Financial markets, the pattern of industrial specialization and comparative advantage: evidence from OECD countries. European Economic Review 49, 113-144.

Townsend, R. M., 1979. Optimal contracts and competitive markets with costly state verification. Journal of Economic Theory 21, 265-293.

Wolf, H. C., 2000. Intra-national home bias in trade. Review of Economics and Statistics 82, 555-563.

Zia, B. H., 2008. Export incentives, financial constraints, and the (mis)allocation of credit: micro-level evidence from subsidized export loans. Journal of Financial Economics 87, 498-527. 


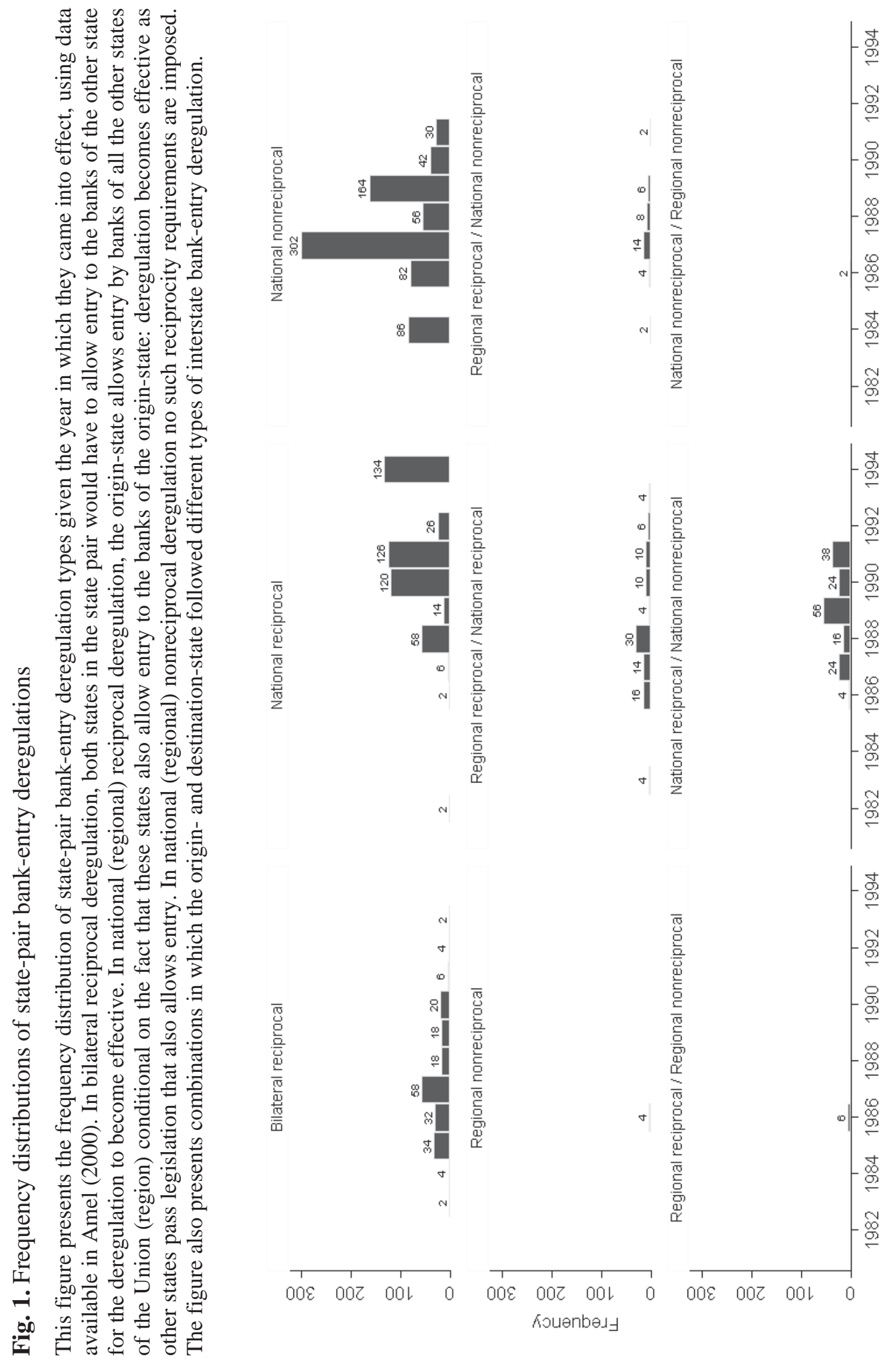




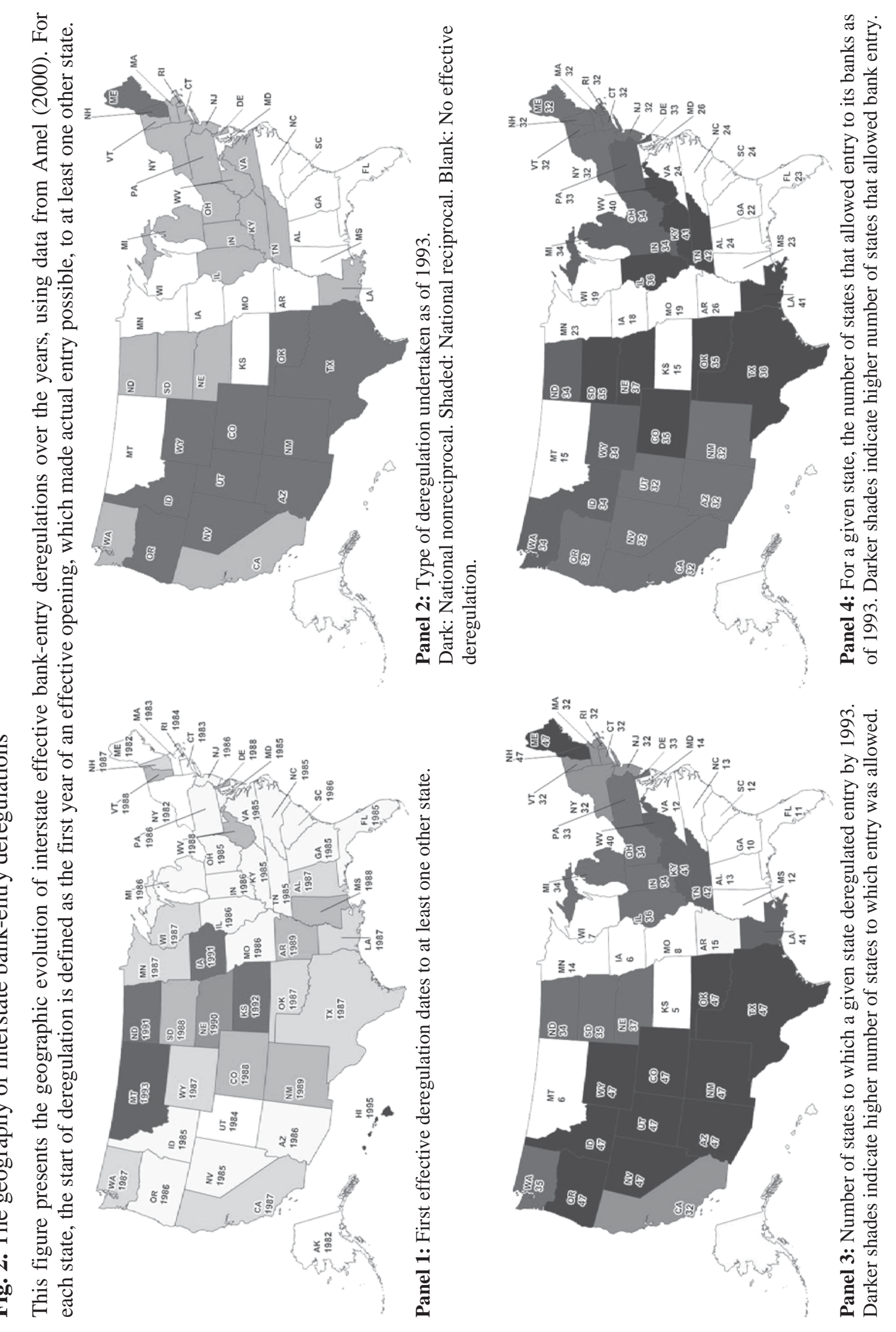




\section{Table 1}

\section{Calibration exercise}

This table presents the results of a calibration exercise of the loan-pricing channel using a standard monopolistic competition model of trade with Dixit-Stiglitz love-of-variety preferences and homogeneous firms. The table presents the percentage increase in trade flows between states that enjoy a bank link in comparison to a pair where no link is present for different levels of decreases in marginal costs of production (across the columns) and for given levels of markups (across the rows).

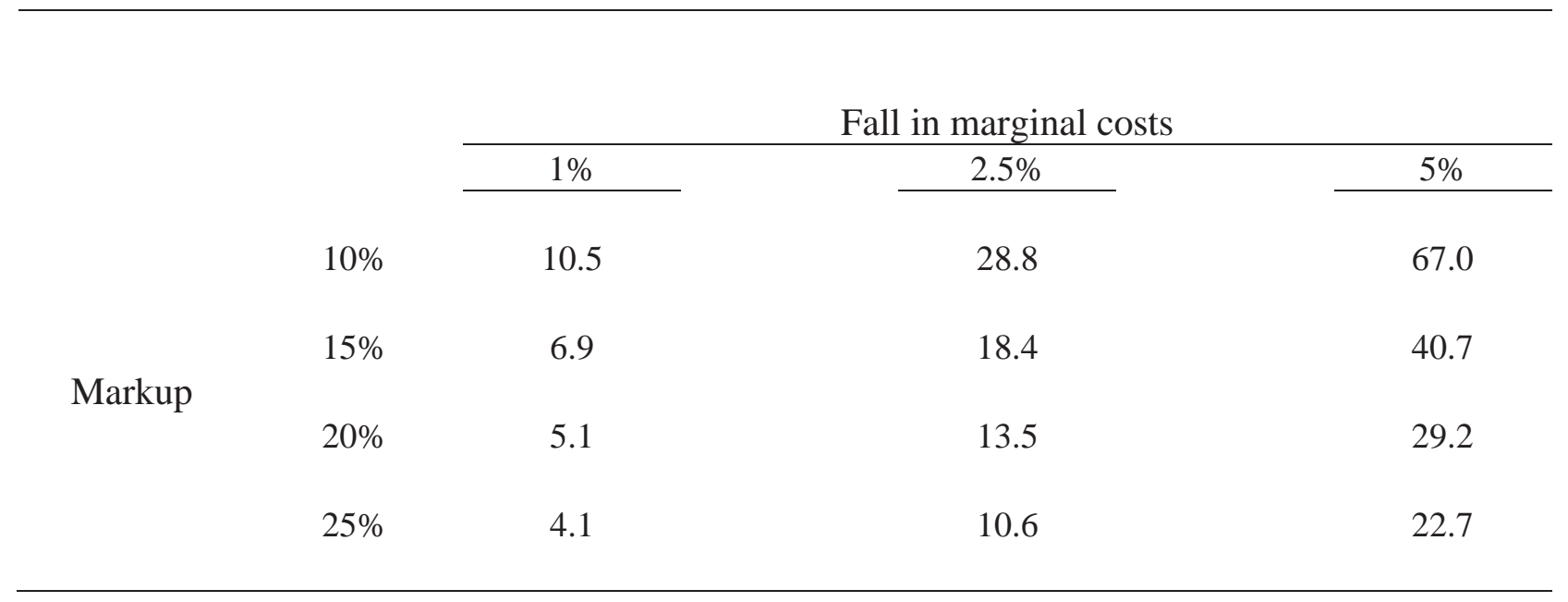




\section{Table 2}

Descriptive statistics

This table presents the summary statistics for the variables used in the analysis. The dependent variables come from the Commodity Flow Surveys of 1977 and 1993 on 48 US states. Our sample consists of the 48 contiguous states, which results in 4,512 state-pair-year observations $(=48 \times(48-1) \times 2)$, as we exclude Alaska, Hawaii, and the District of Columbia. TRADE_FLOW is the trade size (in millions of dollars) as sampled by the Commodity Flow Survey from the origin-state to a destination-state. $\ln \left(T R A D E \_S H A R E\right)$ is the trade share of the destination-state among origin-state's exports using the previous variable for volume of trade. The explanatory variables are as follows (indicator variable names are preceded by the prefix D_): $\ln \left(G D P \_D E S T\right)$ is the destination-state's GDP; $\ln \left(W A G E \_D E S T\right)$ is the destination-state's wage index; $D \_1993$ is equal to one if year is equal to 1993 , and zero if it is equal to 1977 ; $D \_D E R E G$ is equal to one if the state deregulated interstate banking entry as of 1993, and zero otherwise (as none of the states had deregulated interstate banking entry as of 1977); ADJACENCY is equal to the inverse of the number of states with which the origin-state has a common border if the origindestination state-pair have a common border, and zero otherwise; $D \_B O R D E R \_D E S T$ is equal to one if the destination state is on the US national border, and zero otherwise; D_COASTAL_DEST is equal to one if the destination state has a maritime border; DISTANCE_CAPS is the distance between an origindestination state-pair's capitals in kilometers; $D \_R I V E R$ is equal to one if the origin-destination state-pair is part of the Missouri or Columbia river systems or if both states have shores on the Great Lakes, and zero otherwise; D_SAME_COAST is equal to one if origin-destination state-pairs are both on the Eastern or Western seaboards of the US; BIRTH_INTEG $G_{i m t}$ is the sum of the number of people living in state $i$ who were born in state $m$ plus the number of people living in state $m$ who were born in state $i$, divided by the sum of the number of people living in states $i$ and $m$ who were born outside of these states. The endogenous variable BANK_INTEG is the fraction of banking assets owned by out-of-state banks that belongs to the other state in a given state-pair (i.e., it is the total banking assets owned by state $m$ 's banks in state $i$ plus the total banking assets owned by state $i$ 's banks in state $m$, divided by the sum of the banking assets of states $i$ and $m$ ). IVs are as in Morgan, Rime, and Strahan (2004): D_DEREG_ORIG (D_DEREG_DEST) is an indicator variables that equals one if the origin- (destination-) state has deregulated entry by 1993, and zero otherwise; and YEARS_DEREG_ORIG (YEARS_DEREG_DEST) is the number of years the origin- (destination-) state has deregulated interstate entry.

\begin{tabular}{|c|c|c|c|c|c|}
\hline Variable & $\begin{array}{r}\text { Number of } \\
\text { observations }\end{array}$ & Mean & Std. dev. & Min & Max \\
\hline \multicolumn{6}{|c|}{ Dependent variables: } \\
\hline TRADE_FLOW & 4,512 & 930.85 & $2,188.75$ & 0 & $34,463.00$ \\
\hline TRADE_SHARE & 4,512 & 0.0213 & 0.0353 & 0 & 0.4770 \\
\hline \multicolumn{6}{|c|}{ Explanatory variables: } \\
\hline $\ln \left(G D P \_D E S T\right)$ & 4,512 & 10.6958 & 1.1787 & 8.1244 & 13.6336 \\
\hline $\ln \left(W A G E \_D E S T\right)$ & 4,512 & 2.0973 & 0.3931 & 1.4455 & 2.7709 \\
\hline D_1993 & 4,512 & 0.5000 & 0.5001 & 0 & 1 \\
\hline$D \_D E R E G$ & 4,512 & 0.7190 & 0.4496 & 0 & 1 \\
\hline$A D J A C E N C Y$ & 4,512 & 0.0213 & 0.0730 & 0 & 1 \\
\hline
\end{tabular}




\begin{tabular}{lccccc} 
D_BORDER_DEST & 4,512 & 0.3333 & 0.4715 & 0 & 1 \\
D_COASTAL_DEST & 4,512 & 0.4375 & 0.4961 & 0 & 1 \\
DISTANCE_CAPS & 4,512 & $1,677.23$ & 994.41 & 77.78 & $4,286.96$ \\
D_RIVER & 4,512 & 0.2270 & 0.4189 & 0 & 1 \\
D_SAME_COAST & 4,512 & 0.1383 & 0.3453 & 0 & 1 \\
BIRTH_INTEG & 4,512 & 0.0213 & 0.0341 & 0.0003 & 0.3695 \\
Endogenous (instrumented) variable & & & & 0 & 0.1845 \\
\hline BANK_INTEG & 4,512 & 0.0019 & 0.0118 & 0 & 1 \\
Instrumental (excluded) variables (IVs) & & & & 0 & 1 \\
\hline D_DEREG_ORIG & 4,512 & 0.3225 & 0.4675 & 0 & 12 \\
D_DEREG_DEST & 4,512 & 0.3225 & 0.4675 & 0 & 12 \\
YEARS_DEREG_ORIG & 4,512 & 1.7453 & 2.7794 & 0 & 0 \\
YEARS_DEREG_DEST & 4,512 & 1.7453 & 2.7794 & & \\
\hline
\end{tabular}




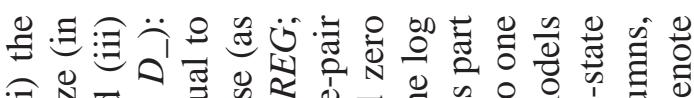
$\Theta$.

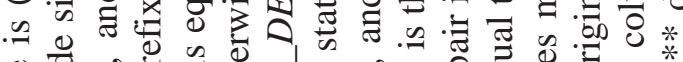

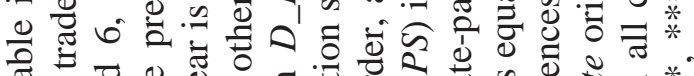

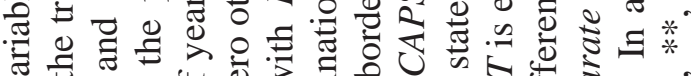

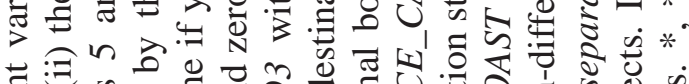

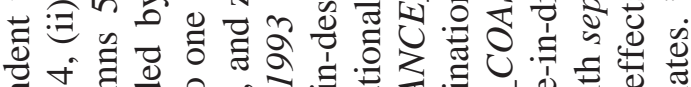

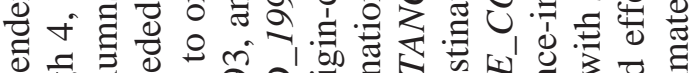

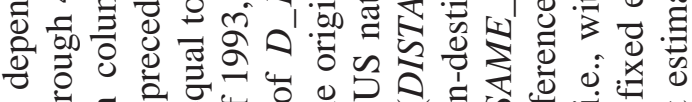

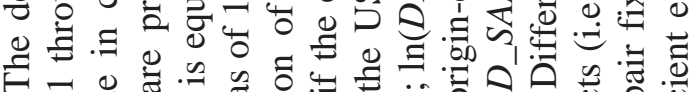
F-

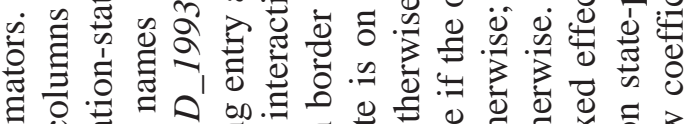

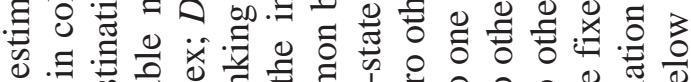

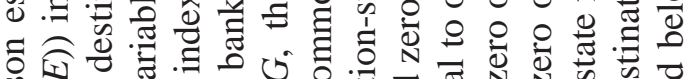

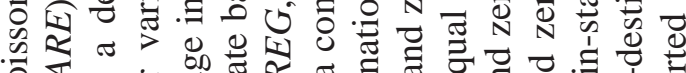

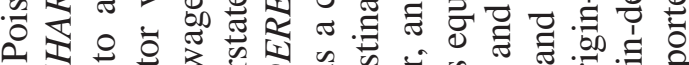
क क o

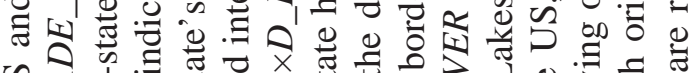

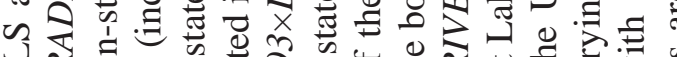

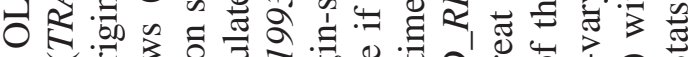
on

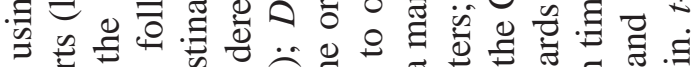
我

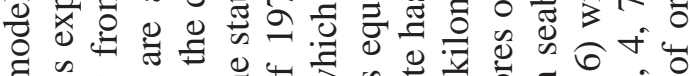

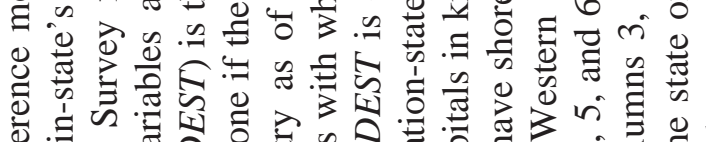

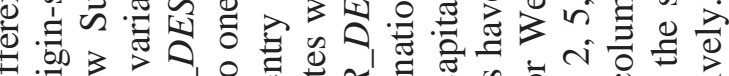

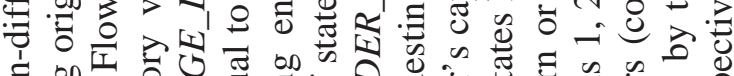
定 o

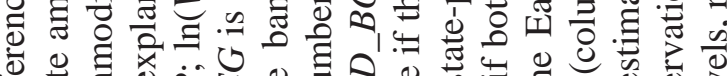

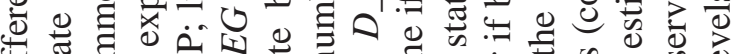

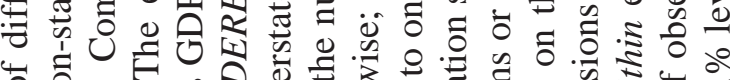

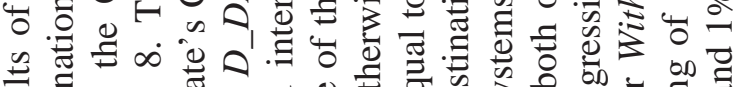

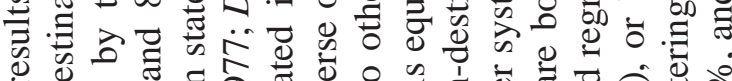

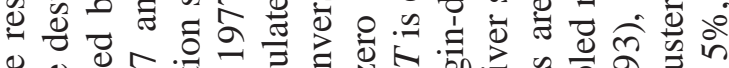

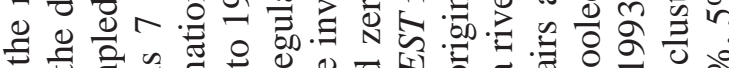

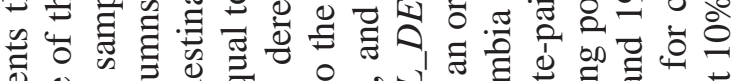

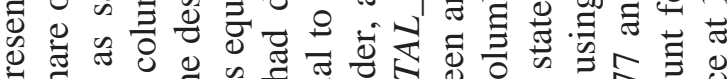

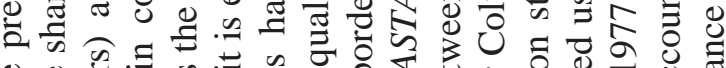

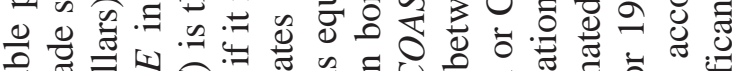

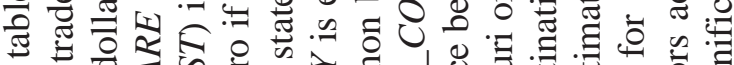

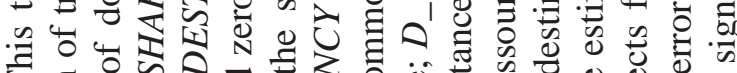

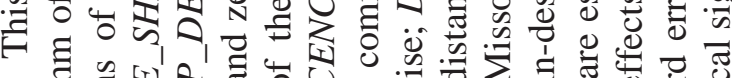

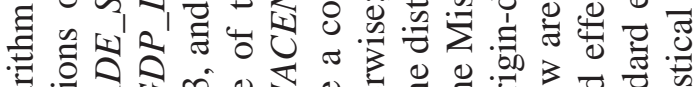

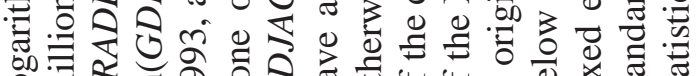

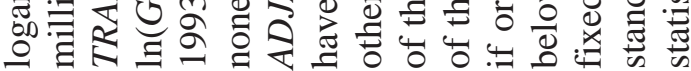

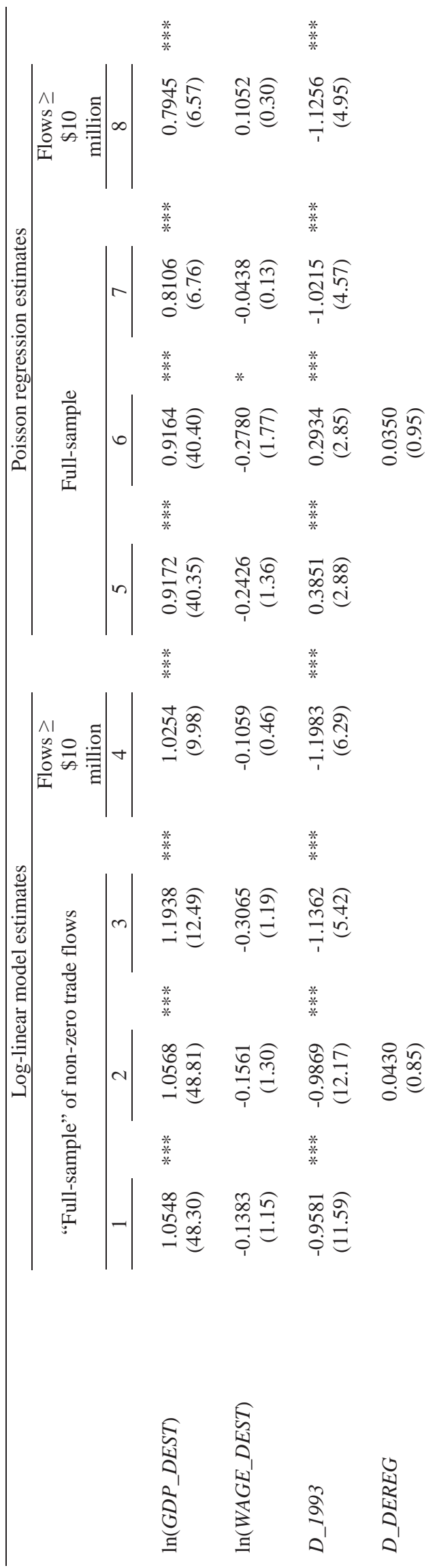




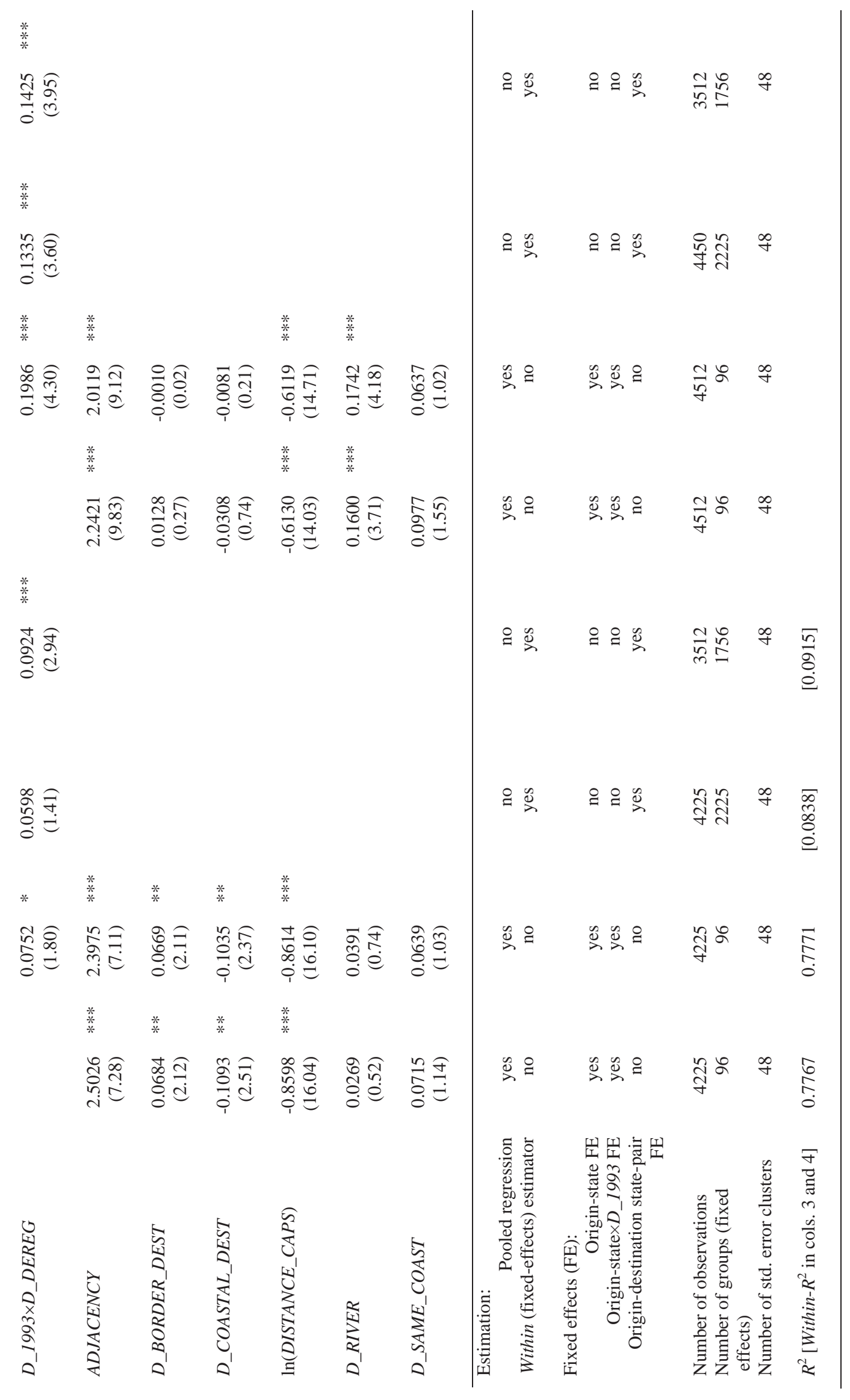




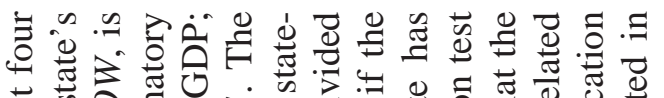

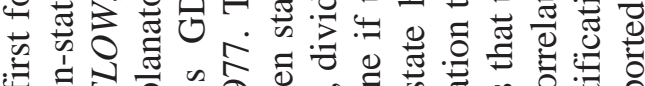

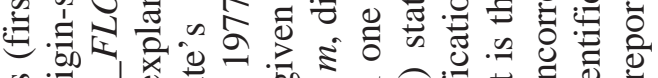

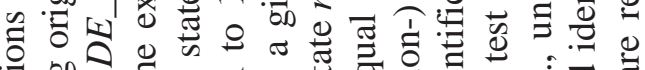
b on 。

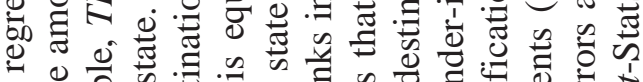

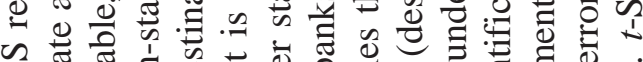

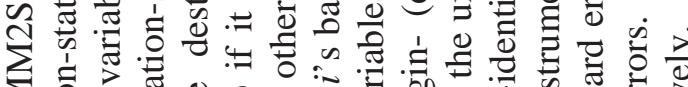

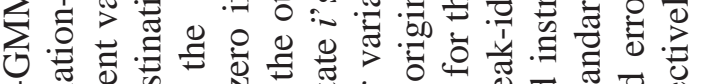

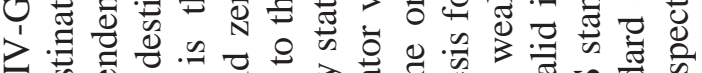

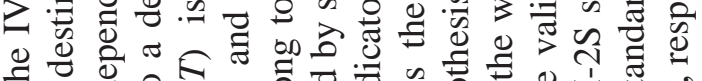

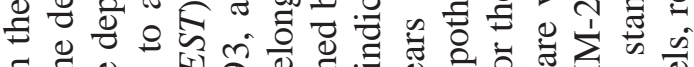

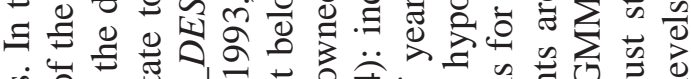

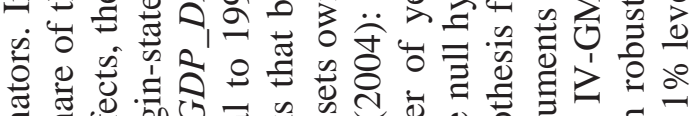

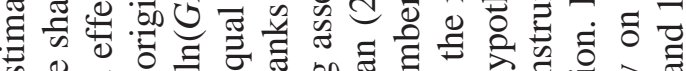

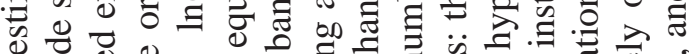

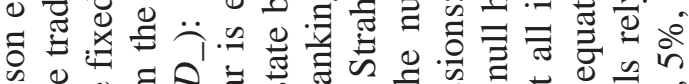
D

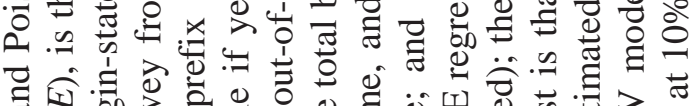

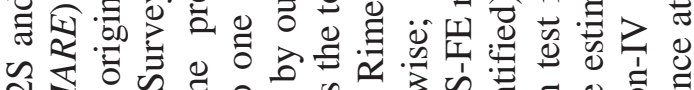

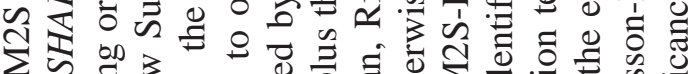

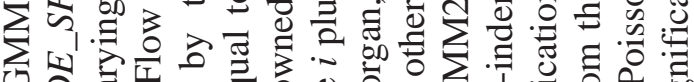

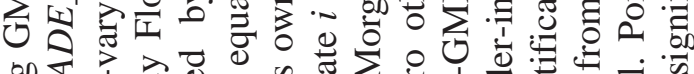

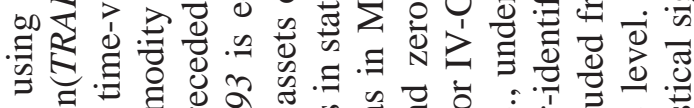

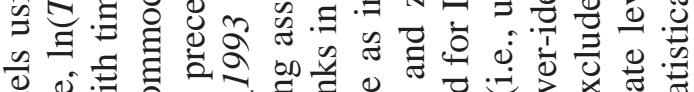

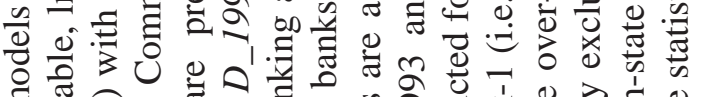

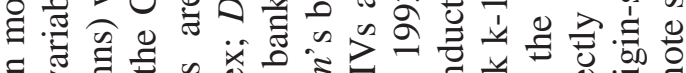

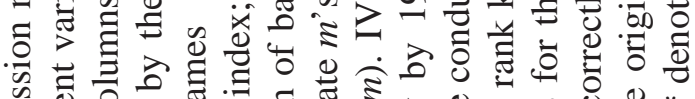

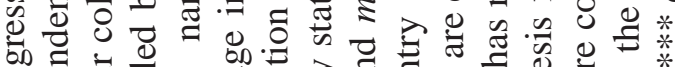

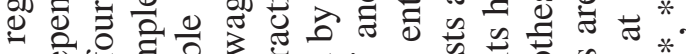

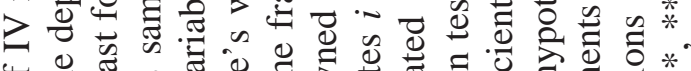
प

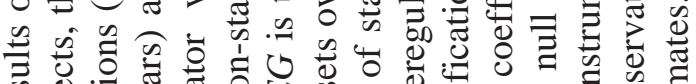

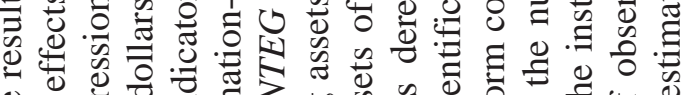

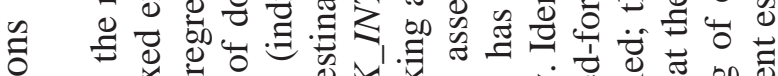

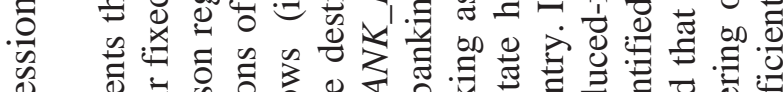

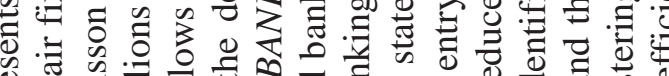

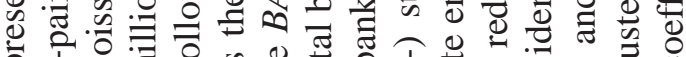

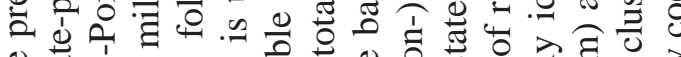

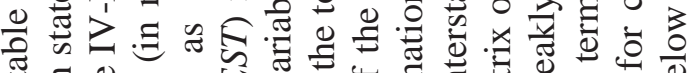

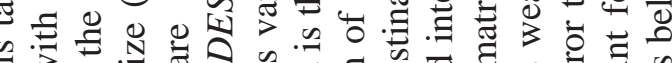

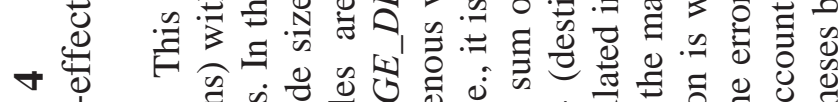

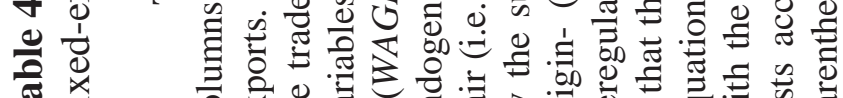
है

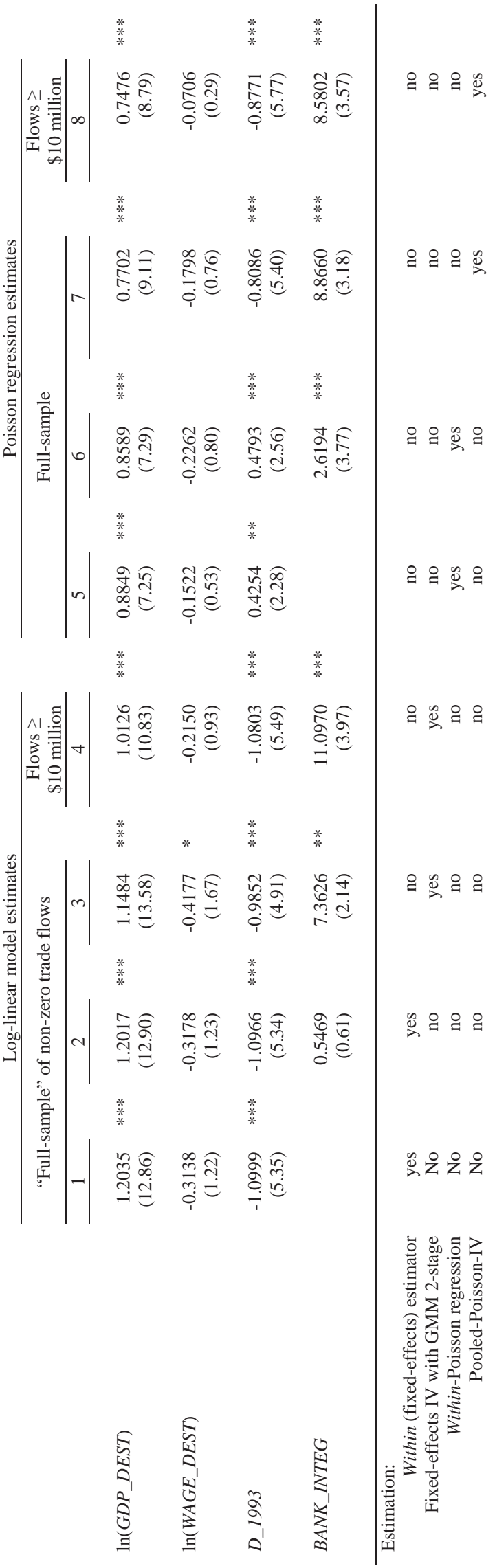




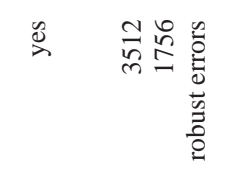

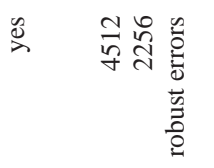

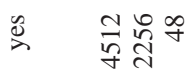

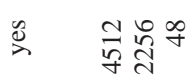

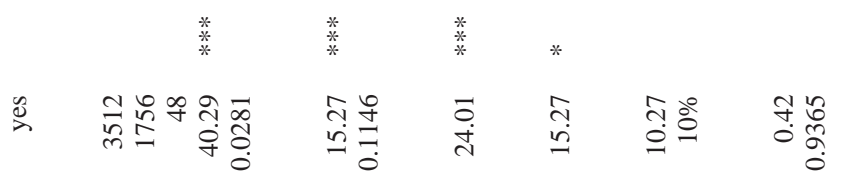

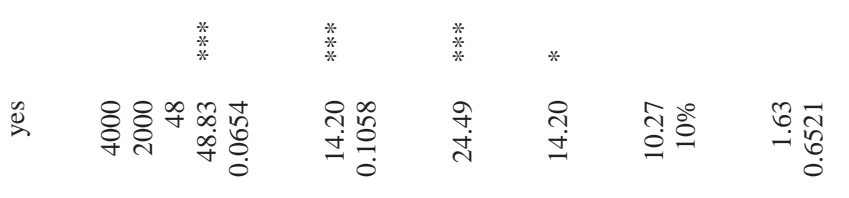

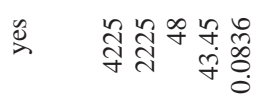

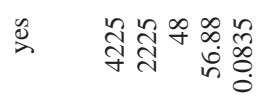

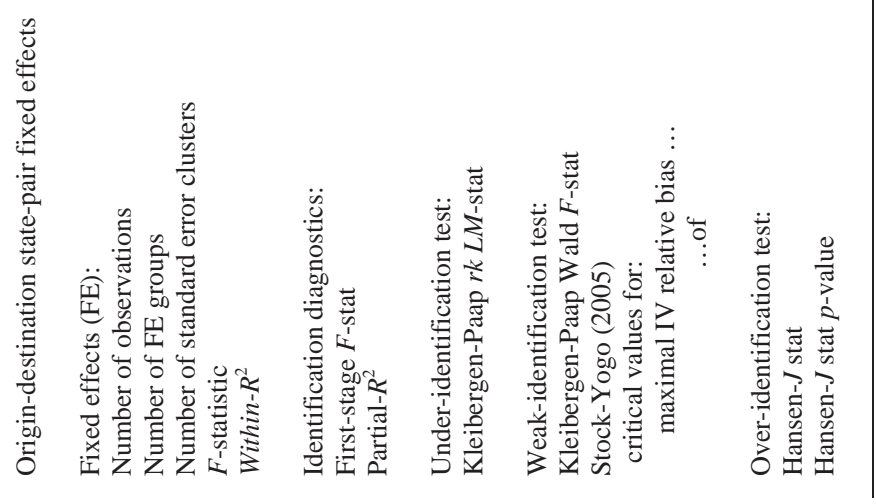




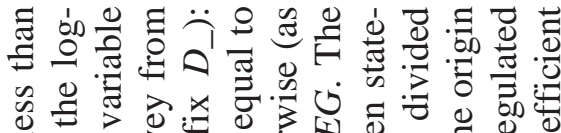

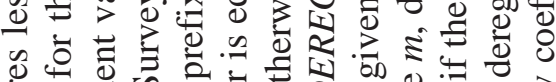

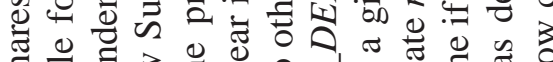

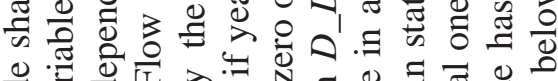

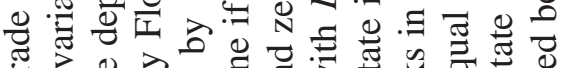

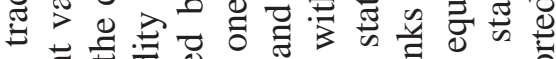

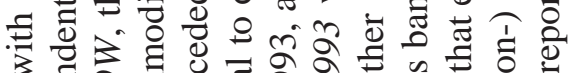

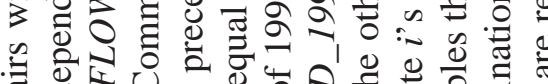

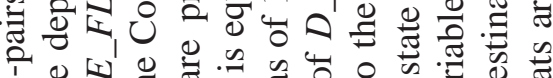

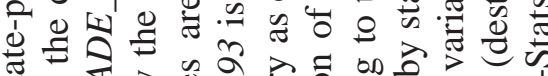
चै

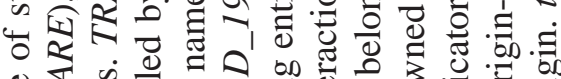

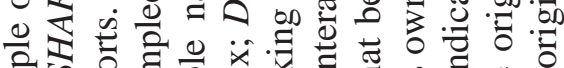

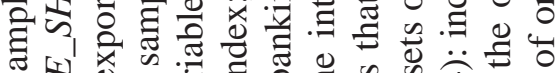

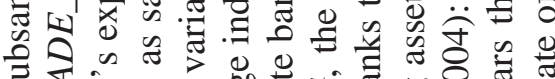
के

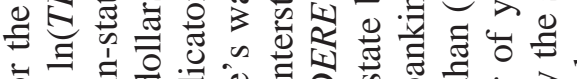

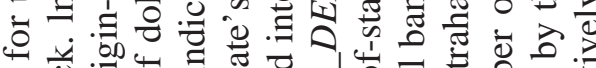

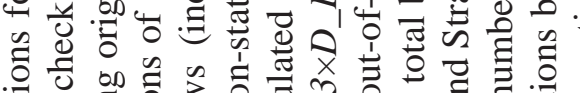

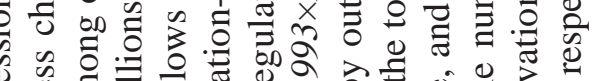

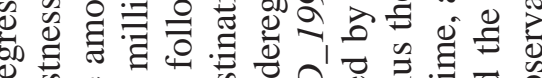

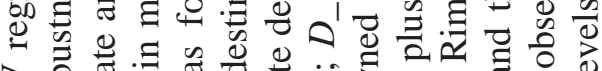

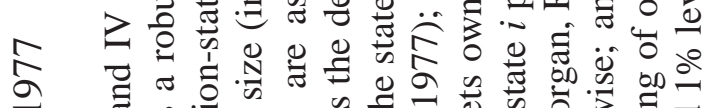

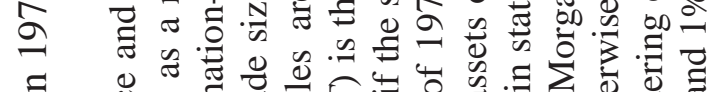

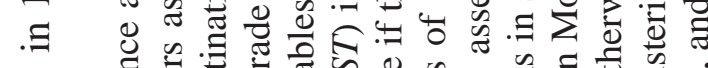

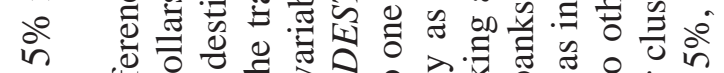

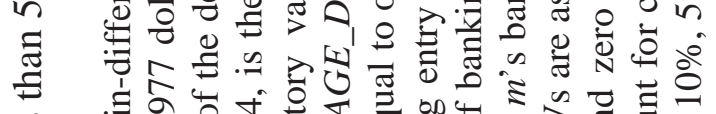

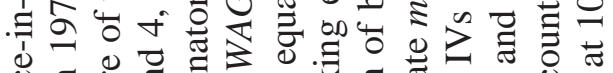

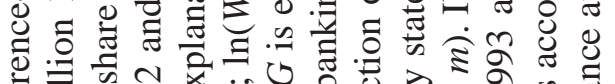

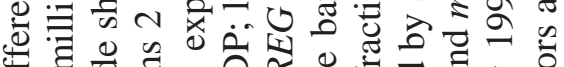

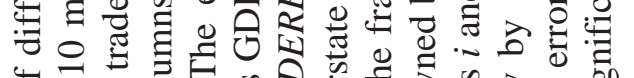

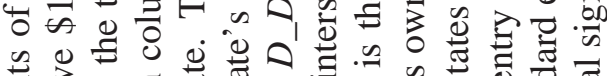

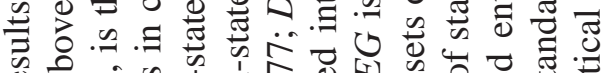

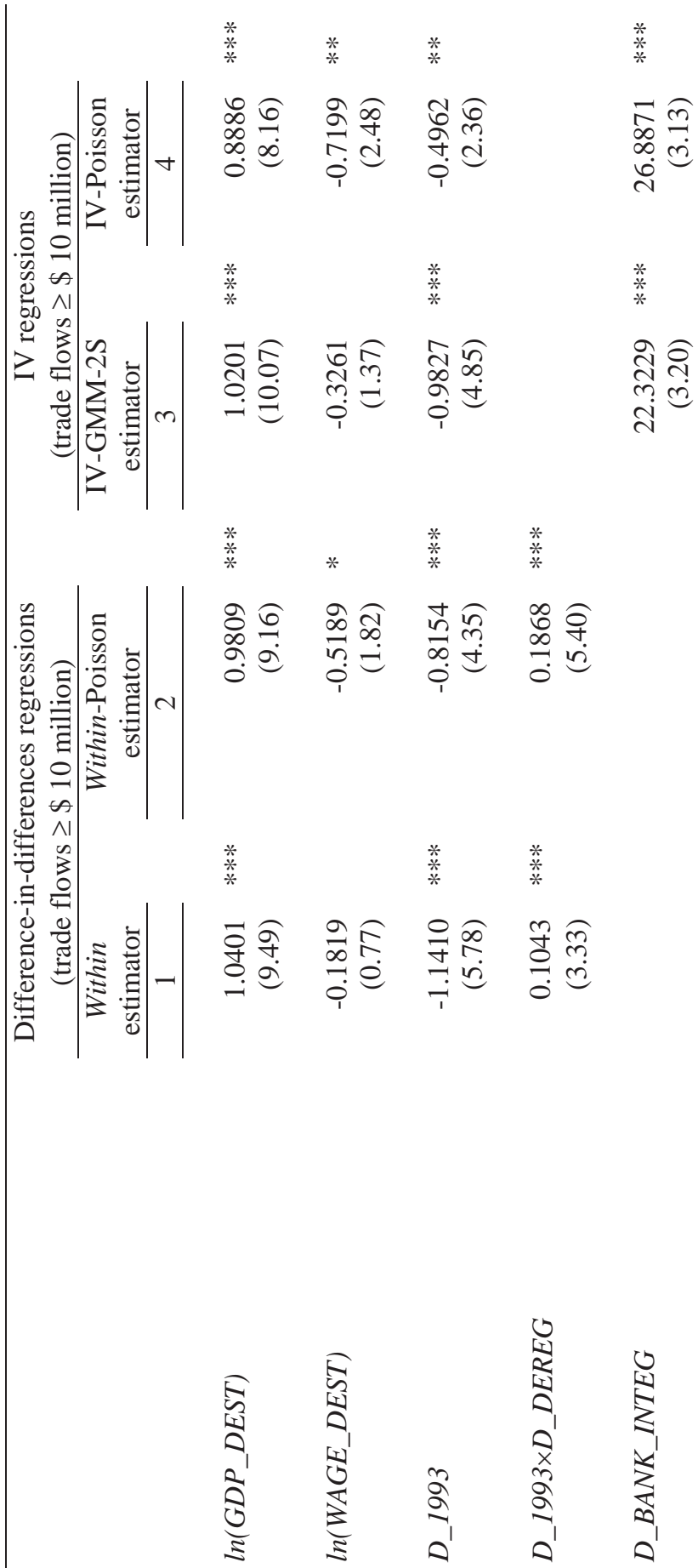

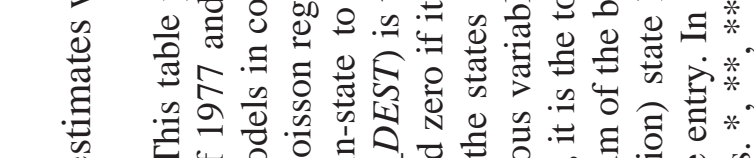

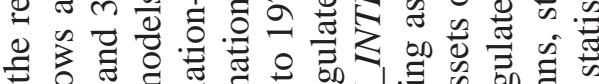

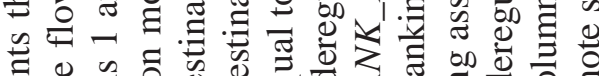

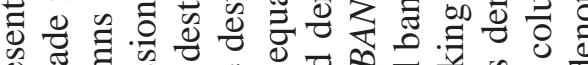
政 느의 L

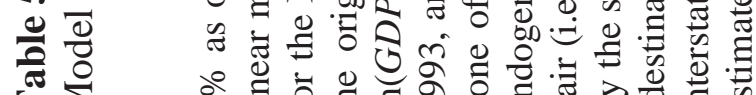

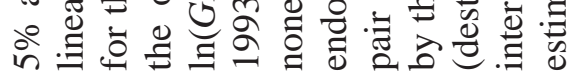




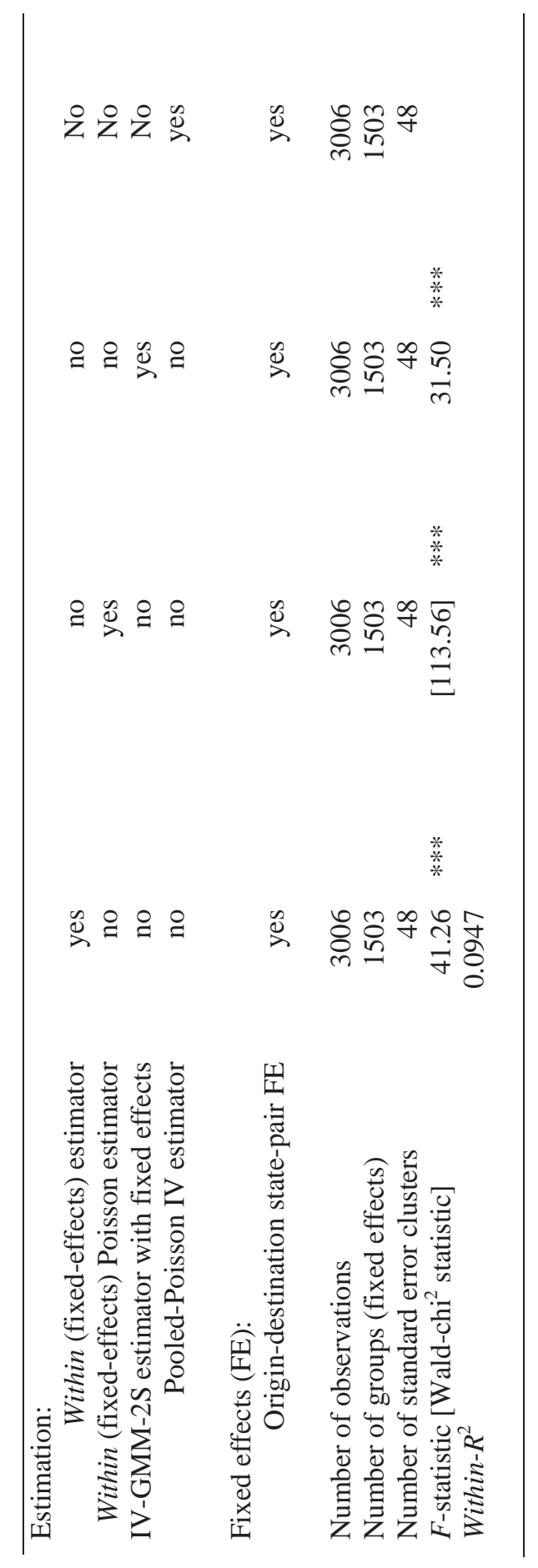




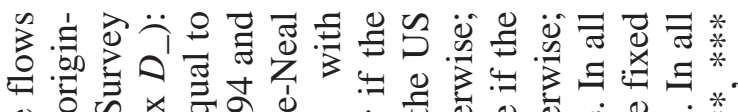

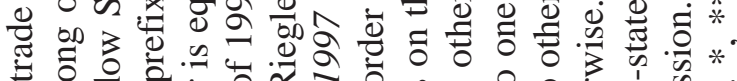

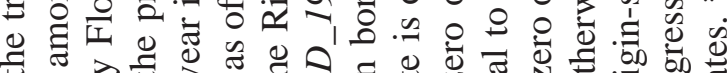
厅

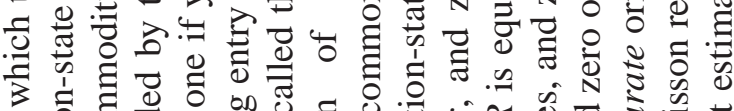

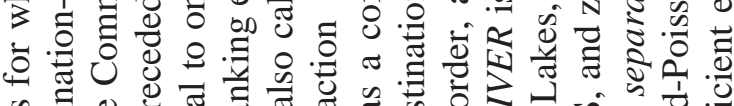

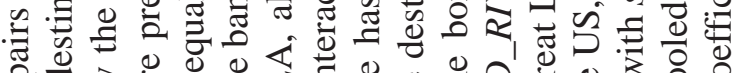

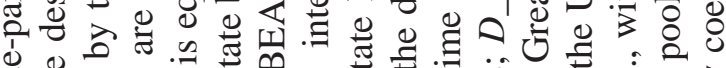

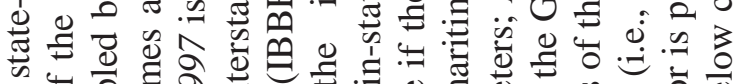
पे

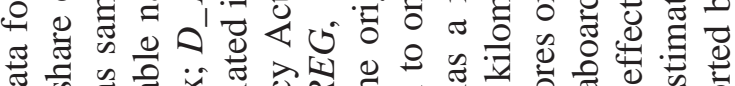

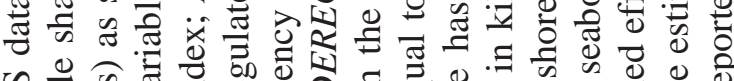

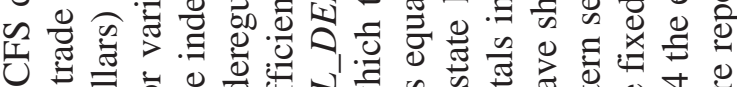

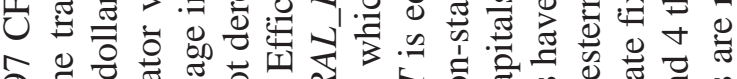

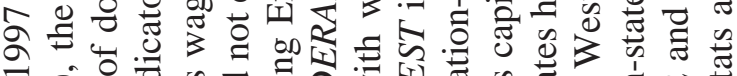

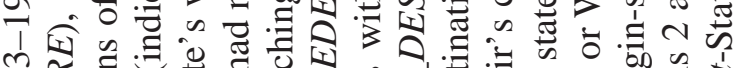

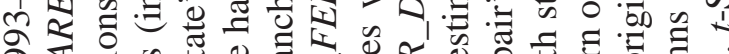

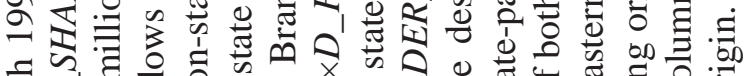

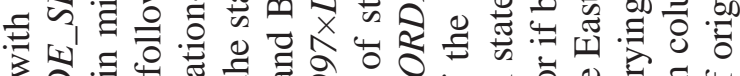

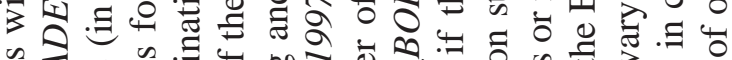

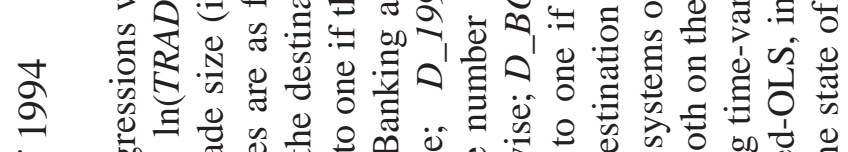

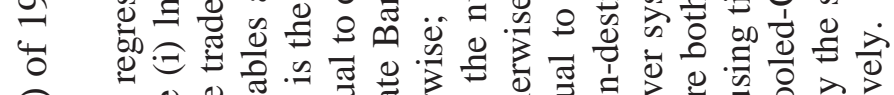

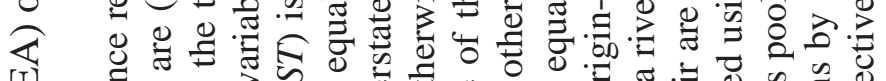

I

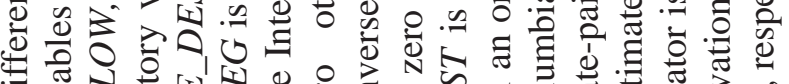

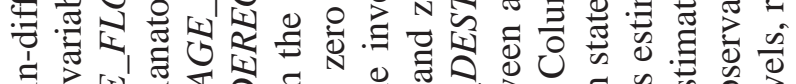

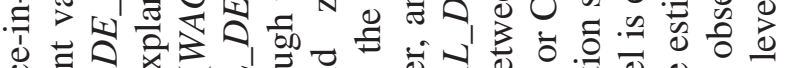

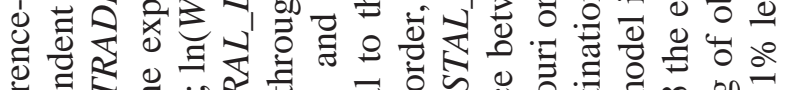

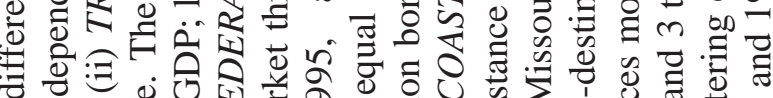

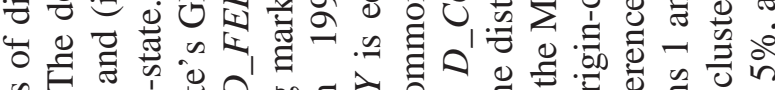

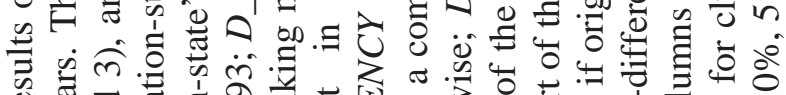

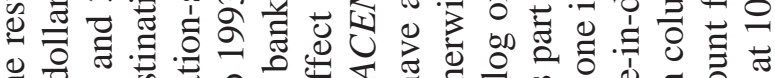

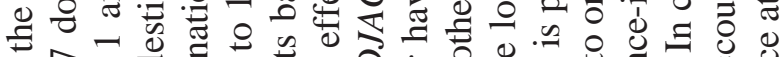

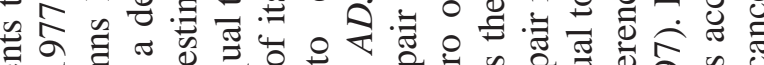

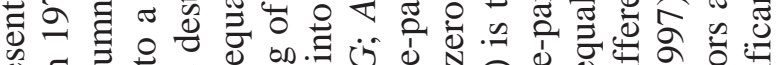

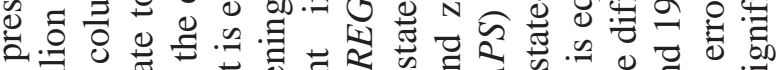

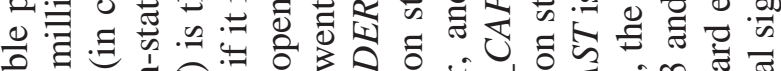
बै

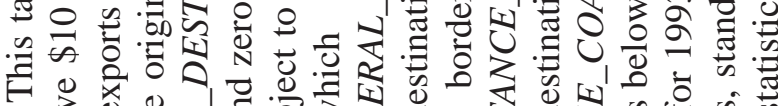

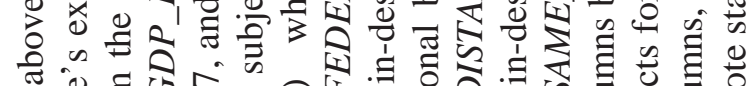

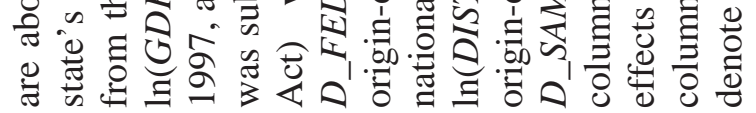

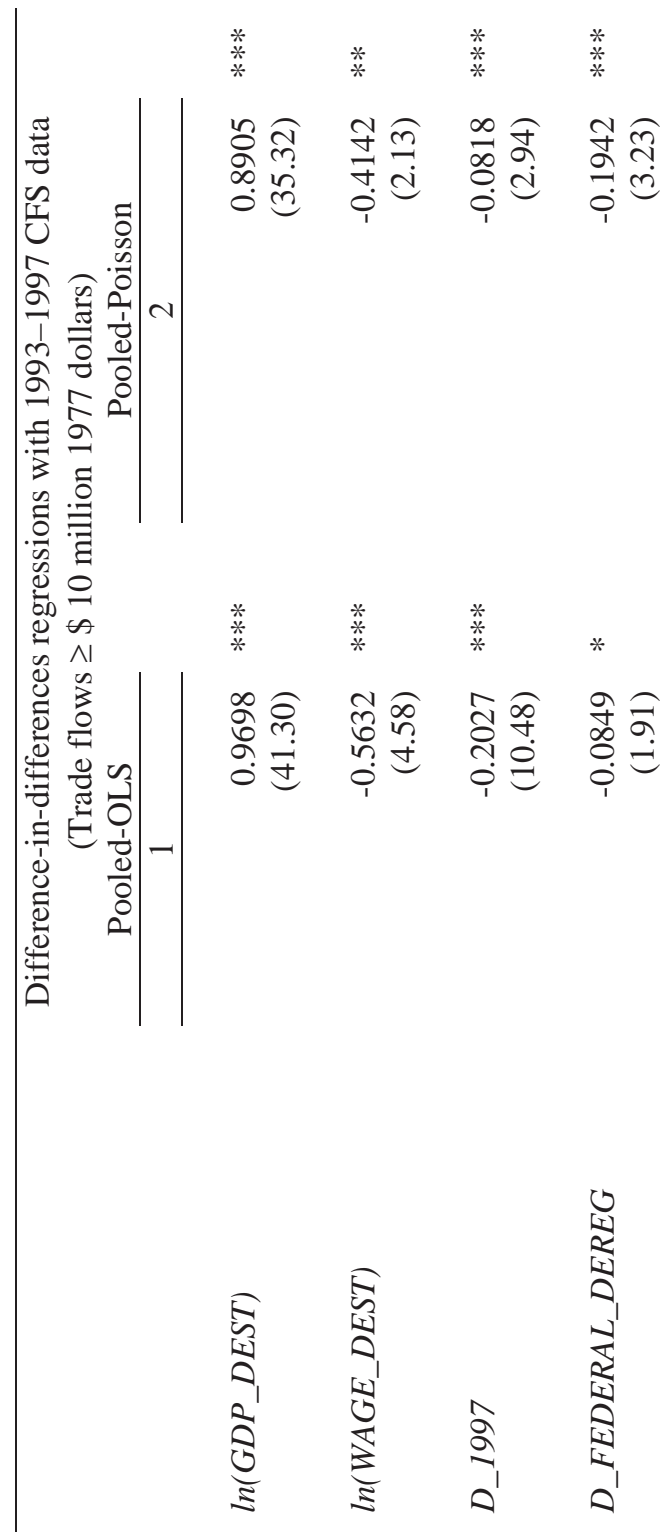




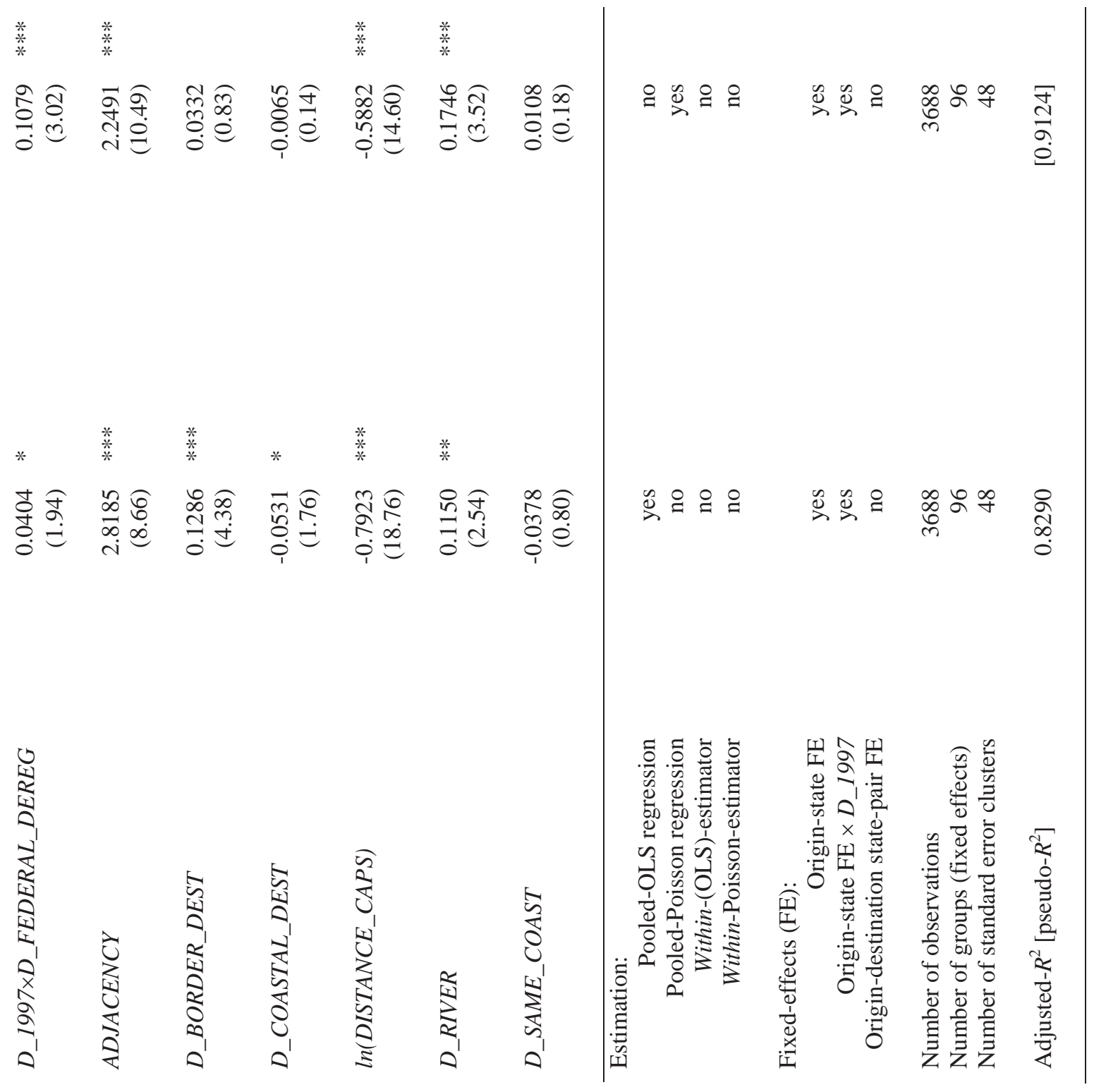




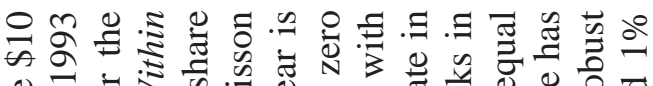

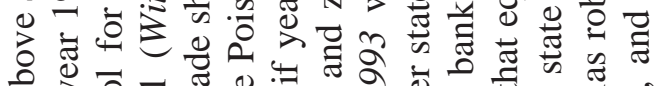
ने गे च

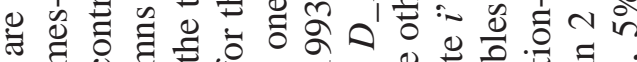

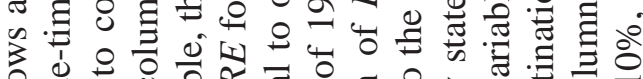

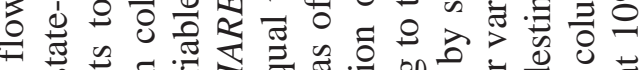

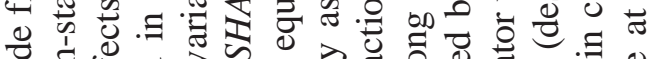

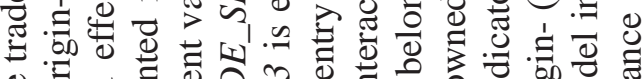

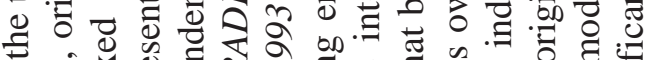

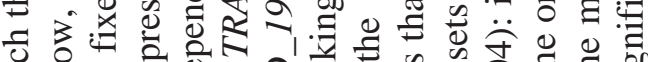
等

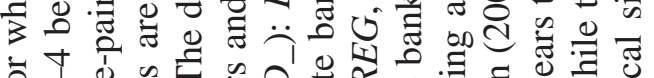

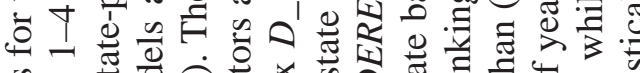

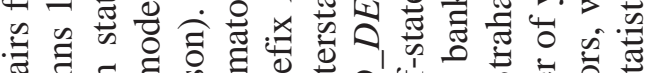

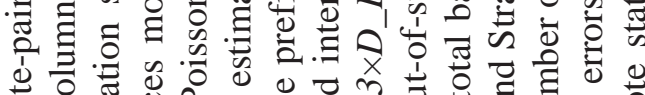

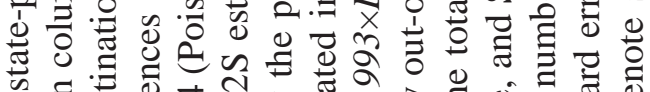
कo $\left\{\begin{array}{l}0 \\ 0\end{array}\right.$

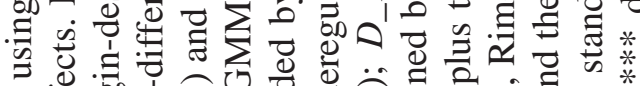

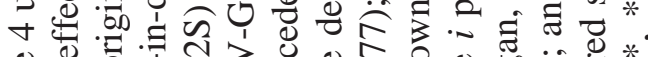

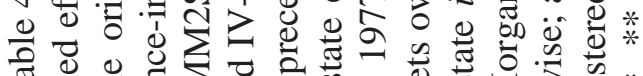

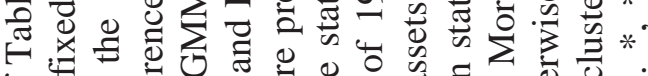

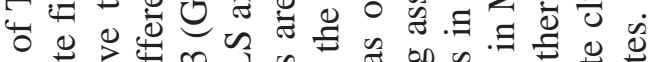

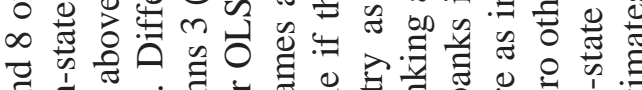

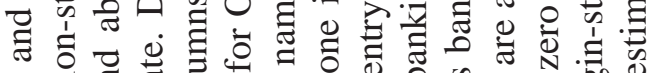

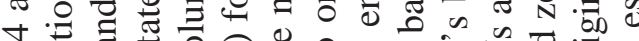

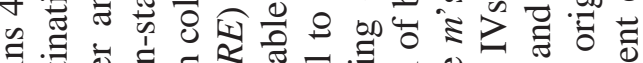

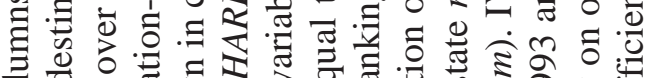

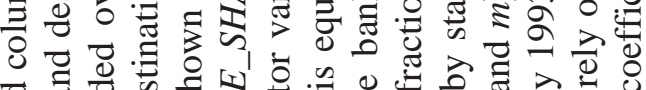

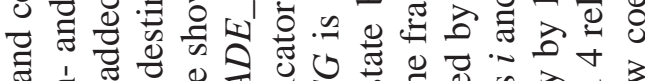

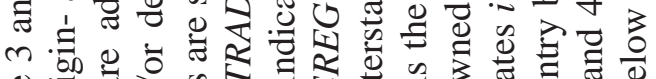

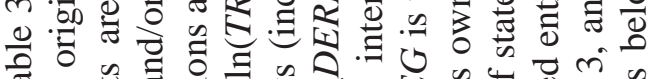

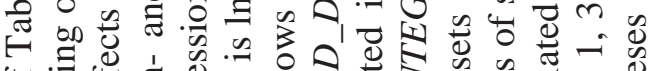

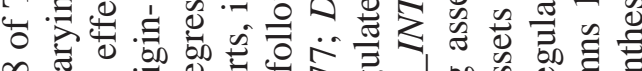

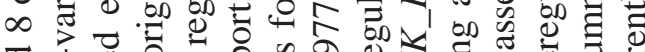

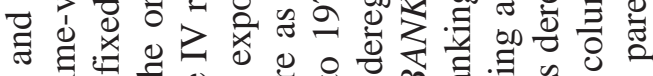

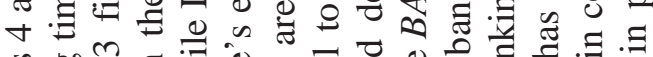

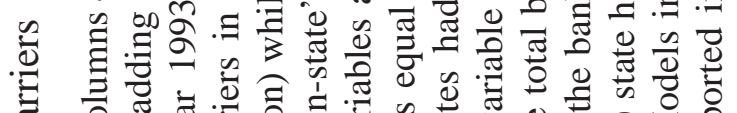

昰

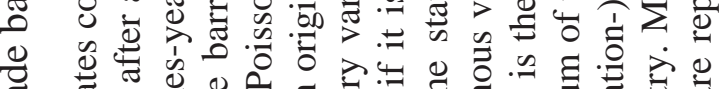

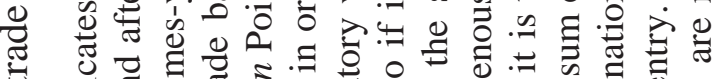

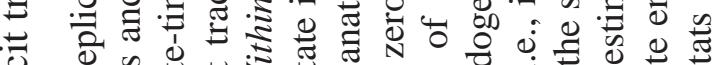

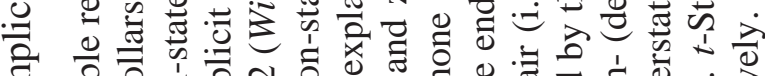

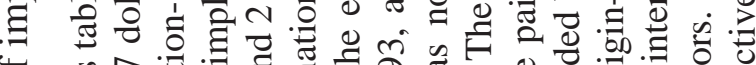
Ч

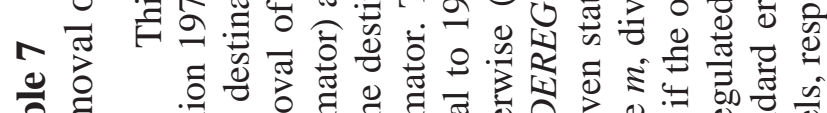

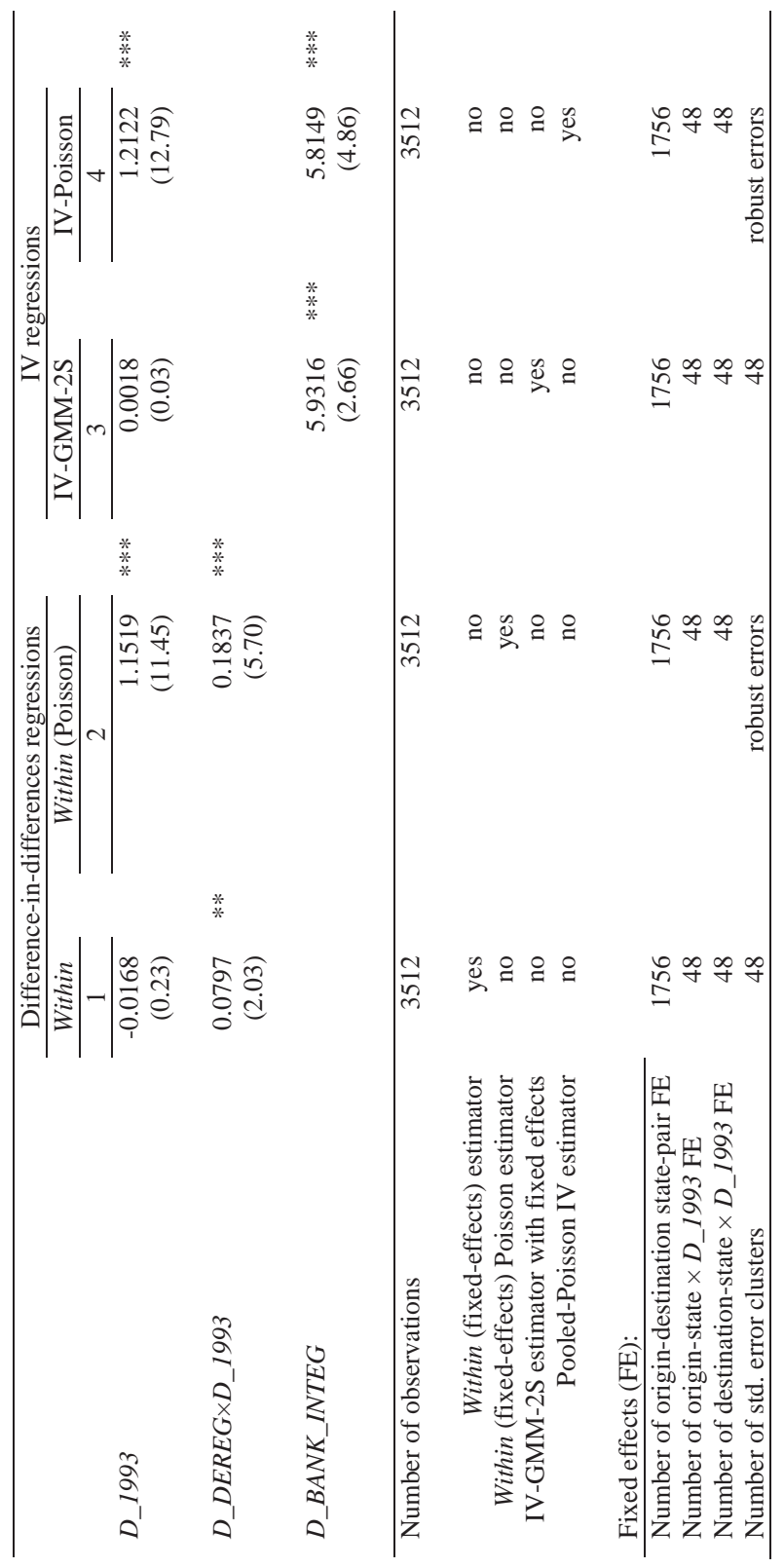




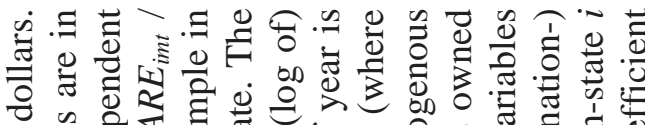

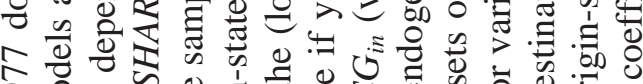

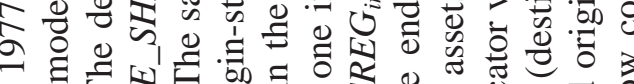
ี E .0

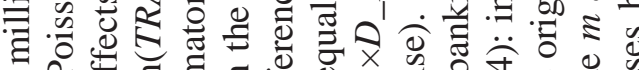

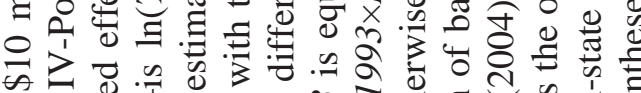

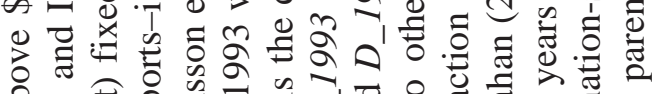

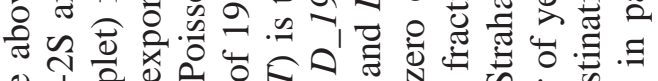

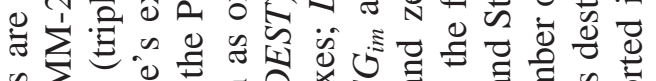

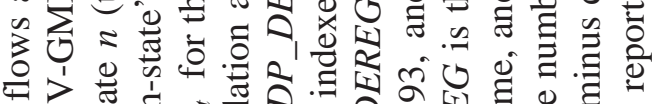

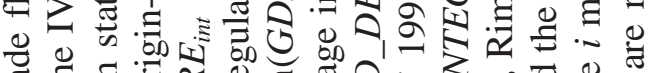
先

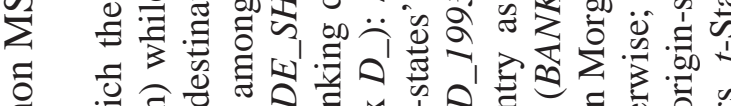
ฮี

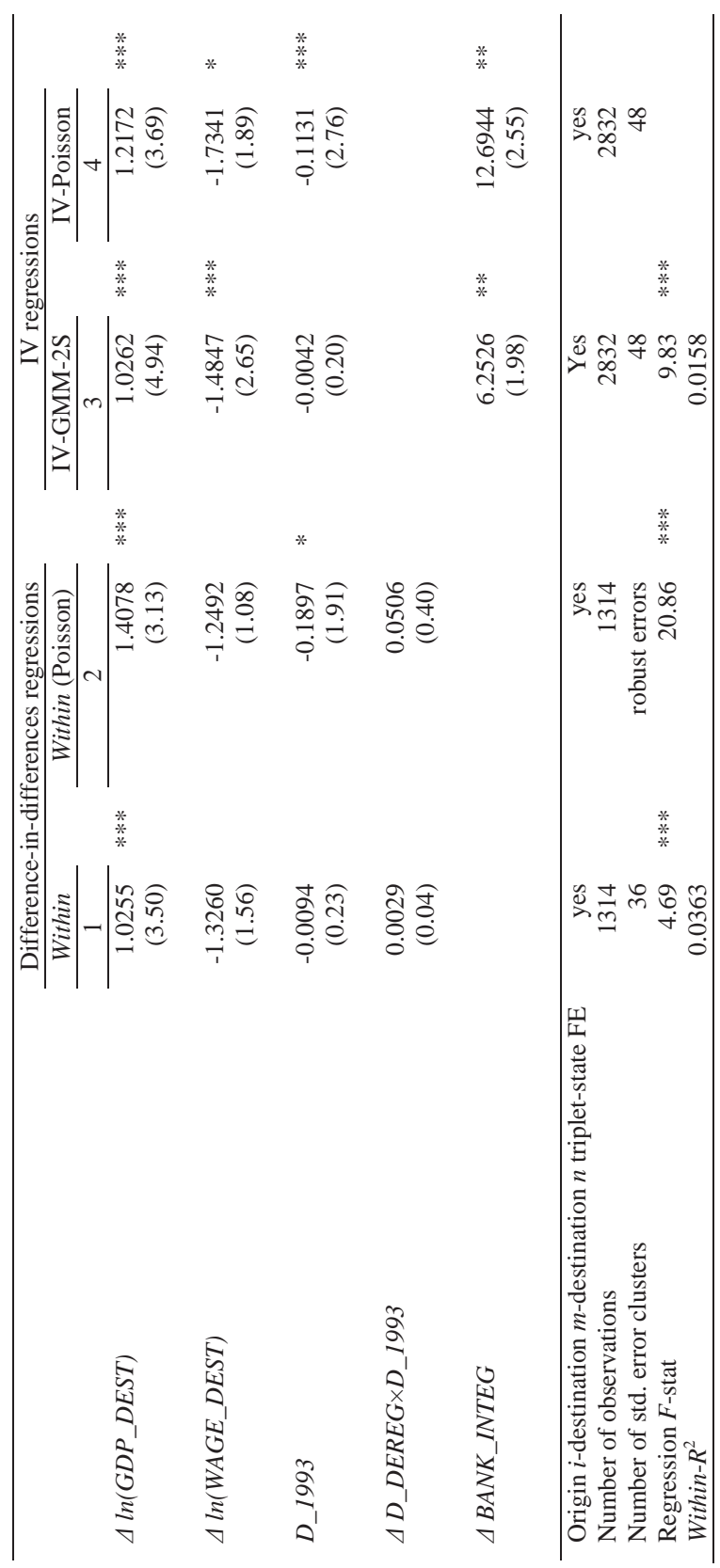

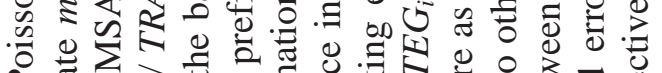

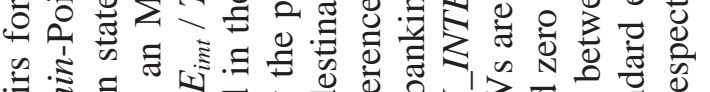
.

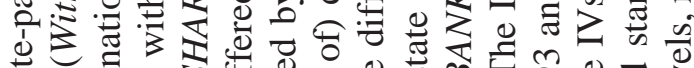

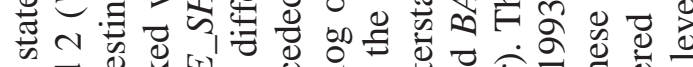

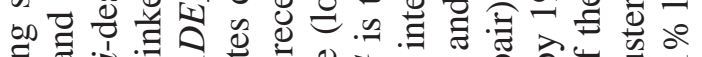

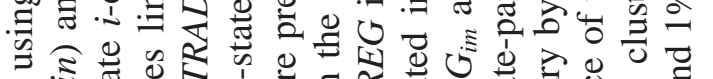

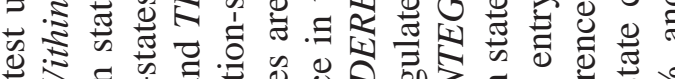

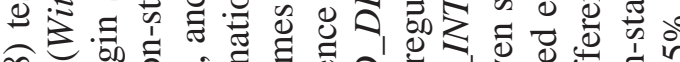

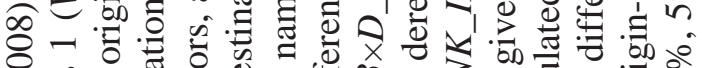
¿

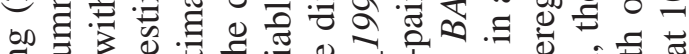

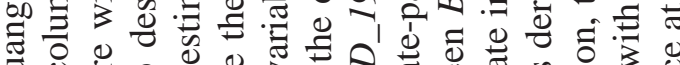

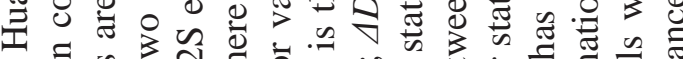

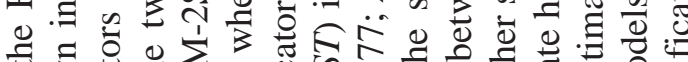

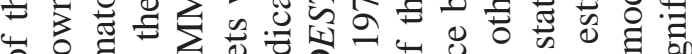

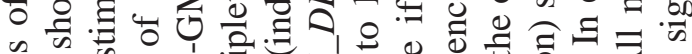

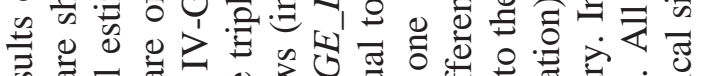

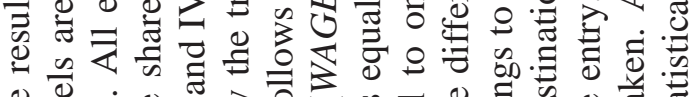

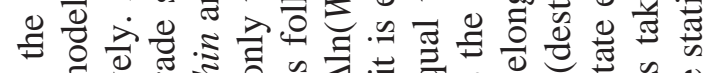

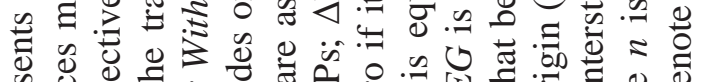
ڤิ

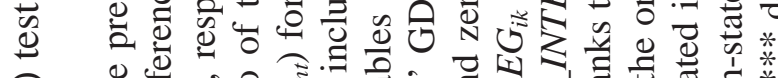

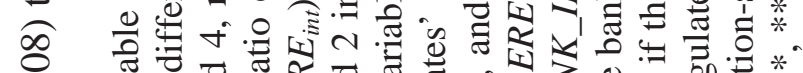
¿

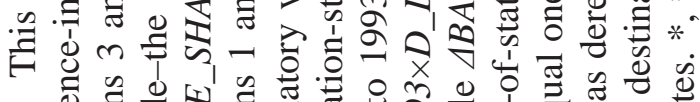

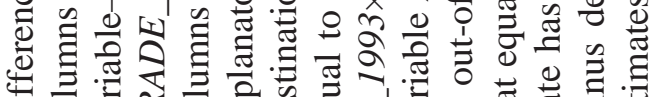

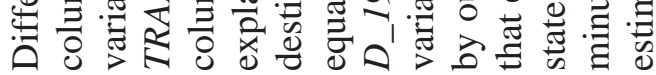




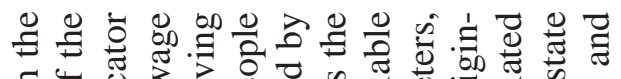

눵 त

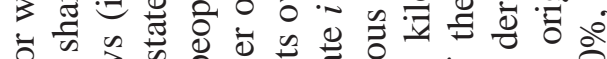
은

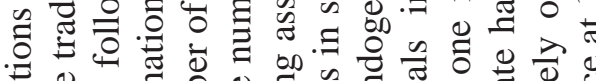

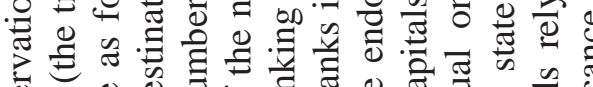

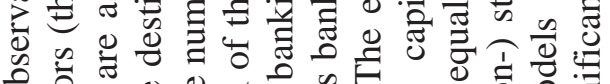

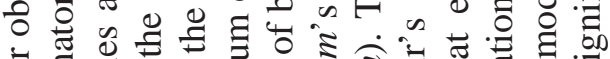

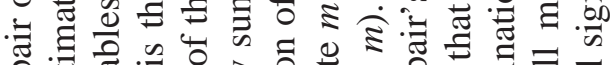

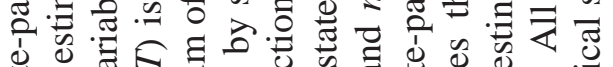

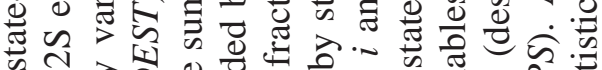
का मे

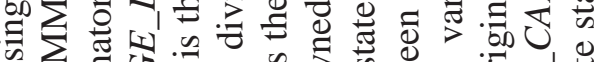

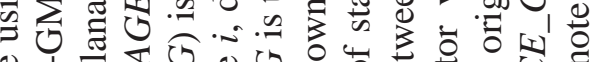

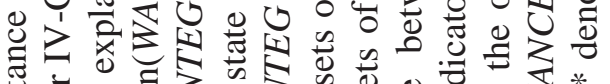

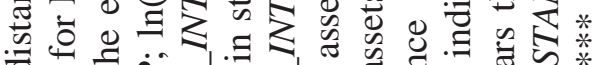

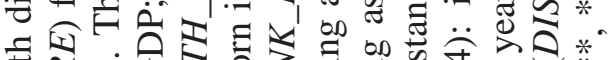

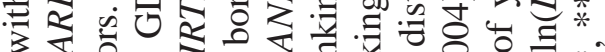

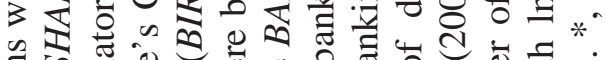

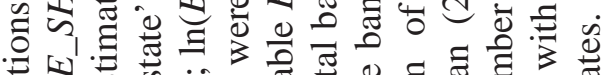

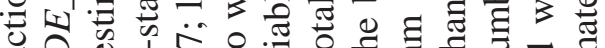

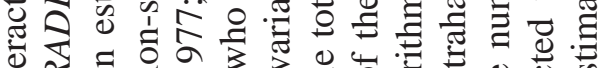

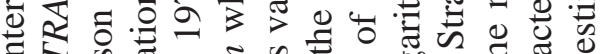
on . 0 के \%

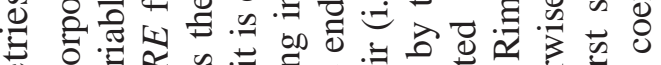

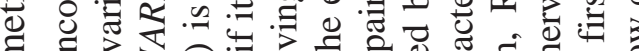

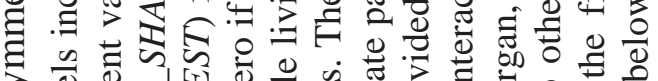
ब

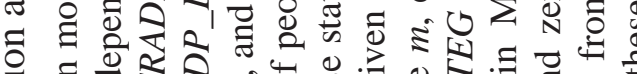

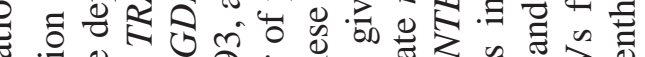

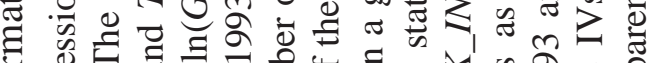

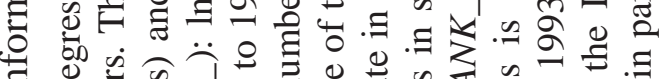

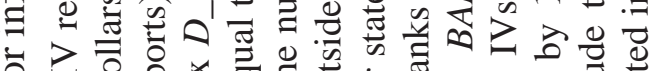

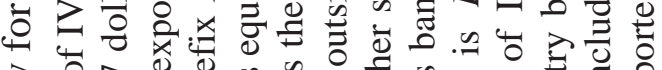

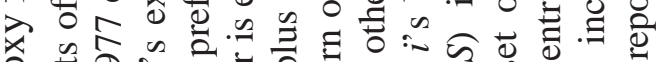
윤 \%

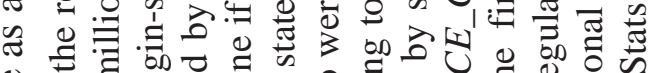

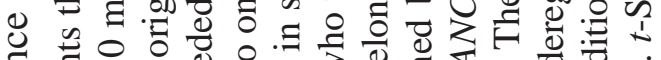
ज़ :

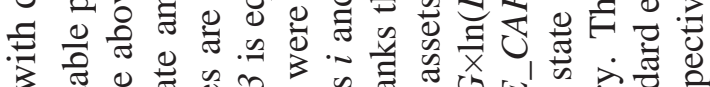

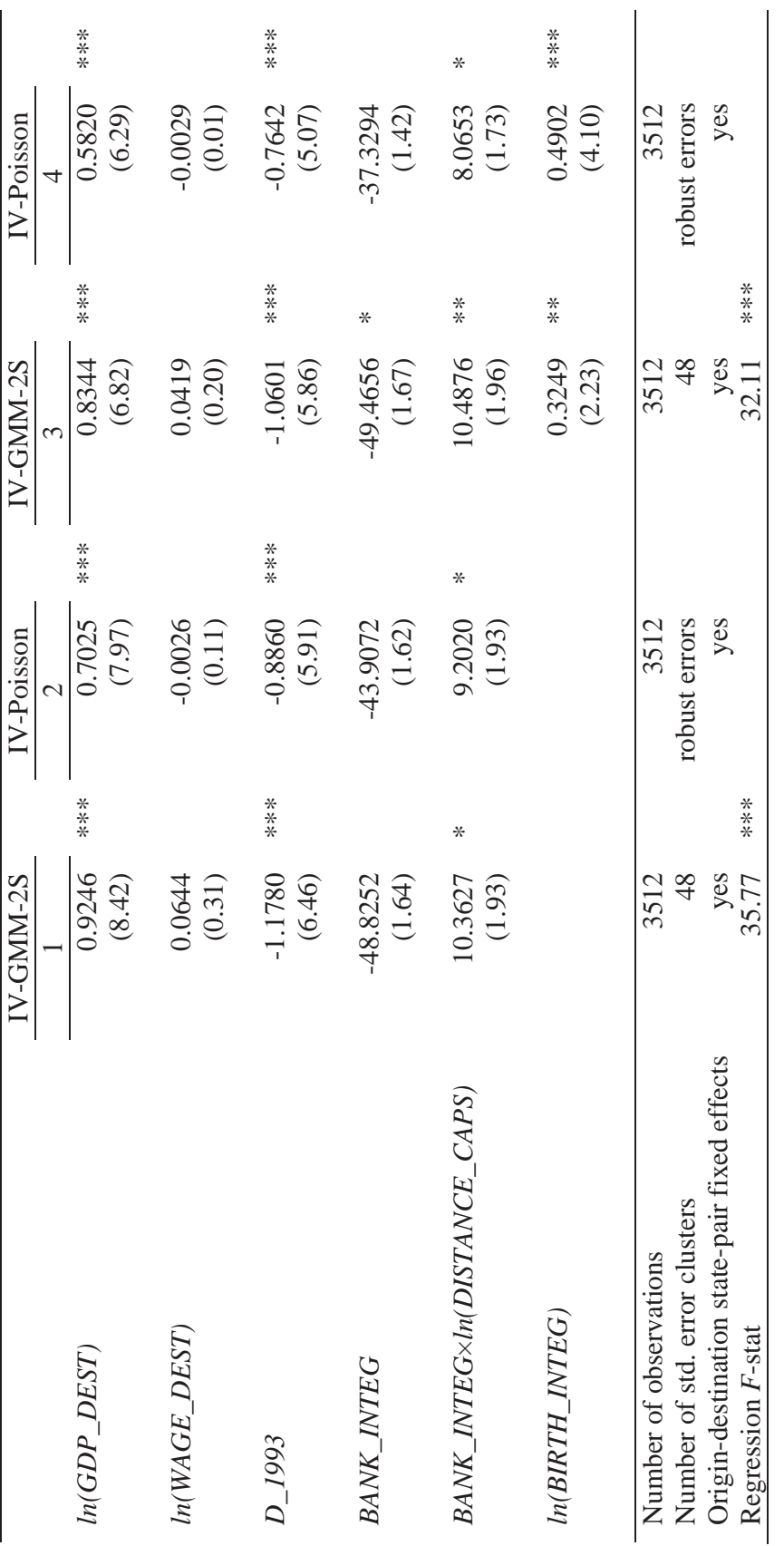
क

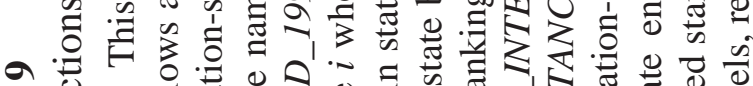

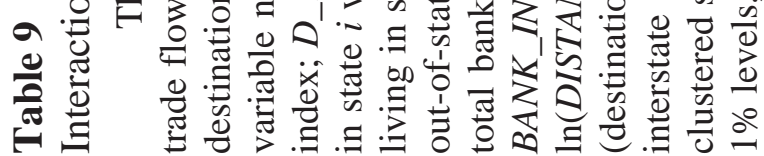




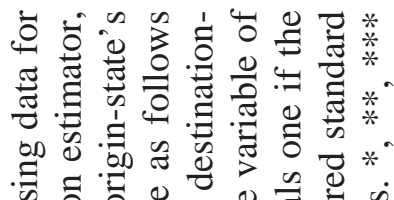

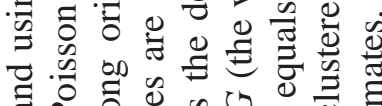
完

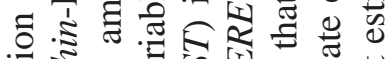

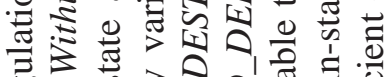
का 政

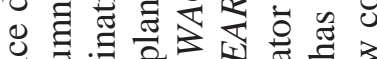

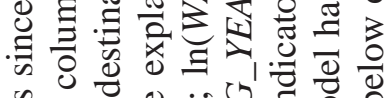

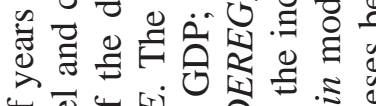

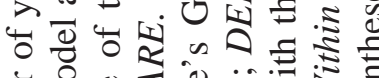

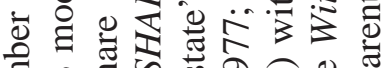
的衫 क人

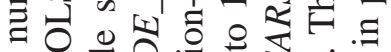

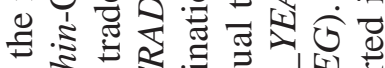
on .

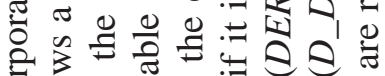

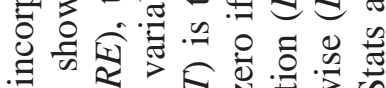

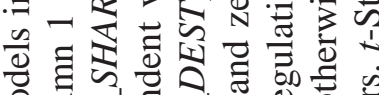

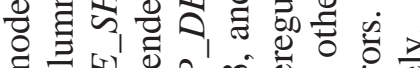

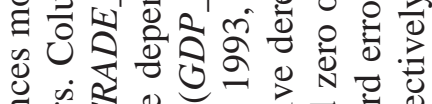
ฮี 跑

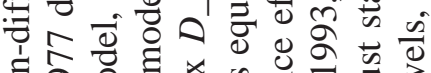
. נ่

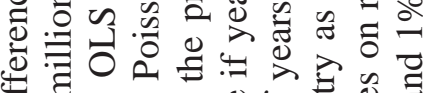

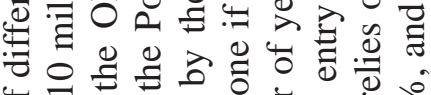

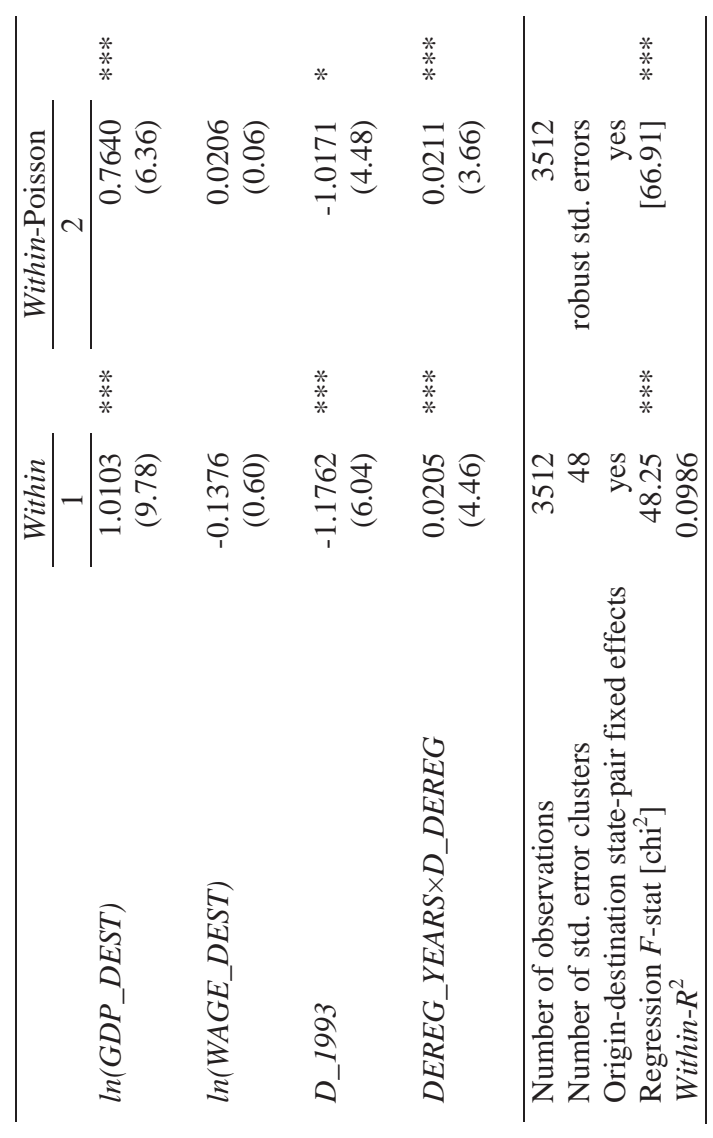

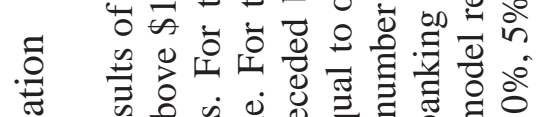

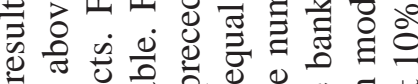
至

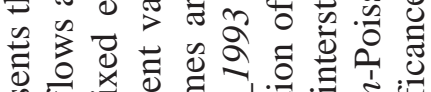

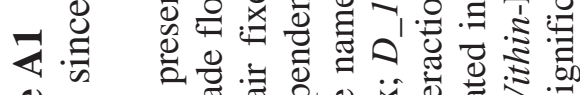

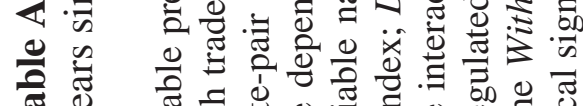
चि Ð

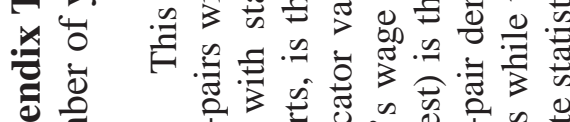

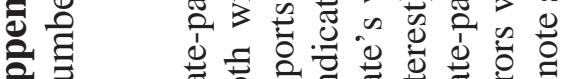

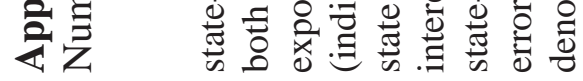




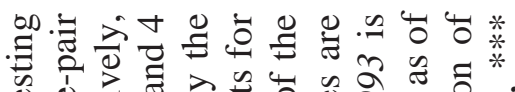
ญ造宅

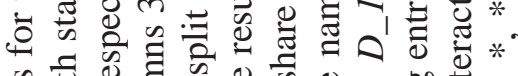

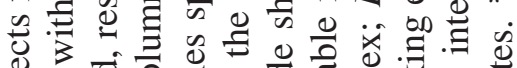

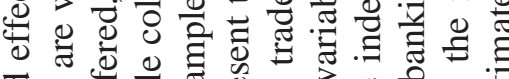

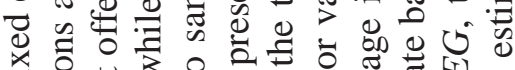

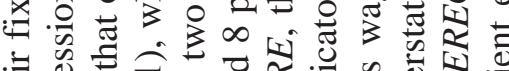
.

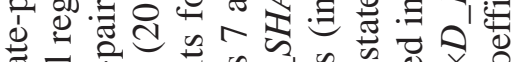

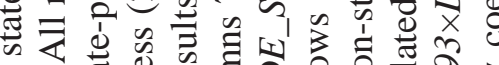
Ð

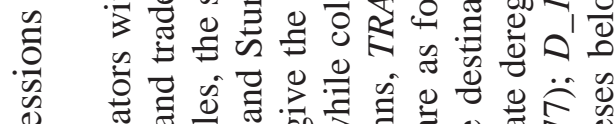

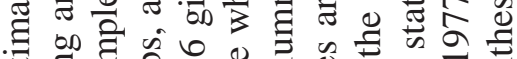

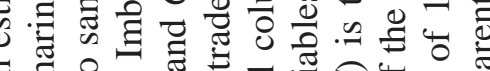
ธ ธี

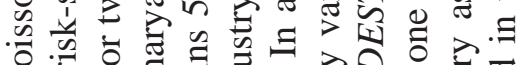

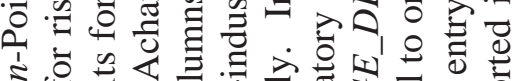

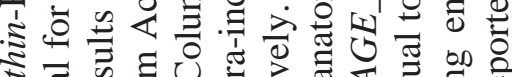

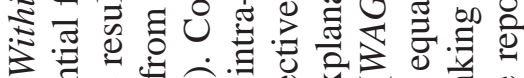

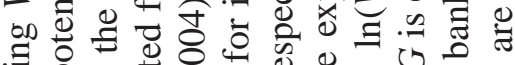

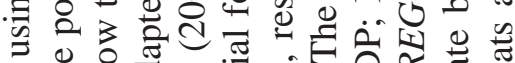

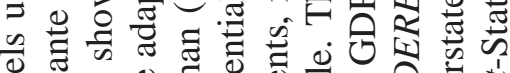

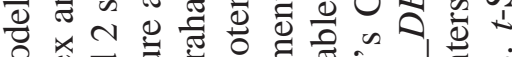

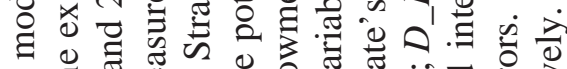

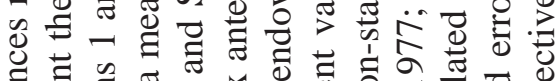
司言先 巳

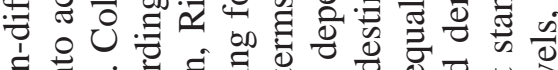
.」. 光

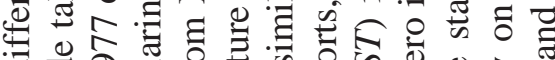

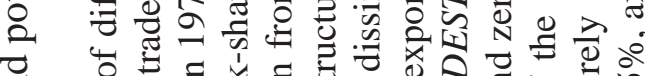
च

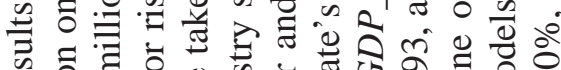

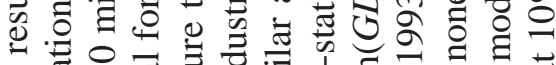

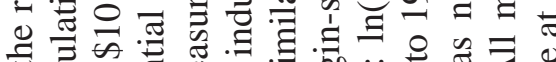

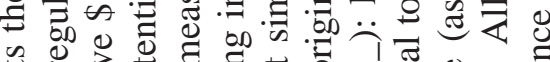

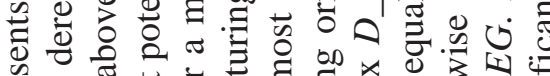
ये

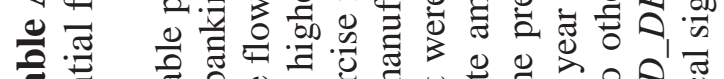

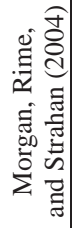

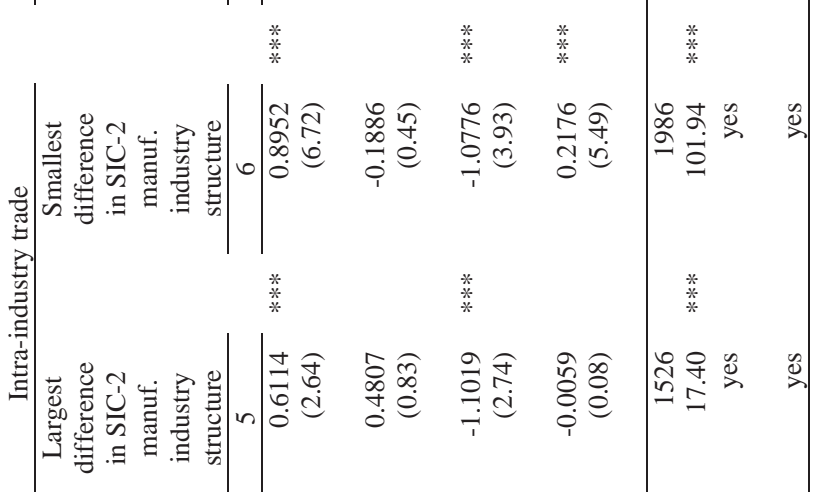

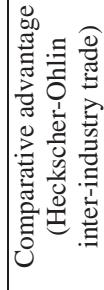

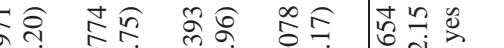

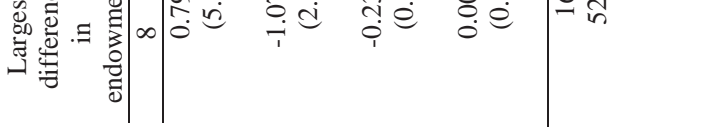

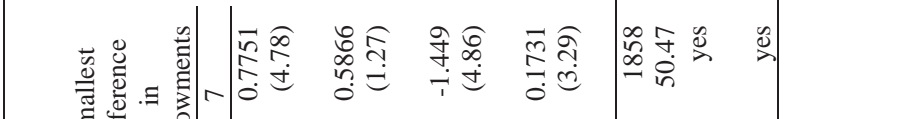
1

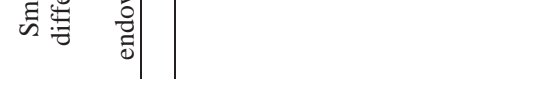

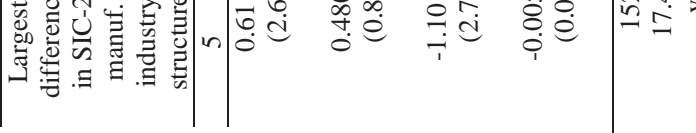

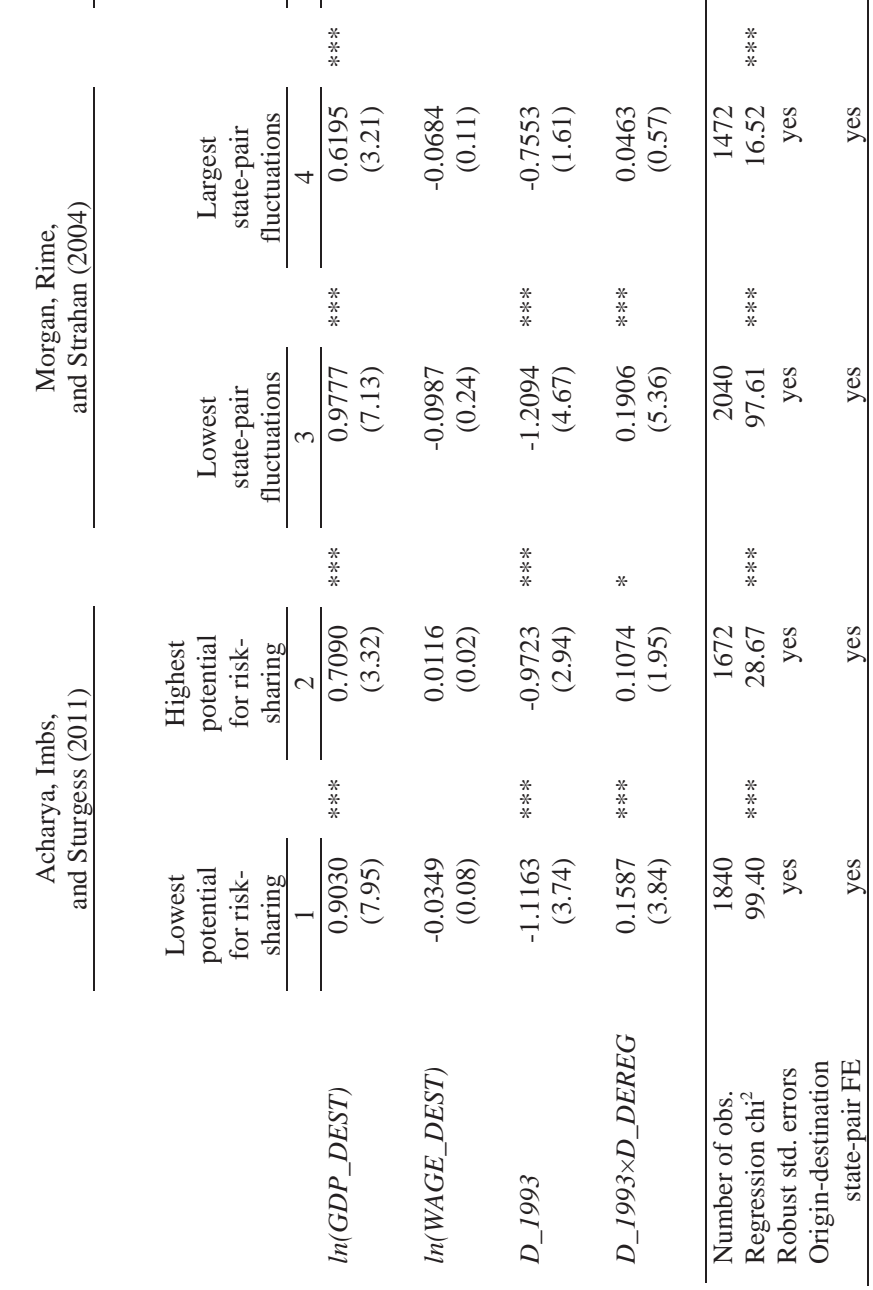




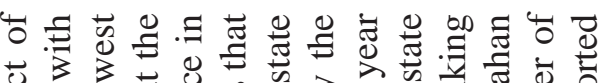

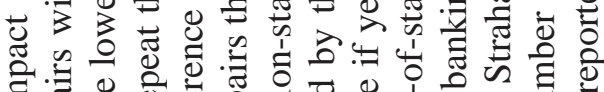

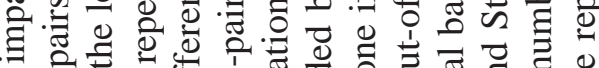

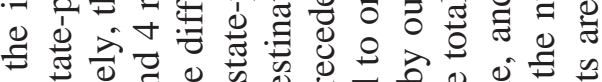
on

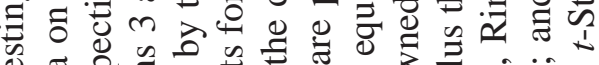

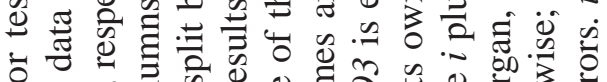

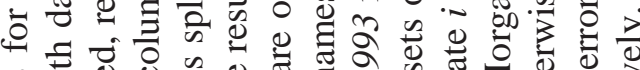

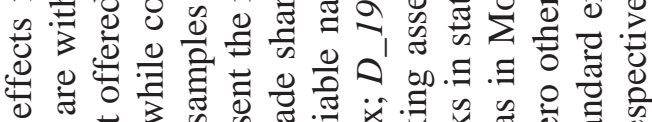

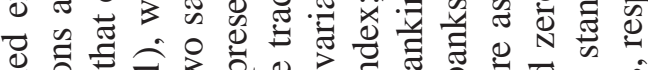
$x$.

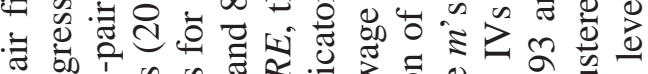

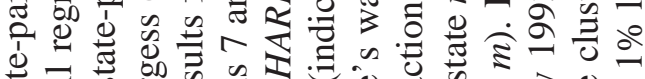

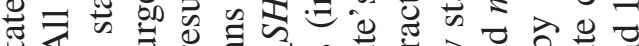

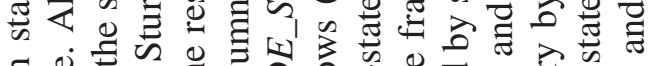

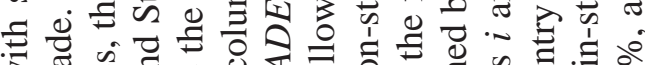

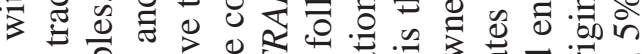

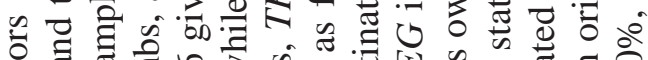
휴 है है

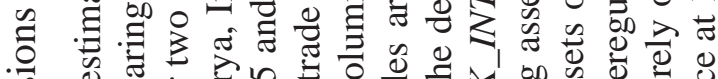

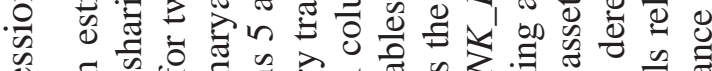

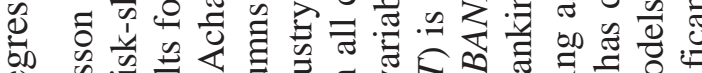

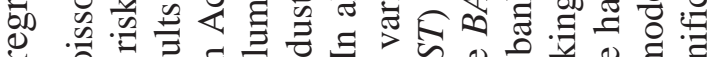

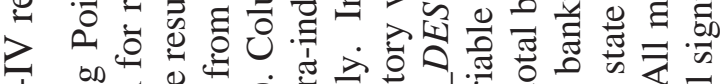

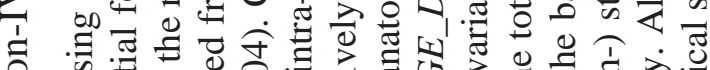

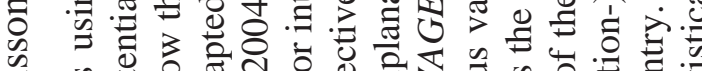

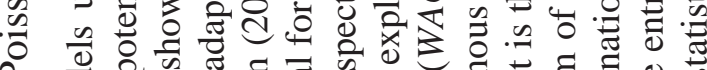
2

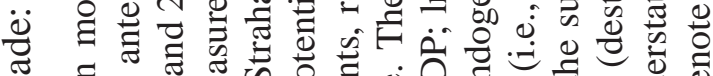

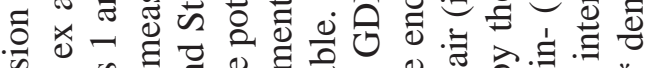
क ส

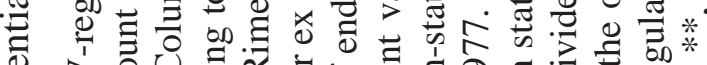

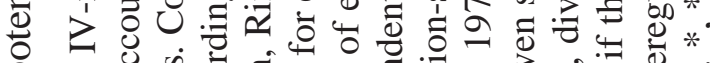
之

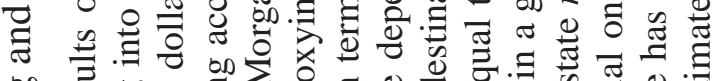

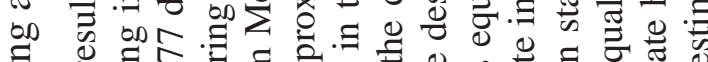

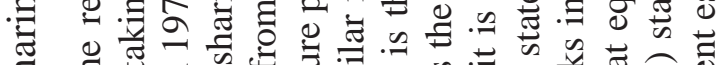
क 4

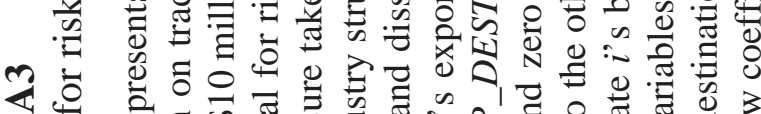

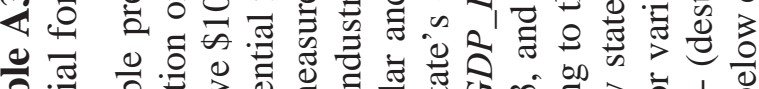

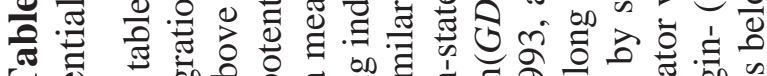
$\because$ ए

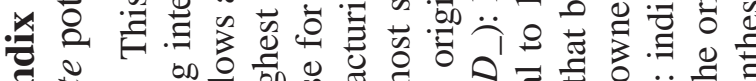
施

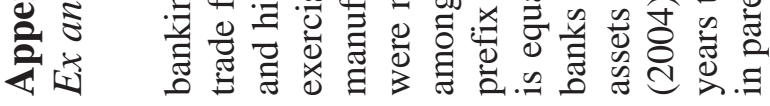

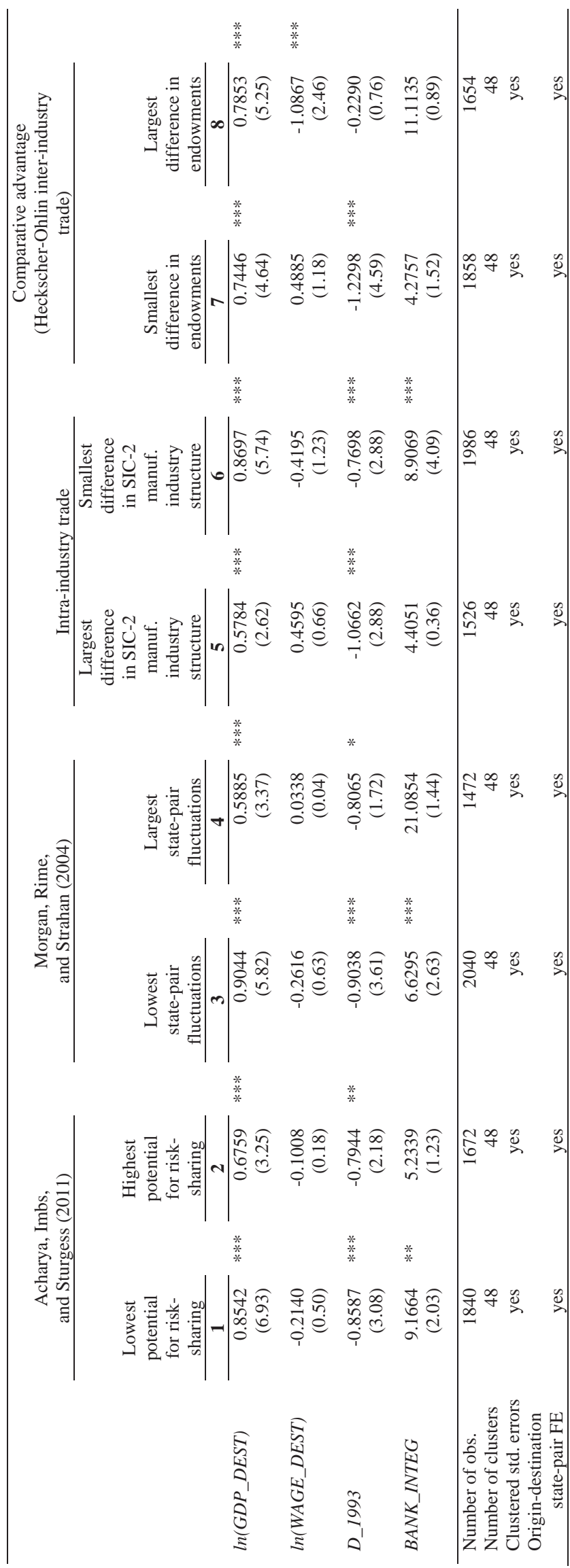




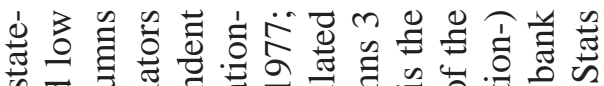

के

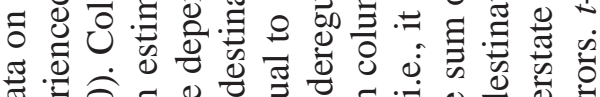

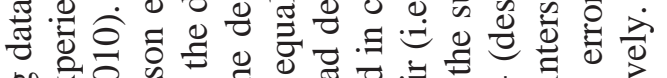
on जू

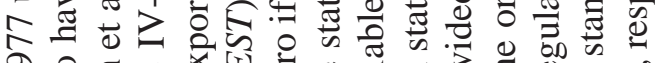

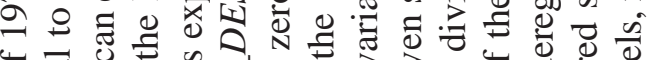
प्चु

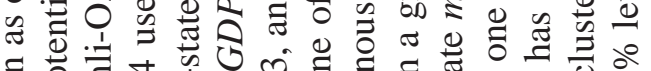
б

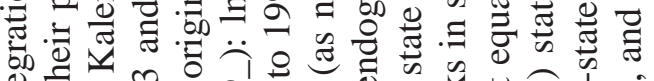

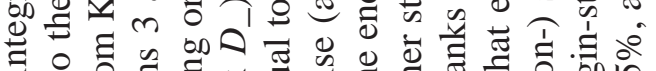

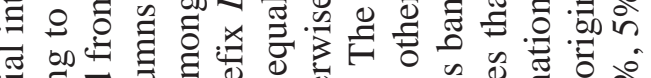

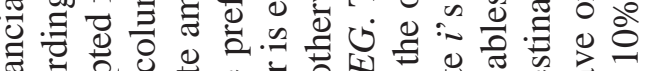

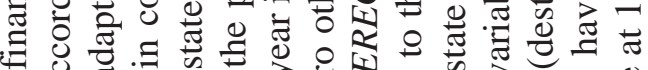

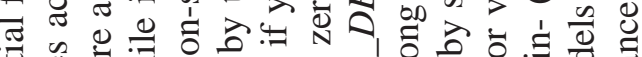

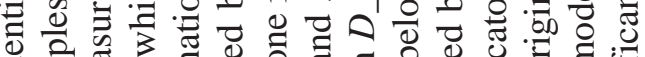
응 局

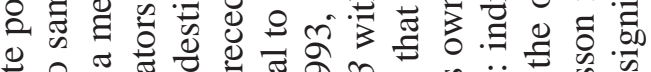

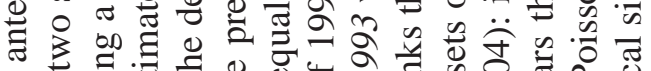
ऍ

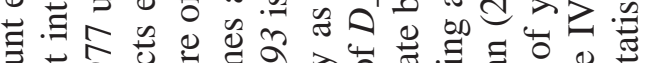

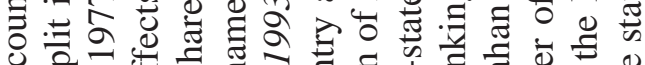

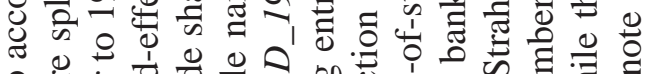

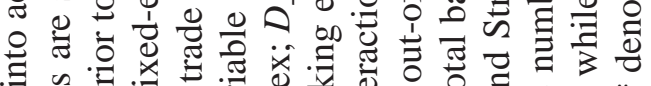

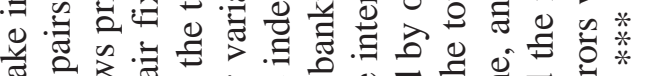

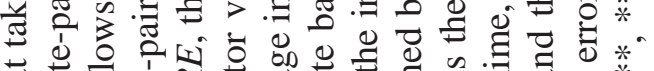

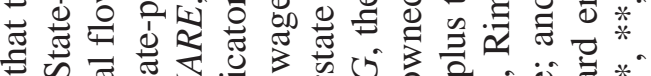

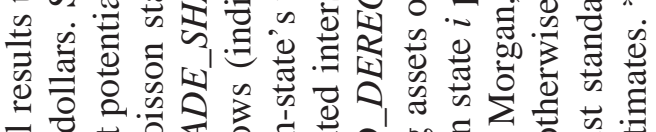

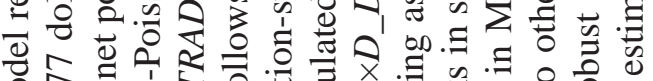

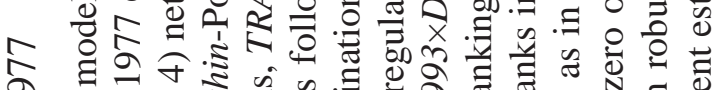

a

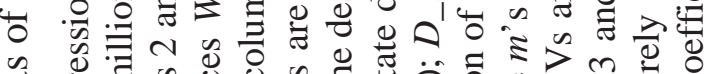
o

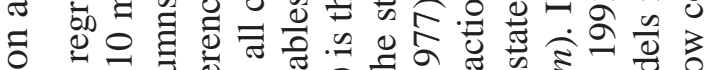

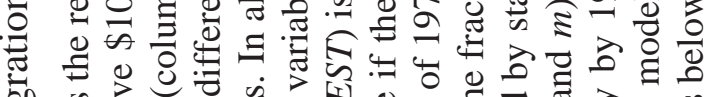
D.

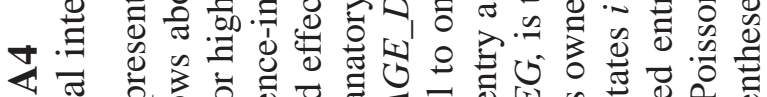

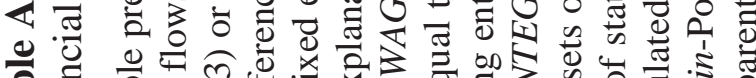

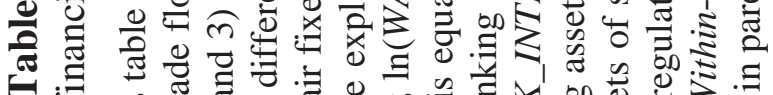

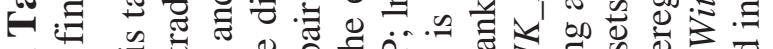

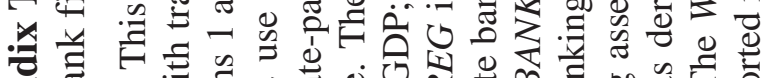

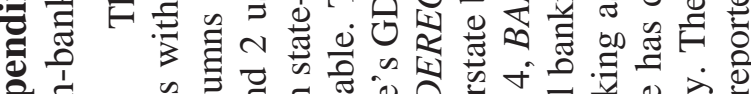

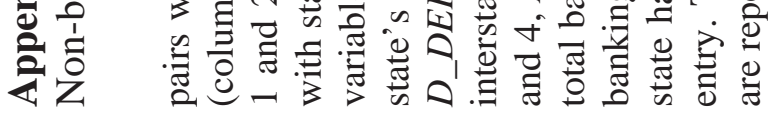

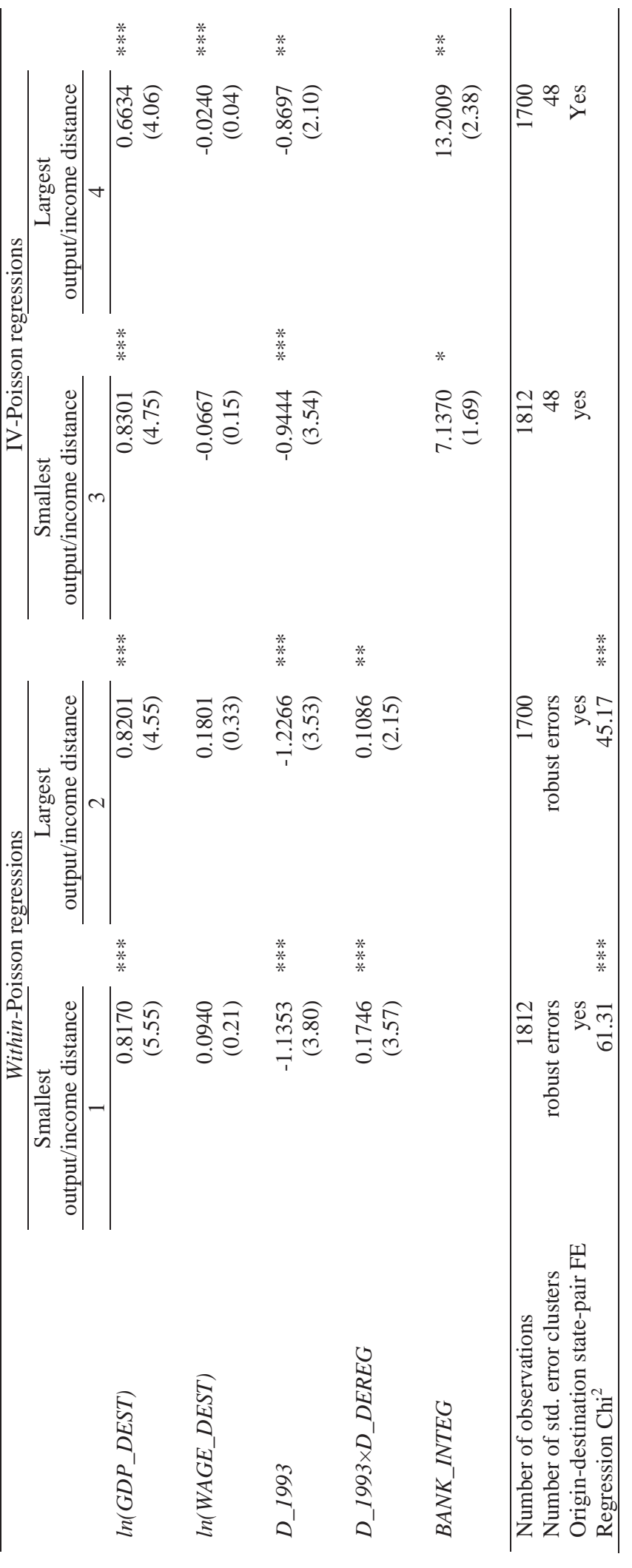




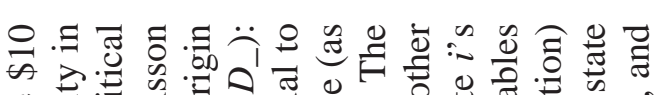

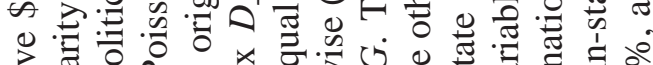

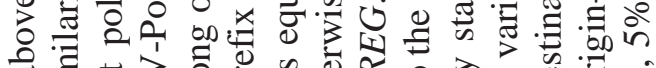

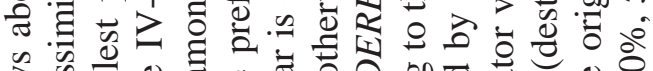

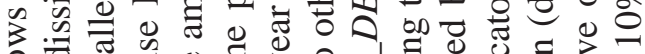

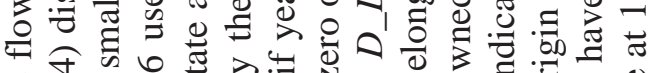

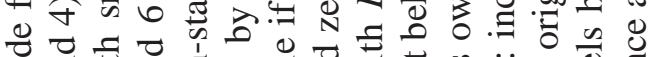

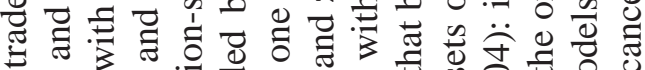
$\exists \sim$ ñ

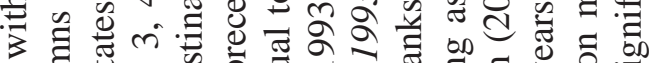

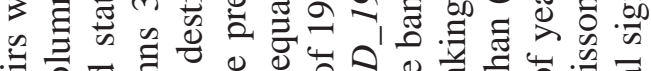

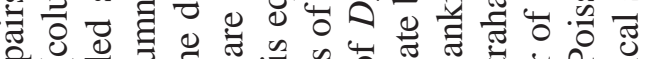

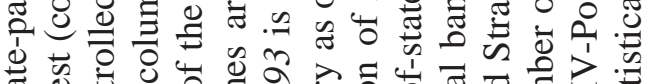

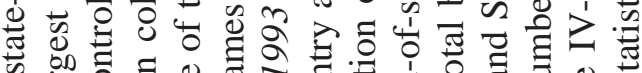
के

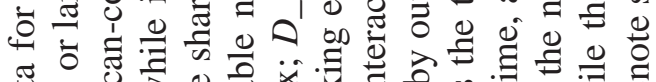

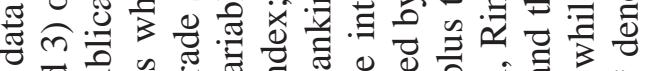
op 灵

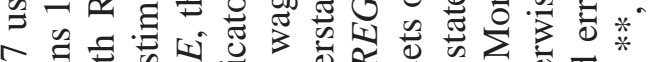

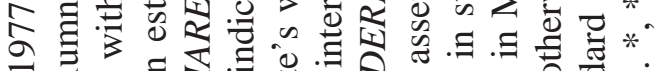
-

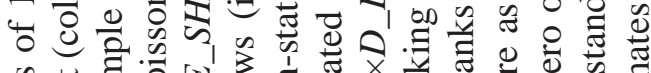

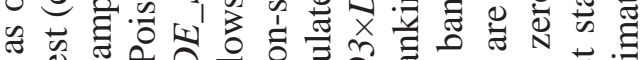

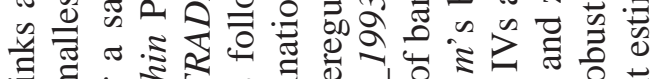

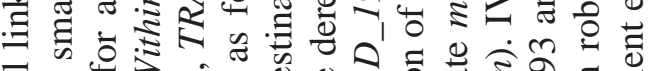
ซึ

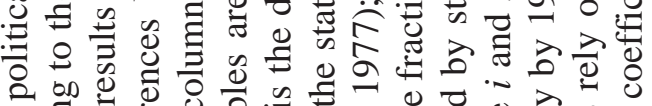

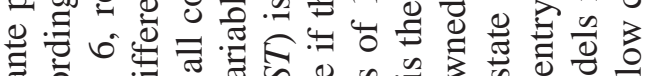

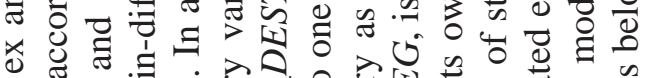

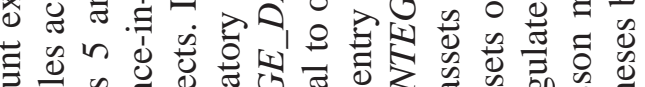

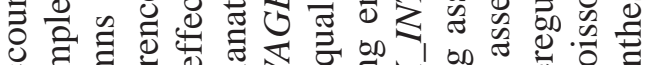

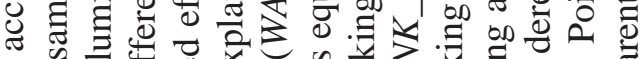

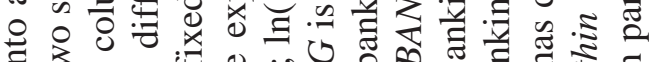

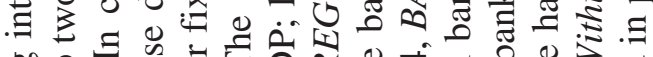
on

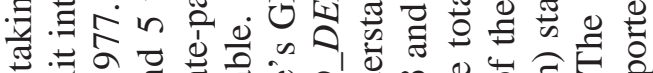

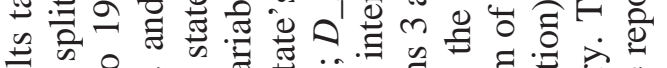

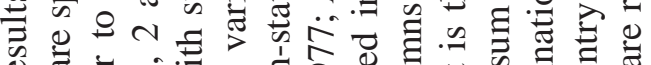

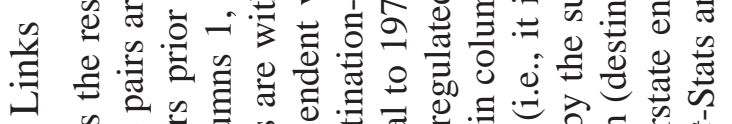

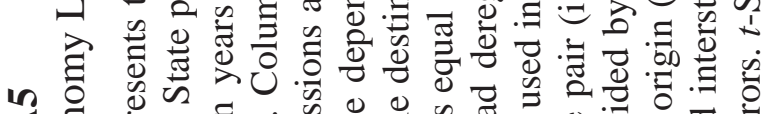

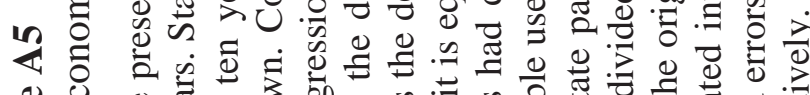

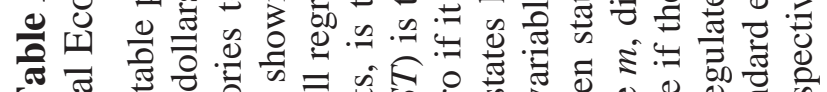
त ज्ञ

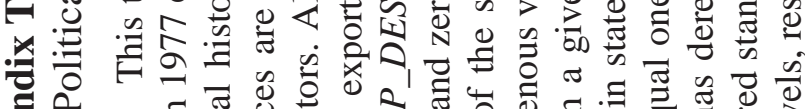

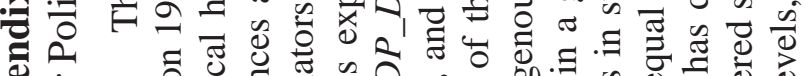

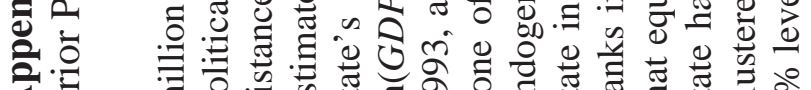

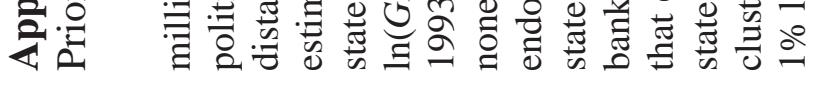

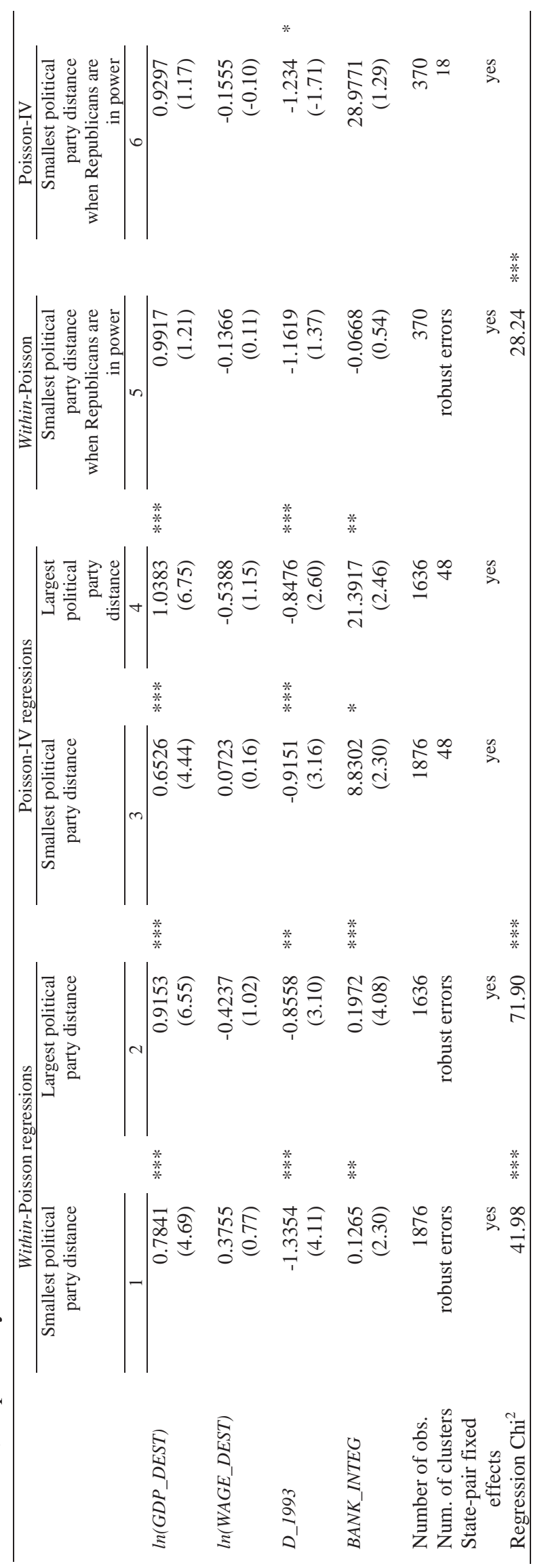

